\title{
Metalated heterocycles in organic synthesis: recent applications
}

\author{
Rafael Chinchilla,* Carmen Nájera,* and Miguel Yus* \\ Departamento de Química Orgánica and Instituto de Síntesis Orgánica (ISO), \\ Universidad de Alicante, Apartado 99, 03080 Alicante, Spain \\ E-mails: chinchilla@ua.es, cnajera@ua.es, yus@ua.es
}

\section{Dedicated to Professor Alain Krief on occasion of his 65th birthday}

\section{Contents}

1. Introduction

2. Group 1 Metalated Heterocycles

2.1. Lithium heterocycles

2.1.1. Aromatic five-membered rings

2.1.2. Aromatic six-membered rings

2.1.3. Nonaromatic heterocyles

3. Group 2 Metalated Heterocycles

3.1. Magnesium heterocycles

3.1.1. Aromatic five-membered rings

3.1.2. Aromatic six-membered rings

3.1.3. Nonaromatic heterocyles

4. Group 3 Metalated Heterocycles

4.1. Boron heterocycles

4.1.1. Aromatic five-membered rings

4.1.2. Aromatic six-membered rings

4.1.3. Nonaromatic heterocyles

5. Group 4 Metalated Heterocycles

5.1. Silicon heterocycles

5.1.1. Aromatic five-membered rings

5.1.2. Aromatic six-membered rings

5.1.3. Nonaromatic heterocyles

5.2. Germanium Heterocycles

5.3. Tin Heterocycles

5.3.1. Aromatic five-membered rings

5.3.2. Aromatic six-membered rings

5.3.3. Nonaromatic heterocyles

6. Group 5 Metalated Heterocycles

6.1. Selenium heterocycles 
6.2. Tellurium heterocycles

7. Transition-Metal-Substituted Heterocyles

7.1. Titanium heterocycles

7.2. Copper heterocycles

7.3. Zinc heterocycles

7.4. Mercury heterocycles

8. Conclusions

9. Acknowledgements

10. References

\section{Introduction}

Heterocycles are ubiquitous in all kind of compounds of interest, and among all the possible synthetic methods of achieving their introduction into an structure, probably the use of a metalated analogue is the most direct one. The present review deals with the generation and synthetic uses of organometallics formed by metalation of a heterocyclic ring, and can be considered as an update of our revision published in 2004 on this topic. ${ }^{1}$ Therefore, only references published from the second quarter of 2003 until the third quarter of 2006 are included, and the same restrictions to the literature coverage applies. Thus, only metalated heterocycles which have found applicability are considered and transient metalated species forming part of a catalytic cycle are excluded. In addition, metalated species where the metal cannot be appropriately situated on a carbon but on a more electronegative atom after metalation due to, for instance, delocalization will also be excluded.

As previously, ${ }^{1}$ the present review is organized by the type of metal and subdivided by the type of metalated heterocycle, including methods for their preparation and their synthetic uses.

\section{Group 1 Metalated Heterocycles}

\subsection{Lithium heterocycles}

Organolithiums keep their leading position as the most frequently employed metalated heterocycles, being useful on their own as nucleophiles or as the starting point in the preparation of many other metalated systems from less electropositive metals. ${ }^{1-4}$ Their generation generally involves an alkyllithium-promoted halogen-lithium exchange ${ }^{5}$ or the simple direct deprotonation of the most acidic and stabilizating position of the heterocyclic nucleus with alkylithiums or lithium amides. A stabilization which can be produced by an adjacent atom or group in the socalled "directed ortho-metalation" (DoM). 


\subsubsection{Aromatic five-membered rings}

$\mathrm{N}$-Silylated 2-lithiopyrroles, prepared by bromo-lithium exchange using $n$-butyllithium, have been used recently in an addition reaction to a chiral Weinreb amide in the total synthesis of the marine alkaloids (+)- ${ }^{6 \mathrm{a}}$ and (-)-dragmacidin $\mathrm{F}^{6 \mathrm{~b}} \mathrm{~N}$-Methylated 2-lithiopyrrole can be prepared by $n$-butyllithium/ $N, N, N^{\prime}, N^{\prime}$-tetramethylethylendiamine (TMEDA)-induced lithiation and has been employed in a ring-opening of a chiral lactam, as well as $\mathrm{N}$-triisopropylsilyl-3-lithiopyrrole, obtained by bromo/lithium exchange, both involved in the preparation of dopaminergic tetrahydroindoles. ${ }^{7}$ Moreover, two methoxycarbonyl groups can be introduced at C-2 and C-5 of $\mathrm{N}$-Boc-protected pyrrole in one step by lithiation using lithium tetramethylpiperidide (LiTMP) and methyl chloroformate, as in a recent racemic synthesis of the pyrrolizidine alkaloids hyacinthacine $\mathrm{A}_{1}$ and 1-epiaustraline. ${ }^{8} \mathrm{~N}$-Substituted indoles have been directly lithiated at C-2 and used as nucleophiles in addition to ketones, ${ }^{9}$ as well as in nitration and iodination reactions. ${ }^{10}$ The 3-lithiation has been achieved by bromo-lithium exchange and the resulting indolylithium employed, for instance, in addition reactions to imines ${ }^{11}$ or to chromium hexacarbonyl. ${ }^{12}$

The 2-lithiation of the furan ring, achieved by direct deprotonation with an alkylithium, and the further use of the lithiated species as nucleophile has been frequently used in the last years for the introduction of this important moiety. Thus, 2-furanyllithium has been used in alkylation reactions ${ }^{13}$ and addition to carbonyls, ${ }^{14}$ isoxazolines ${ }^{15}$ and $1,2,4$-triazines, ${ }^{16}$ as well as in the ringopening of lactones. ${ }^{17}$ 2-Lithiated benzofurans have been obtained similarly and used, for instance, for an addition reaction to quinones, in a route to pterocarpins. ${ }^{18}$

When an halide is present at C-3, the furan ring is directly 2-lithiated using LDA in order to avoid a halide-lithium exchange. ${ }^{19}$ In addition, the tetralithiated tetrakis(2-furyl)methane derivative $\mathbf{2}$ has been generated from the corresponding tetrabrominated derivative $\mathbf{1}$ after bromo-lithium exchange and has been transformed into the tetraformyl derivative 3 by reaction with DMF (Scheme 1). ${ }^{20}$ Moreover, 2,5-dilithiofuran has been obtained and used in double addition reactions to carbonyls for the preparation of core-modified porphyrins. ${ }^{21}$

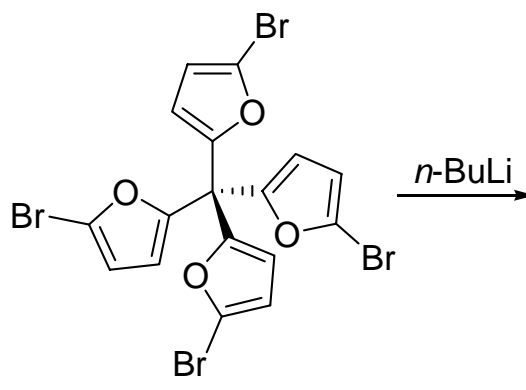

1

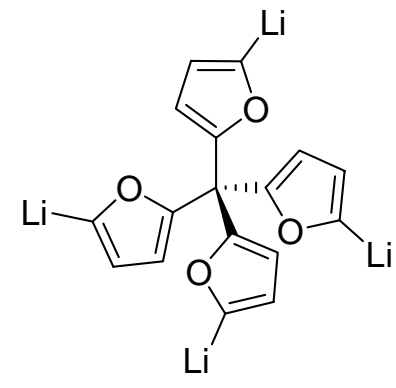

2

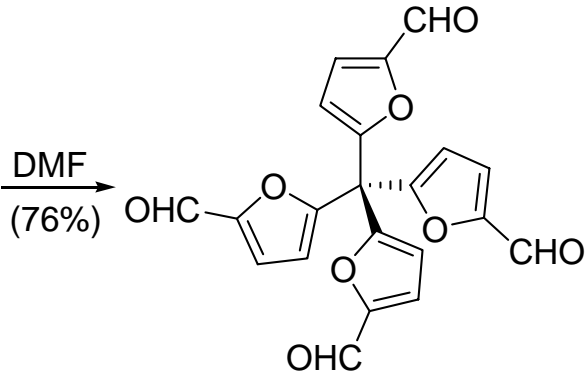

3

\section{Scheme 1}

Some substituents at C-3 on the furan ring have shown ortho-directing properties for the 2metalation. Thus, 3-aryl and 3-styryl furans have been regioselectively lithiated at C-2, probably 
by stabilization of the furyl anion by through-space donation of $\pi$-density. ${ }^{22}$ This DoM has also been achieved in $\mathrm{N}$-Boc protected 3-aminofuran (4), this group acting as a stabilizer of the corresponding 2-furyllithium after preliminary deprotonation through species 5 (Scheme 2). Subsequent reaction with electrophiles such as tert-butyl isocyanate gave rise to the furancarboxamide $6 .^{23}$

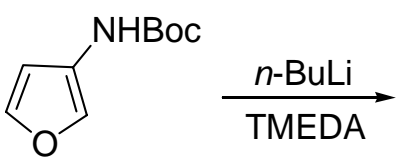

4<smiles>CC(C)COC(=Nc1ccoc1[Tl])O[Ga]</smiles>

5

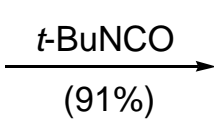

(91\%)

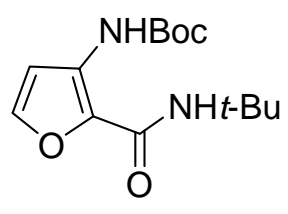

6

\section{Scheme 2}

3-Lithiofurans, obtained by bromo or iodo/lithium exchange using an alkyllithium, have been used, for instance, in addition to carbonyl compounds ${ }^{24}$ or to carbon dioxide. ${ }^{25}$ A recent example is the 3-lithiation of 3-iodo-2-silyloxyfuran 7 affords metalated species $\mathbf{8}$, which reacted with electrophiles such as benzaldehyde affording the tetronate $\mathbf{9}$ after mild hydrolysis (Scheme 3 ). ${ }^{26}$ 3-Lithiobenzofurans have been generated similarly and used, for example, in the synthesis of diarylethene derivatives with photochromic properties. ${ }^{27}$ There are examples of DoM lithiation at the 3-position of a furan or a thiophene ring, as in the 3-cyanation of these systems by lithiation and further reaction with phenyl cyanate. ${ }^{28}$

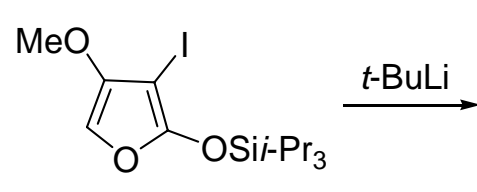

7

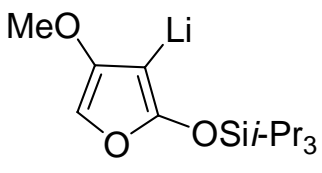

8

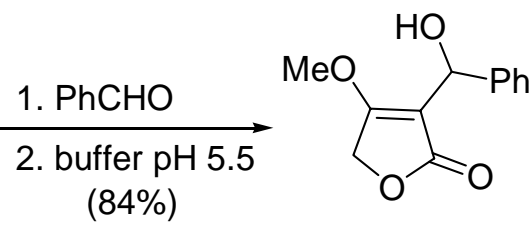

9

\section{Scheme 3}

2-Lithiated thiophenes, generated similarly to 2-lithiofurans, have also been employed frequently in recent years as nucleophiles, being also the origin of many boron- and tinderivatives frequently employed in the preparation of thiophene-derived compound with interesting electrooptical properties (see below). The solution structure and chelation properties of some of these 2-thienyllithiums have being studied recently by NMR techniques. ${ }^{29}$ In some cases, temperature-dependent behaviors have been observed, as in the LDA-promoted lithiation of 2-bromothiophene at $-78{ }^{\circ} \mathrm{C}$ which afforded the expected 5-substituted-2-bromothiophene. However, the same process at room temperature or $0{ }^{\circ} \mathrm{C}$ gave a 5-alkylated-2,4dibromothiophene according to a halogen-transfer-based halogen dance process. ${ }^{30}$ 
Examples of the use of 2-lithiothiophenes for bromination reactions in the synthesis of oligothiophenes, ${ }^{31}$ or for double addition to 2-thienylcarboxylated compounds in the preparation of multicharged methinium compounds can be found. ${ }^{32}$ There are also examples of the use of these heteroaryllithiums in addition reactions to aldehydes for the preparation of core-modified porphyrins, ${ }^{33}$ hetero-calix[4]pyrroles, ${ }^{34}$ benzo[b]thiophene analogues of pentacene ${ }^{35}$ or inhibitors of type II $17 \beta$-hydroxysteroid dehydrogenase, ${ }^{36}$ as well as in additions to phenanthrolines. ${ }^{37} 2$ Alkylation reactions of the corresponding 2-thienyllithiums have been used, for instance, in the synthesis of dialkyloligothiophenes for molecular electronic applications. ${ }^{38}$

Other examples of the use of 2-lithiothiophenes as nucleophiles can be found in formylation reactions, ${ }^{39}$ achieved even using a 2,5-dilithiated thiophene in a synthesis of oligothienylenevinylenes. ${ }^{40}$ Sulfur can also be used as electrophile, allowing the preparation of dithienothiophene $^{41}$ and annulated oligothiophene derivatives. ${ }^{42}$ A recent example of the introduction of a sulfur atom using 2-thienyllithium reagents is shown in Scheme 4 where the reaction of 2-thienyllithium $(\mathbf{1 0})$ with sulfur, followed by in situ treatment of the formed thiolate salt with $\alpha$-(bromomethyl)acrylic acid gave the sulfanylated thiophene 11, which can be converted into dihydrothiopyran 12 upon heating. ${ }^{43}$ 2-Thienyl-derived phosphanes can be obtained by treatment of 2-lithiated thiophenes with chlorodiphenylphosphane. ${ }^{44}$ 2Thienyllithium can also be used for substitution reactions to dialkyldichlorosilanes driving to bis(2-thienyls)silanes, which are precursors to arylsilanediols. ${ }^{45}$ In addition, benzo[b]thiophene can be similarly lithiated at C-2, being used as nucleophile, for instance, in alkylations ${ }^{46}$ and azidations, ${ }^{47}$ as well as in reactions with Weinreb amides in the synthesis of agonists for the $\alpha 7$ nicotinic acetylcholine receptor. ${ }^{48}$ Furthermore, 2-iodoseleniophenes and 2-iodotellurophenes have been obtained by direct 2-lithiation of the corresponding chalcogenophenes and subsequent reaction with iodine. ${ }^{49}$

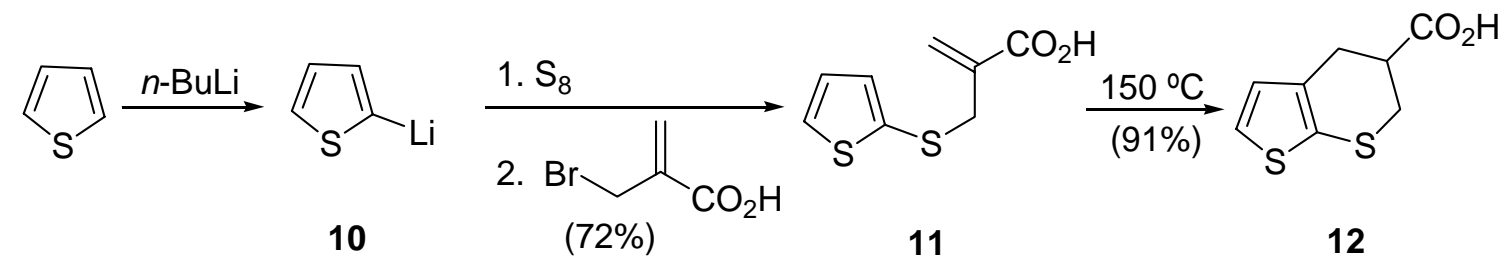

\section{Scheme 4}

3-Lithiothiophenes have been generated, as usual, by halogen-lithium exchange and used for addition reactions to the carbonyl group of $9 H$-thioxanthen-9-one in the synthesis of modified thiophene oligomers, ${ }^{50}$ to aldehydes in the preparation of ligands for the glucocorticoid receptor $^{51}$ or to sulfur powder in tiolate generation for substituted thiophenes with blue emission characteristics. $^{52}$ However, there are also examples of DoM 3-lithiation performed on appropriately substituted thiophenes. Thus, the lithiation of chiral thienyloxazoline $\mathbf{1 3}$ generated 
the 3-thienyllithium species 14, which can be formylated affording thiophenecarbaldehyde 15, a precursor in a synthesis of chiral ligands for asymmetric catalysis (Scheme 5). ${ }^{53}$

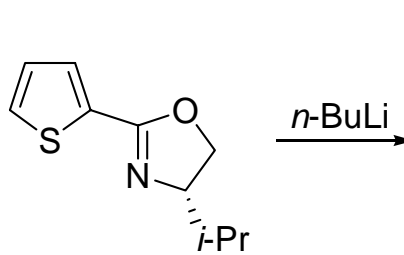

13

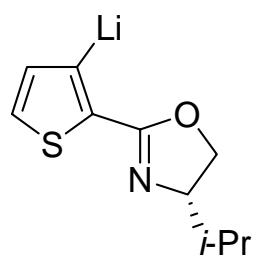

14

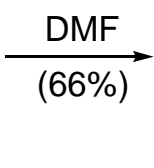

$66 \%)$

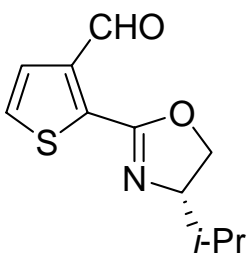

15

\section{Scheme 5}

$N$-Methylpyrazoles, as other $N$-alkylated analogues, are lithiated at the methyl group when treated with alkylithium reagents such as $n$-butyllithium under kinetic conditions, whereas reaction under thermodynamically-controlled conditions affords lithiation at the 5-position, the corresponding 5-lithio-1-methylpyrazole showing NMR data in solution consistent with an oligomeric structure. $^{54}$

$\mathrm{N}$-Substituted imidazoles tend to lithiate with alkyllithiums at C-2 driving to a carbenoid species that can be used as a bulky base, as the case of 2-lithio-1-methylimidazole which has been used in stereoselective deprotonation of cyclohexene oxides when combined to a chiral lithium amide. ${ }^{55}$ However, 2-lithioimidazoles are employed normally as nucleophiles, for instance in addition reactions to aldehydes, ${ }^{56}$ ketones $^{57}$ and isocyanates, ${ }^{58}$ as well as in silylation, ${ }^{59}$ sulfenylation ${ }^{60}$ and cyclic sulfate ring-opening ${ }^{61}$ reactions. Benzimidazoles have also been lithiated at C-2 using LDA and acylated with esters. ${ }^{62}$ 2-Lithioimidazoles can also be generated by treatment of $N$-methylimidazole (16) with an excess of lithium powder in the presence of a catalytic amount of an electron-carrier ${ }^{63}$ such as isoprene, the lithiated species 17 being used in addition reactions to carbonyl compounds or imines such as benzylidenebenzenamine to give the corresponding 2-substituted imidazole 18 (Scheme 6 ). ${ }^{64}$ The halogen/lithium exchange has been used for generating 2-lithioimidazoles, an example being the $n$-butyllithium-promoted 2-metalation of a $N$-protected 2,4,5-triiodinated imidazole, followed by addition reaction to 3-indolylcarbaldehydes in the synthesis of anti-inflammatory homocarbonyltopsentine derivatives. ${ }^{65}$

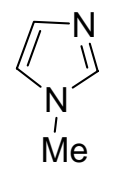

16

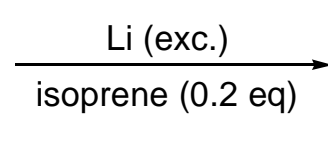

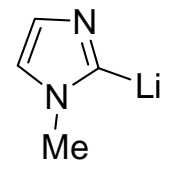

17

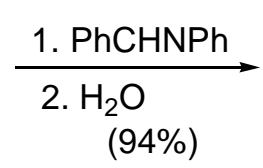

$(94 \%)$

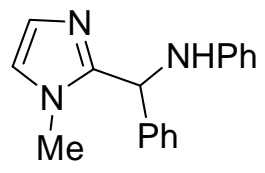

18

\section{Scheme 6}


When the C-2 in $\mathrm{N}$-substituted imidazoles is blocked, the alkyllithium-promoted metalation takes place at C-5. Frequently, this metalation-blockage at C-2 is produced by an easily removable trialkylsilyl group, the formed 5-lithiated imidazole thus being suitable as nucleophile, for instance, in addition reactions to aldehydes ${ }^{66}$ or ring-opening of lactones. ${ }^{67}$

Isoxazoles can not be lithiated at C-5 by deprotonation with alkyllithiums, as the resulting anion suffers fragmentation to benzonitrile and ethynolate ion or enaminones, depending on the alkyllithium and the substituents present on the ring. ${ }^{68}$ When the 5-position is blocked, lithiation of the ring is possible, as in the case of the treatment of 3,5-disubstituted isoxazole 19 with $n$ butyllithium generating 4-isoxazolyllithium species 20, which added to amino acrylate 21 in a Michael fashion affording trisubstituted isoxazole 22 in the search of agonists at AMPA receptors (Scheme 7). ${ }^{69}$

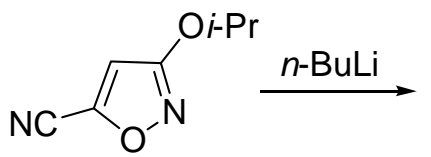

19

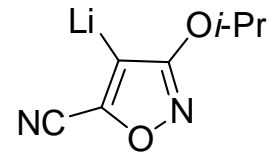

20

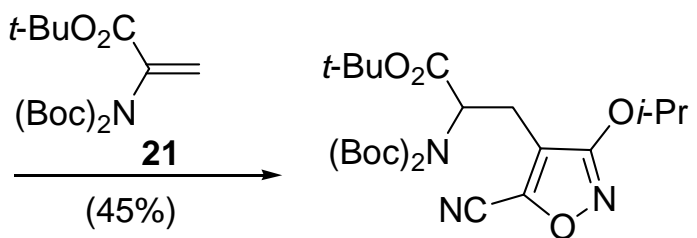

22

\section{Scheme 7}

Oxazole and benzoxazole can be readily lithiated at the 2-position giving species such as 23, although this resulting anion equilibrates by $\alpha$-elimination/ring-opening with a $\beta$-isocyano enolate 24, this latter being the dominating form according to NMR. ${ }^{70}$ Reaction of this equilibrating anion are dependent of the electrophile, acyl chlorides such as acetyl chloride giving rise to the corresponding isonitrile 25 (Scheme 8). ${ }^{71}$ This kind of isonitriles are fragant and are an interesting alternative to conventionally used isonitriles, which usually have hazardous properties and a piercing odor. Concerning 5-bromo-2-phenyloxazole, 5-lithiation and further reaction with electrophiles has been achieved through an initial LDA-promoted 4lithiation followed by halogen dance, driving to a 4-bromo-5-lithio-2-phenyloxazole intermediate. $^{72}$

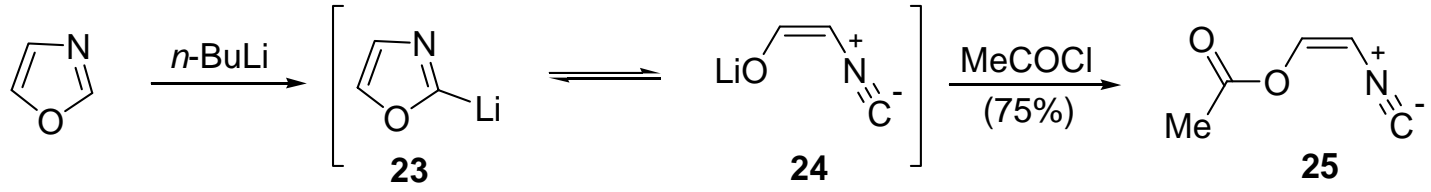

\section{Scheme 8}

The lithiation of isothiazoles and their further reaction with electrophiles has been reviewed. $^{73 a}$ 2-Lithiothiazole derivatives have been used as nucleophiles, for instance in addition 
to aldehydes, ${ }^{73 b, c}$ the thiazole moiety being used frequently as a formyl anion equivalent. ${ }^{74}$ This heteroaryllithium has been also employed in addition reactions to benzyloxyacetaldoximes. ${ }^{75}$ In addition, 2-lithiobenzothiazoles have been used recently in addition reactions to a fuconolactone ${ }^{76}$ and to an arginine-derived Weinreb amide. ${ }^{77}$ If the 2-position in thiazoles is blocked, the lithiation takes place directly at the 5-position, an example being the synthesis of 5thiazole ketones by reaction of $n$-butyllithium-generated 5-thiazolyllithiums with nitriles. ${ }^{78}$ The 5-lithiation has also been achieved in 2-thiazolamines bearing a bromine atom at C-5 through a halogen dance process starting from a LDA-promoted 4-lithiation. ${ }^{79}$ However, when a 4lithiation at a C-2-substituted thiazole is intended, the usual route is a halogen-lithium exchange, as illustrated in Scheme 9 for the metalation of the brominated thiazole $\mathbf{2 6}$ to give the 4-lithiated species 27. This intermediate can be formylated using DMF to give thiazolylcarbaldehyde $\mathbf{2 8}$, which is an intermediate in a total synthesis of the marine sponge metabolite $( \pm)$-mycothiazole. ${ }^{80}$

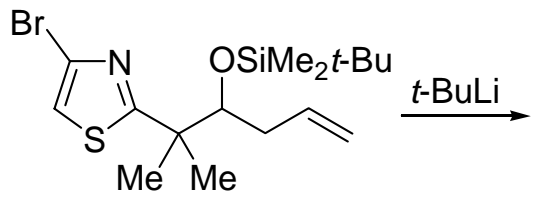

26

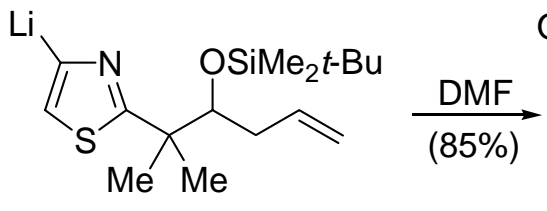

27<smiles>C=CCC(OCC(C)(C)C)C(C)(C)c1nc(C=O)cs1</smiles>

28

\section{Scheme 9}

\subsubsection{Aromatic six-membered rings}

Pyridines, as other electron-deficient six-membered heteroaromatic rings, are deprotonated using lithium amides, instead of alkylithiums, in order to avoid addition to the heteroaromatic ring. The use of the combination of $n$-butyllithium and lithium diethylamino ethoxyde (LiDMAE) has shown to be a "superbase" able to efficiently deprotonate the C-2 of pyridines by increasing the basicity and nucleophilicity of the alkylithium reagent. ${ }^{81}$ Thus, recent applications of the use of this lithiating combination on 4-picoline and 3,4-lutidine, ${ }^{82}$ 4-(1-pyrrolyl)pyridine, ${ }^{83}$ (S)nicotine ${ }^{84}$ anisylpiridines ${ }^{85}$ and 3-methylthiopyridine were reported. ${ }^{86} \mathrm{~A}$ new related "superbase" has been developed by combining [(trimethylsilyl]methyl)lithium $\left(\mathrm{TMSCH}_{2} \mathrm{Li}\right)$ and $\mathrm{LiDMAE}$, and it has found efficient application for the C-2 lithiation of sensitive chloro- and fluoropyridines. ${ }^{87}$

The DoM process, combined to the use of a lithium amide base such as LiTMP, can also be used for the C-2 lithiation of the pyridine nucleus of 2-(pyridyl)-phenols and anilines. ${ }^{88}$ This DoM methodology has been used in the 2-lithiation of 3-fluoropyridine and further reaction with carbon dioxide ${ }^{89}$ and has also allowed the extensive and regioselective functionalization of many pyridine systems. ${ }^{90}$ However, probably the alkyllithium-promoted bromo-lithium exchange has been the most frequently employed methodology when 2-lithiated pyridines have been required for synthetic purposes. Thus, 2-lithiopyridine, obtained by treatment of 2-bromopyridine with $n-$ butyllithium, has been used in addition reactions to ketones, ${ }^{91}$ nitriles, ${ }^{92}$ amides ${ }^{93}$ and the ring- 
opening of sulfamates. ${ }^{94}$ Other substituted 2-pyridyllithium reagents have been obtained similarly and used recently in addition reactions to aldehydes, ${ }^{95}$ Weinreb amides, ${ }^{96} \mathrm{DMF},{ }^{97}$ and acyl chlorides, as in the reaction of the organolithium 30, prepared from 2-bromopyridine 29 by the typical exchange procedure, with pivaloyl chloride (Scheme 10). ${ }^{98}$ The so-obtained ketone 31 is an intermediate in the synthesis of a chiral 2,2'-bipyridine oxide catalyst for enantioselective aldol reactions.

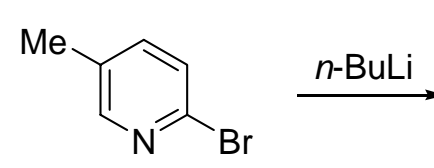

29<smiles>Cc1ccc(Cl)nc1</smiles>

30<smiles>Cc1ccc(C(=O)C(C)(C)C)nc1</smiles>

31

\section{Scheme 10}

Examples of the generation of 2-lithiopyridines by iodo-lithium exchange in formylation reactions has been also reported. ${ }^{99}$ In addition, the halogen-lithium exchange has been used in the 2-metalation of quinoline derivatives, ${ }^{100}$ and in the intramolecular cyclization of 2-pyridyl- and 2-quinolidyllithium reagents such as 33, generated from the corresponding bromoquinoline 32 , driving to the corresponding indolizone-based compound 34 (Scheme 11). ${ }^{101}$

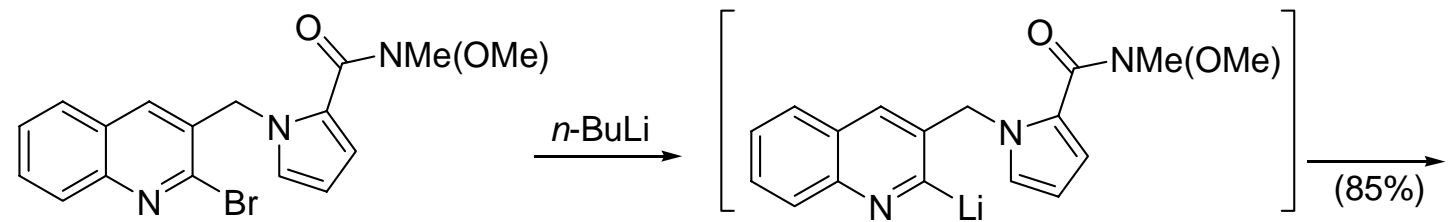

32

33<smiles>O=C1c2nc3ccccc3cc2Cn2cccc21</smiles>

34

\section{Scheme 11}

Examples of the use of 3-pyridyllithium reagents (obtained by halogen-lithium exchange) can be found in the iodination of bromopyridines, ${ }^{102}$ in the addition to triphenylacetaldehyde (for the synthesis of chiral pyridine catalysts ${ }^{103}$ ), or to a conjugated dienic aldehyde (in a total synthesis of the kinase inhibitor pyridovericin ${ }^{104}$ ). The $n$-butyllithium-promoted bromo-lithium exchange has also been used in the generation of 3,5-dilithiopyridine, which has been employed in the addition to aromatic aldehydes for the synthesis of carbaporphyrinoids containing a pyridine moiety. ${ }^{105}$ Interestingly, a selectivity has been shown in the tert-butyllithium-mediated 
metalation of 3-bromopyridines, the addition order of substrate and metalating agent being crucial for lithiation at C-3 by bromo-lithium exchange, or to C-4 by a DoM process. ${ }^{106}$

The DoM reaction applied to the generation of 3-pyridyllithium species has been carried out with tert-butyllithium in the case of 4-methoxypyridine, ${ }^{107}$ although the use of lithium amides is more frequent. Thus, 3-lithiated pyridines obtained using LDA as lithiation agent have found recent application in the 3-iodination of 2-fluoropyridine for the preparation of scaffolds for peptidomimetics, ${ }^{108}$ and also in the iodination of 2-chloro-4-cyanopyridine for the total synthesis of louisianin A. ${ }^{109}$ This lithiation agent has also been used for the 3-lithiation of 4-substituted 2chloropyridines such as $\mathbf{3 5}$ to generate a didehydropyridine (pyridyne) $\mathbf{3 7}$ by elimination of lithium chloride from lithiated species 36 (Scheme 12). ${ }^{110}$ The pyridyne 37 can be trapped with furan to give the corresponding adduct 38.

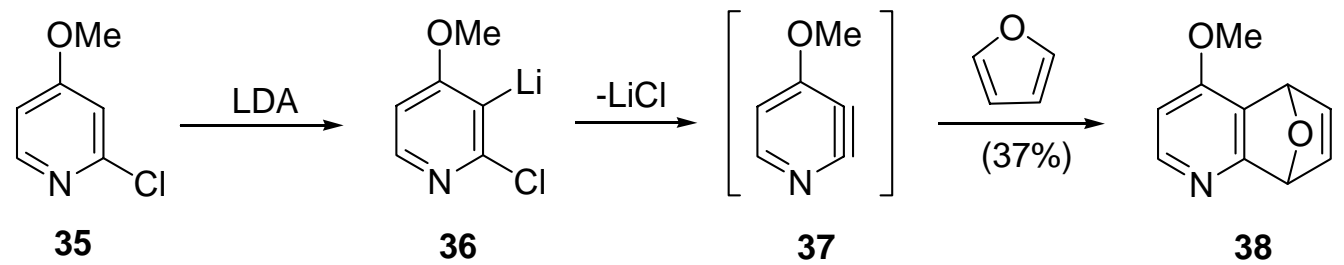

\section{Scheme 12}

3-Lithiated pyridines generated by the DoM procedure using LiTMP have been used for internal cyclization reactions to amide groups, ${ }^{111}$ and in the synthesis of heterocyclic quinones by metalation of pyridines and quinolines, in the presence of a remote carboxylate group. ${ }^{112}$ The same metalating agent has also been used for the synthesis of ortho-substituted cyanopyridines, an example being shown in Scheme 13, where the LiTMP-promoted metalation of 4cyanopyridine (39) gave the lithiated species $\mathbf{4 0}$ which reacts at 3-position with electrophiles, such as tetrabromomethane, to give the corresponding brominated compound 41. ${ }^{113}$ LiTMP has also been employed for the metalation of the pyridine moiety of pyridopyrimidin- $4(3 H)$-ones and subsequent reaction with aldehydes. ${ }^{114}$ In addition, the above mentioned combination $\mathrm{TMSCH}_{2} \mathrm{Li} / \mathrm{LiDMAE}$ has recently been employed for a C-3 lithiation of 4(dimethylamino)pyridine. ${ }^{115}$

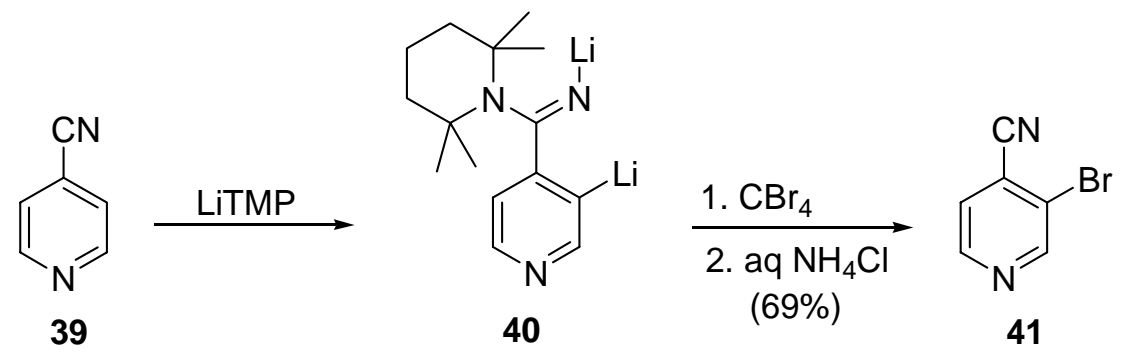

\section{Scheme 13}


Recent examples of the use of different 4-lithiopyridines, generated by DoM of 3-pyridyl pivaloamides using $n$-butyllithium, are an iodination reaction for the synthesis of 6 -aza-Ltryptophan $^{116}$ and 4 -alkoxycarbonylations in the preparation of pyridopyrimidin-ones. ${ }^{117}$ In the case of 3-bromopyridine, LDA has been used as metalating agent for the generation of the corresponding brominated 4-pyridyllithium reagent, which has been employed in an addition reaction to acrolein in the synthesis of restricted nicotine analogues. ${ }^{118}$ An illustrative example of a DoM reaction for preparing a synthetically useful 4-pyridyllithium species is the one-pot synthesis shown in Scheme 14. Thus, 3-pyridyl carboxylic acid 42 was treated with $n$ butyllithium to give the corresponding carboxylate anion 43, and further lithiation with LiTMP afforded the organolithium species 44. Subsequent reaction with acetone gave the dilithium salt 45, with was transformed into a lactopyridone after acid treatment. Final $N$-methylation under basic conditions gave the pyridinone alkaloid cerpegin 46. ${ }^{119}$ 2-Bromo-3-fluoroquinolines have been lithiated by DoM at C-4 for the preparation of the corresponding carboxylic acids, ${ }^{120}$ whereas 4,6-disubstituted dihydropyridopyrazines have been obtained from the corresponding carboxaldehydes via lithiation directed by the $\alpha$-amino alkoxide generated by mixing the starting aldehyde with TMEDA and $n$-butyllithium. ${ }^{121}$

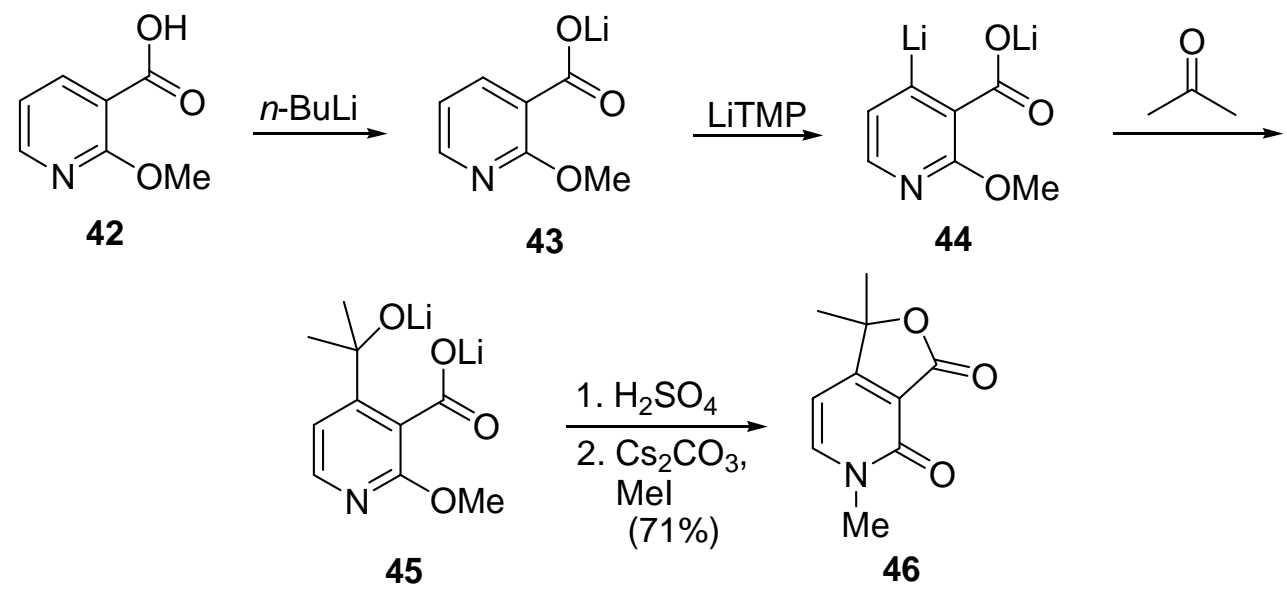

\section{Scheme 14}

In the case of the DoM 4-lithiation of 3,5-dichloropyridine using $n$-butyllithium and LiTMP, a comparison study monitored by infrared spectroscopy has shown similar structures of both lithio derivatives, although total deuteration occurred in the $n$-butyllithium-created species, whereas only partial deuteration was observed when LiTMP was used. ${ }^{122}$ The bromo-lithium exchange has been performed for instance starting from 2,4-dibromoquinoline, which by treatment with $n$-butyllithium gave rise to the corresponding 4-lithiated species, useful for iodination and subsequent palladium-catalyzed cross-coupling reactions. ${ }^{123}$

Pyridin-2-yldiazines have been recently metalated employing the pyridine ring as a orthodirecting group. ${ }^{124}$ For instance, the lithiation of 2-pydidyl pyrazine 47 with LiTMP gave rise to 
the pyrazyllithium intermediate 48, which can be quenched with electrophiles such as $p$ anisaldehyde affording the alcohol 49 as the only product (Scheme 15).

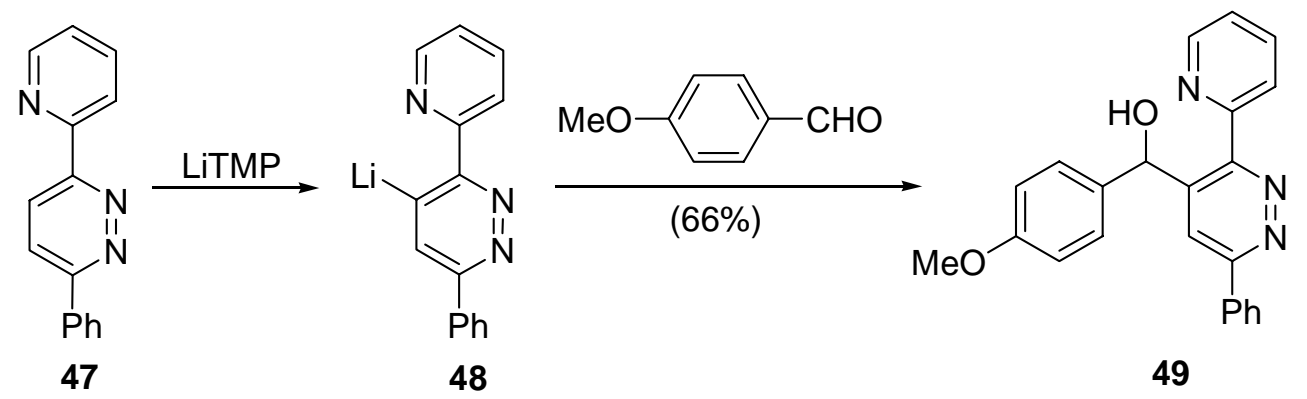

\section{Scheme 15}

In general, it is not very important whether a pyrimidyllithium species is obtained by halogen/lithium exchange or direct deprotonation, the stability of the intermediate rather than the method of generation being the critical issue. Thus, 5-pyrimidyllithium species are fairly stable when the metal is flanked by two electron-withdrawing substituents such as trifluoromethyl and chlorine or bromine, and can be generated by direct $n$-butyllithium-promoted metalation. ${ }^{125}$ Another example of direct metalation on a pyrimidine ring is the LiTMP-promoted lithiation of 4-iodopyrimidine 50 to give 5-pyrimidinyllithium species $\mathbf{5 1}$, which has been formylated to afford the aldehyde $\mathbf{5 2}$ in a synthesis of 14-azacamptothecin, a water-soluble topoisomerase I poison (Scheme 16). ${ }^{126}$ This lithiating agent has also been used for the DoM preparation of 5lithio-2,4-di-tert-butoxypyrimidine, a useful heteroaryllithium used in the synthesis of pseudouridines. ${ }^{127}$ However, there are examples of formation of 5-pyrimidyllithium reagents without close stabilizating groups, as in the case of the tert-butyllithium-promoted bromo-lithium exchange in 5-bromo-2-[(trimethylsilyl)ethynyl)]pyrimidine, although the lithiation had to be performed at $-100{ }^{\circ} \mathrm{C} .{ }^{128}$ Recent examples of the application of 4-lithiopyrimidines, created by bromo-lithium exchange, can also be found, as in an addition to a chiral lactone in a synthesis of (-)-7-epicylindrospermopsin, a toxic metabolite of a freshwater cyanobacterium. ${ }^{129}$<smiles>COc1cc(I)nc(Cl)n1</smiles>

50<smiles>CCOC(=O)c1c(I)nc(Cl)nc1OC</smiles>

51<smiles>COc1nc(Cl)nc(I)c1C=O</smiles>

52

\section{Scheme 16}




\subsubsection{Nonaromatic heterocycles}

Non-stabilized $\mathrm{N}$-anisyl aziridinyllithium reagents have been obtained via sulfoxide-lithium exchange using tert-butyl lithium at low temperature $\left(-100{ }^{\circ} \mathrm{C}\right)$, reacting afterwards with different electrophiles. ${ }^{130}$ The tin-lithium exchange has also been used for creating lithiated aziridines, an application of them being an internal Michael addition reaction to a 3-carboxylated indole in a synthesis of aziridines-containing antitumor agents. ${ }^{131}$ When an $\alpha$-stabilizing group is required for a direct deprotonation, the trifluoromethyl group has been found to be appropriate. Thus, $\mathrm{N}$-tosyl and $\mathrm{N}$-anisyl-protected optically active trifluoromethyl aziridines have been lithiated at low temperature $\left(-102{ }^{\circ} \mathrm{C}\right)$ using alkyllithiums, giving aziridine anions as synthetic precursors of $\alpha$-amino- $\alpha$-trifluoromethylated compounds. ${ }^{132}$ However, more recently, the direct regio- and stereoselective deprotonation of $N$-sulfonyl-protected terminal aziridines has been achieved, as exemplified in the LiTMP lithiation of the aziridine 53 to give the aziridinyllithium species 54, which reacts with pivalaldehyde to give compound 55 as the only isomer (Scheme 17). ${ }^{133}$
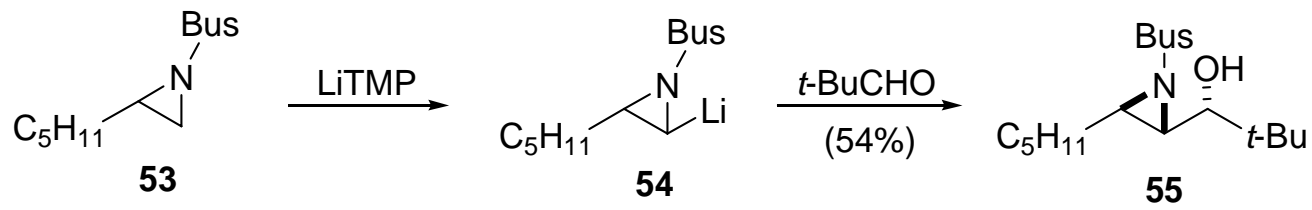

[Bus = tert-Butylsulfonyl]

\section{Scheme 17}

2-Methyleneaziridinyl anions have been produced by C-3 deprotonation of the parent aziridine using sec-butyllithium/TMEDA and reacted with electrophiles affording the corresponding substituted methyleneaziridines. ${ }^{134}$ The process can be performed diastereoselectively when the starting aziridine bears a $(S)$ - $\alpha$-methylbenzyl group on the nitrogen atom, ${ }^{135}$ as in the case of aziridinyllithium species $\mathbf{5 7}$, generated by deprotonation of the aziridine 56, which reacted with an electrophile such as allyl bromide affording the diastereoselectively enriched compound 58 (Scheme 18). ${ }^{134}$ The direct lithiation of aziridines using secbutyllithium/TMEDA has been facilitated when the next carbon atom is occupied by an oxazolinyl group, which can also affect the stereoselectivity of the further reaction with electrophiles due to their complexating properties. ${ }^{136}$ In addition, the formation of an aziridineborane complex facilitates the $\alpha$-metalation and the control of the stereochemistry, ${ }^{137}$ the process being also performed with enantiopure complexes. ${ }^{138}$ 

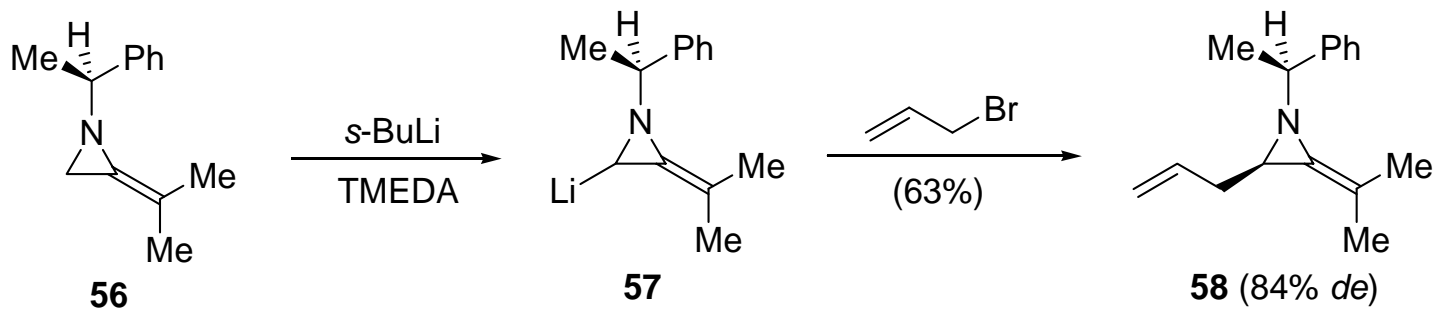

\section{Scheme 18}

The synthesis and applications of stabilized oxiranyllithium reagents has been recently reviewed. ${ }^{139}$ Examples of synthetic applications of lithiated aryloxiranes are the asymmetric synthesis of cyclopropanes from the reaction of oxiranyllithiums and $\alpha, \beta$-unsaturated Fischer carbene complexes, ${ }^{140}$ or the use of a oxazolidine ring for directing and fixing the stereoselectivity of the lithiation, as commented in the case of aziridinyllithium reagents (see above). A recent example of the latter methodology is the diastereoselective lithiation of enantiomerically pure oxazolidinyl-substituted arylepoxide $\mathbf{5 9}$ to generate the organolithium reagent 60 (Scheme 19). ${ }^{141}$ This chiral oxiranyllithium species reacts with nitrones such as compound 61 to give the 1,6-dioxa-4,7-diazaspiro[4.5]decane derivative 62, which after some transformations can be converted into $\gamma$-amino acid derivatives or $\gamma$-butyrolactones.

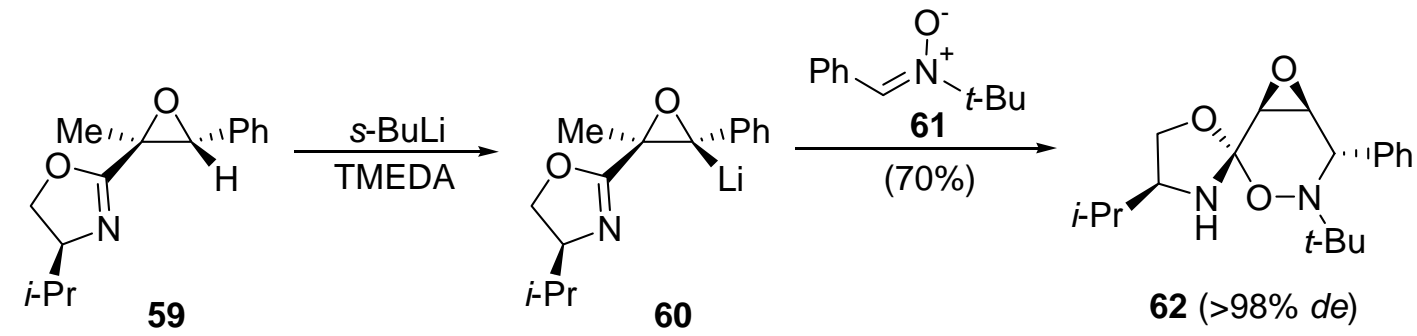

\section{Scheme 19}

The discovery that $N$-Boc-pyrrolidine could be asymmetrically $\alpha$-deprotonated using secbuthyllithium in the presence of an stoichiometric amount of (-)-sparteine represented a key development in chiral organolithium chemistry. ${ }^{142,143}$ The procedure has allowed the synthesis of a series of 2-substituted pyrrolidines with high enantioselectivity, as well as enantiomerically enriched 5-substituted imidazolidines, ${ }^{144}$ although in only one enantiomerically enriched form. A recent example of the application of the thus generated $(R)-N$-Boc-2-lithiopyrrolidine-(-)sparteine complex 63 is the boron trifluoride etherate-assisted ring opening of ethylene oxide to give the alcohol 64 (Scheme 20). ${ }^{145}$ However, recently it has been reported a new sparteine-like diamine that gives predominantly the opposite absolute configuration of the organolithium species, acting as a $(+)$-sparteine surrogate, ${ }^{146}$ being also applied to the lithiation of piperidine. ${ }^{147}$ This diamine has been used in a total synthesis of (-)-kainic acid. ${ }^{148}$ Rationalization for this 
asymmetric deprotonation has been proposed revealing that the A-ring of sparteine is crucial for achieving the enantioselectivity, ${ }^{149}$ experimental and computational studies being extended to sparteine-like diamines. ${ }^{150}$

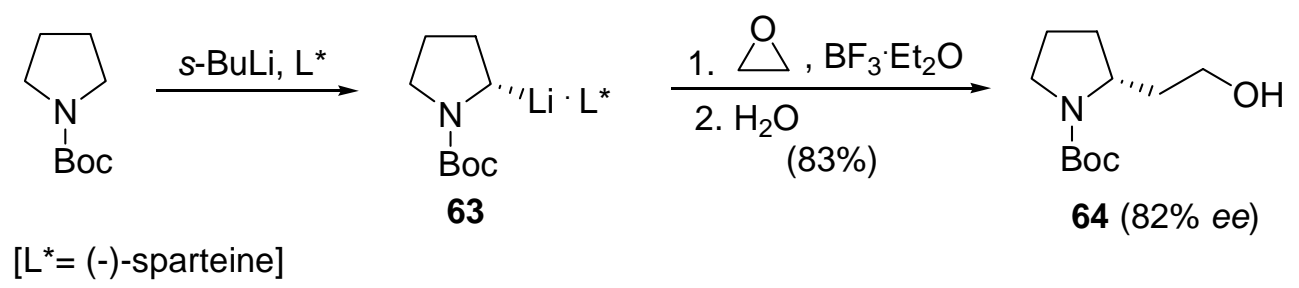

\section{Scheme 20}

The usually high enantioselection achieved in the asymmetric deprotonation-electrophilic trapping when stoichiometric amounts of (-)-sparteine are used, drops down when substoichiometric amounts are employed. However, its has been discovered that a ligand exchange approach can be used using a substoichiometric amount of (-)-sparteine, or the former $(+)$-sparteine surrogate, and an stoichiometric amount of an achiral diamine. ${ }^{151}$

In the asymmetric deprotonation of $N$-Boc-pyrrolidine, the enantiomeric ratios are reduced when the chiral organolithium species is allowed to warm to $-40{ }^{\circ} \mathrm{C}$ prior to quenching. Kinetic studies on unstabilized (alkyl group on nitrogen), chelated (methoxyethyl group on nitrogen) and dipole-stabilized and chelated (Boc group on nitrogen) lithiopyrrolidines have shown that the barrier to enantiomerization is in the range of $19-22 \mathrm{Kcal} / \mathrm{mol}$ at $0{ }^{\circ} \mathrm{C} .{ }^{152}$ The ability of this organolithium species to undergo racemization has prompted the study of the dynamic thermodynamic resolution of racemic $N$-Boc-2-lithiopyrrolidine (generated by tin-lithium exchange) in the presence of a chiral diamine ligand, the enantioselectivity arising from the faster reaction of the minor diastereomeric complex with the electrophile. ${ }^{153}$ The knowledge on 2-lithiopyrrolidines has been completed with structural studies on aggregation and dynamic solvation effects using NMR spectroscopy. ${ }^{154}$

(4,5-Dihydrofuran-2-yl)lithium (65) has been prepared by tert-butyllithium-promoted metalation of 2,3-dihydrofuran, ${ }^{155}$ and there are examples of its use in alkylation reactions. For instance, when reacting intermediate 65 with the iodide 66 compound 67 was obtained (Scheme $21),{ }^{156}$ the same organolithium being used in the ring opening of $N$-alkyl oxazolidinones. ${ }^{157}$

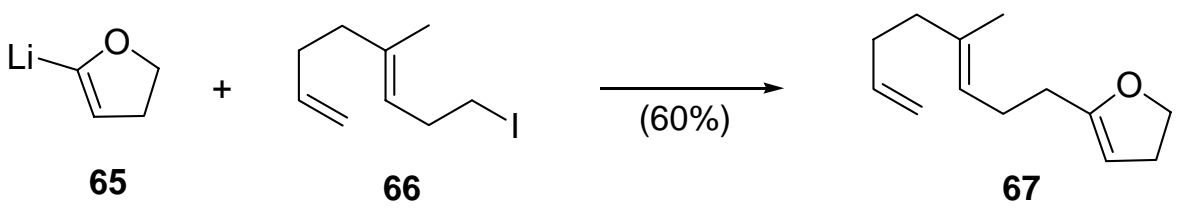

\section{Scheme 21}


There are recent examples of the generation of synthetically useful racemic $\mathrm{N}$-protected 2lithio-pyrrolidine and piperidine systems, as in the synthesis of the lupin alkaloid ( \pm )-cytisine via lithiation of $N$-Boc-bispidine, ${ }^{158}$ or the selective lithiation of $N$-Boc-2-phenyl-piperidine and pyrrolidine, with $n$-butyllithium. For instance, intermediate 68 (Scheme 22). reacts with an electrophile such as enantiomerically pure bromide 69 giving rise to the 2,2-disubstituted piperidine $\mathbf{7 0}$ as a mixture of diastereomers, one of them acting as an orally active $\mathrm{NK}_{1}$ receptor antagonist. ${ }^{159}$ In addition, there are examples of the use of (1,2,3,4-tetrahydroisoquinolin-1yl)lithium reagents as nucleophiles, generated by treatment of the corresponding $N$-substituted tetrahydroisoquinolines with alkyllithiums, ${ }^{160}$ or by reductive cleavage of 1-alkoxy-substituted systems employing lithium metal and a catalytic amount of naphthalene. ${ }^{161}$

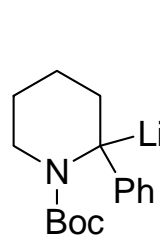

68<smiles>[CH2]C(OCBr)c1cc(C(F)(F)F)cc(C(F)(F)F)c1</smiles>

69<smiles>CC(OCC1(c2ccccc2)CCCCN1C(=O)OCc1ccccc1)c1cc(C(F)(F)F)cc(C(F)(F)F)c1</smiles>

70

\section{Scheme 22}

The lithiated heterocyclic species 72, obtained upon metalation of $N$-Boc-protected 1,3oxazinane 71 with sec-butyllithium, has been quenched with trimethylsilyl chloride affording the silylated derivative 73 (Scheme 23), as part of a formal synthesis of the alkaloid ( \pm )pancratine. ${ }^{162}$ Finally, 2-lithio-1,3-dithianes are very well known lithiated heterocycles in organic synthesis as formyl or acyl anion equivalents, ${ }^{163}$ recent examples of their synthetic use in the last years being frequent. ${ }^{164}$

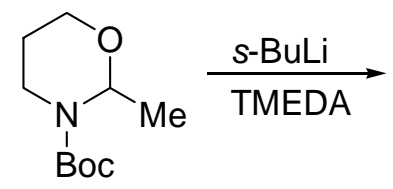

71<smiles>CC1OCCC([AlH])N1C(=O)OCc1ccccc1</smiles>

72
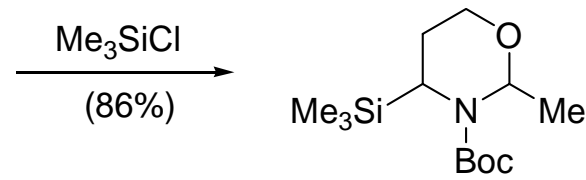

73

\section{Scheme 23}

\section{Group 2 Metalated Heterocycles}

\subsection{Magnesium heterocycles}

The synthesis of heterocyclic organomagnesium reagents, especially for nitrogenated derivatives or compounds bearing different functionalities, is frequently problematic since the insertion of 
magnesium metal to heteroaryl halides is inhibited when electron-withdrawing groups are present in the ring. However, the halogen/magnesium exchange performed by treatment of hateroaryl bromides or iodides with alkyl Grignards has shown nowadays to be a very useful and frequent methodology for the preparation of many functionalized heteroaromatic organomagnesium reagents. ${ }^{1,4,165}$ These organometallics can react with electrophiles or be used in transition-metal catalyzed cross-coupling reactions (the so-called Kharasch or Kumada coupling). ${ }^{166}$

\subsubsection{Aromatic five-membered rings}

The usual metalating methodology with alkyl Grignards has been employed in the treatment of 1- and 2-iodoindoles with methylmagnesium bromide for the preparation of the corresponding 1and 2-indolylmanesium bromides, which have been diastereoselectively added to chiral 1acylpyridinium salts. ${ }^{167}$ Another example is the addition of a 1-carboxylated 2indolylmagnesium chloride, generated by treatment of the corresponding iodide with isopropylmagnesium chloride, to arylazotosylates. ${ }^{168}$

2-Furylmagnesium bromide, obtained from 2-furyllithium by a lithium/magnesium exchange using magnesium bromide, has been used as nucleophile in substitution reaction of allyl acetoxides ${ }^{169}$ and in addition reactions to the nucleus of chiral pyridinium salts. ${ }^{170}$ However, more sensitive [5-(ethoxycarbonyl)furan-2-yl]magnesium chloride (74) has been generated from the corresponding 2-iodofurane by the usual treatment with isopropylmagnesium chloride, and used in an iron-catalyzed coupling reaction to aroyl cyanide 75 at $-20{ }^{\circ} \mathrm{C}$ to give the ketone 76 (Scheme 24). ${ }^{171}$ The former 2-furylmagnesium reagent $\mathbf{7 4}$ can be prepared similarly from the corresponding 2 -iodofurane in $93 \%$ yield at $25{ }^{\circ} \mathrm{C}$ when bis[2-( $N, N$-dimethylaminoethyl)] ether (77) is added during the bromo/magnesium exchange, only a 57\% yield of $\mathbf{7 4}$ being obtained in the absence of this complexating agent. ${ }^{172}$ In addition, the direct $\alpha$-magnesiation of furan has been recently achieved using a sodium magnesiate, generating a disodium dimagnesium hexafuryl complex. ${ }^{173}$

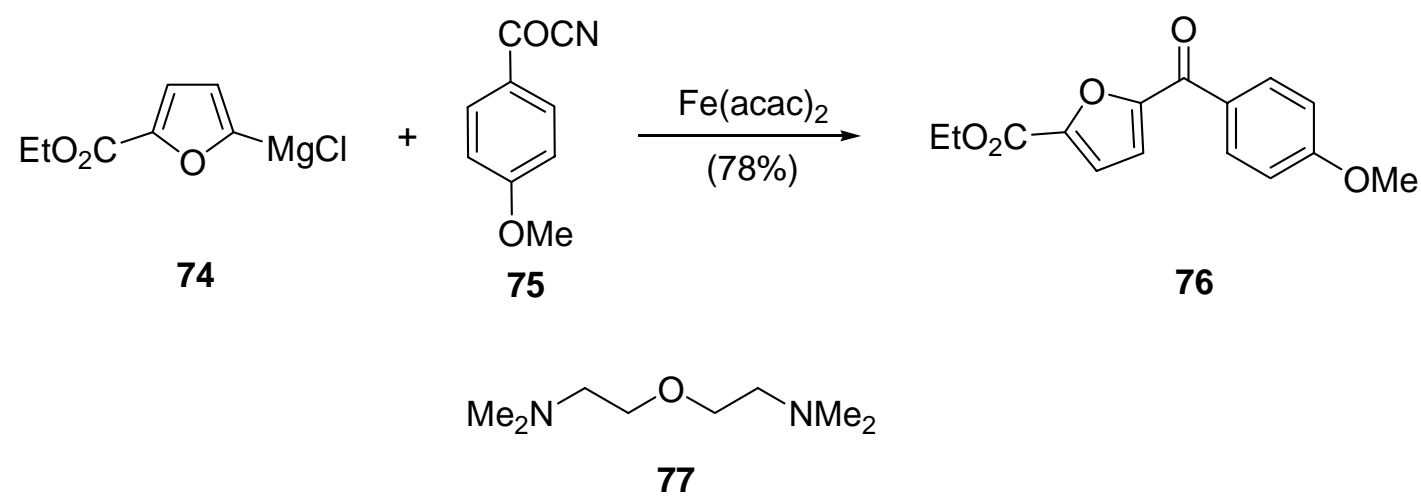

\section{Scheme 24}


2-Thienylmagnesium bromide can be prepared by the traditional halogen-metal exchange using magnesium turnings and used as nucleophile in addition reactions to a decahydroisoquinoline-derived aldehyde, ${ }^{174}$ to vinylogous acyl triflates ${ }^{175}$ or to lactones. ${ }^{176}$ This heteromagnesium reagent has also been used in the copper-catalyzed ring-opening of azabicyclic alkenes, ${ }^{177}$ as well as metalated counterpart in the cobalt-catalyzed cross-coupling with alkyl halides. ${ }^{178}$ In addition, 2-thienylmagnesium bromide and some alkylated derivatives have been frequently employed in the preparation of highly conjugated compounds with electrooptical properties by means of cross-coupling reactions with haloarenes using palladium, ${ }^{179}$ or more frequently, nickel-catalysts. ${ }^{180}$ Scheme 25 shows some applications of these couplings involving 2-thienylmagnesiums. When other functionalities are present, other metalation procedures are more convenient. Thus, the treatment of the dihalogenated thiophene $\mathbf{7 8}$ with isopropylmagnesium bromide gave place to a iodo-magnesium exchange generating the thienylmagnesium derivative 79, which after nickel(0)-promoted polymerization afforded poly(3-hexylthiophene) (80) with a very defined molecular weight and low polydispersity. ${ }^{181}$ Other example is the nickel-catalyzed coupling of the thienyl Grignard reagent 82, prepared from 2,3-dihydrothieno[3,4-b][1,4]dioxine (81) by lithium-magnesium transmetalation, with the aryl dibromide $\mathbf{8 3}$ to give the bis-thiophene $\mathbf{8 4}$, with blue emission properties. ${ }^{182}$

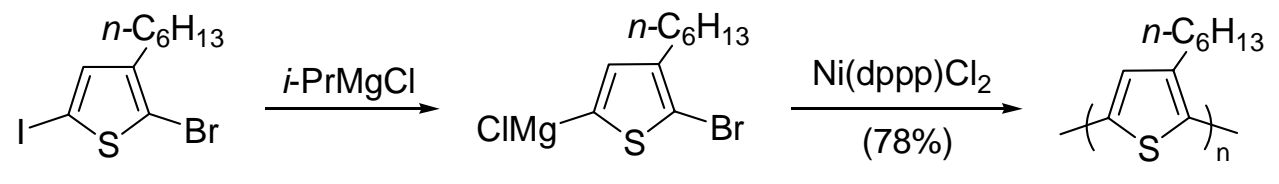

78

79

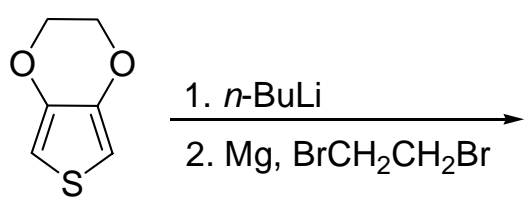

81

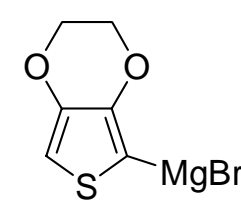

82

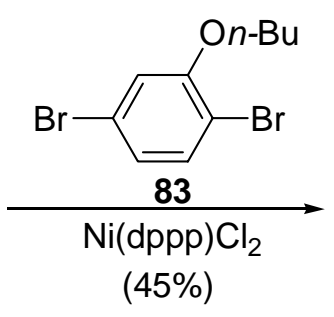

(45\%)

80

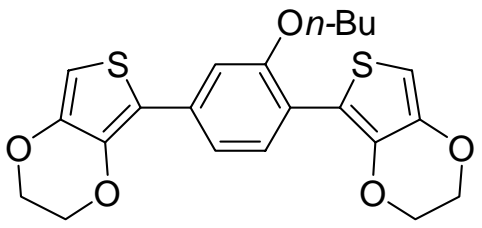

84

[dppp = 1,3-bis(diphenylphosphino)propane]

\section{Scheme 25}


3-Thienylmagnesium reagents have been prepared from the corresponding brominated derivatives by bromine-magnesium exchange using alkylmagnesium halides and used, for instance, in nickel-catalyzed cross-coupling reactions. ${ }^{183}$ This exchange reaction can also be performed using $i$-PrMgCl$\cdot \mathrm{LiCl}$, the lithium salt enhancing the reactivity of the created arylmagnesium by breaking the Grignard polymeric aggregates. ${ }^{184}$ This procedure has been applied to some heteroaryl bromides such as 3-thienyl bromide, the resulting organomagnesium being used in an addition reaction to benzaldehyde. ${ }^{184}$

Thiazolylmagnesiums metalated at C-2 have been obtained by the usual bromine-magnesium exchange using alkyl Grignards, even regioselectively, as it can be seen in Scheme 26 where the 2-thiazolylmagnesium bromide $\mathbf{8 6}$ is obtained from 2,4-dibromothiazole (85). This reagent has been used in an addition reaction to the chiral nitrile $\mathbf{8 7}$ affording, after reduction, the amine $\mathbf{8 8}$, a building block for the synthesis of thiazolyl peptides. ${ }^{185}$ The lithium-magnesium transmetalation can also be used for the generation of thiazolylmagnesiums, an example being the preparation of 2-methylthiazol-4-ylmagnesium bromide, useful in the preparation of a fragment of epothilone via a copper(I)-catalyzed coupling to an allylic bromide. ${ }^{186}$

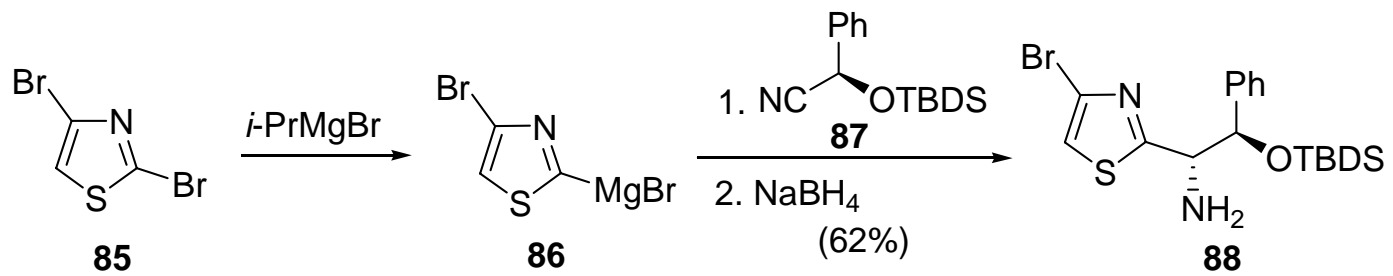

\section{Scheme 26}

\subsubsection{Aromatic six-membered rings}

Magnesiated pyridines are usually prepared by the reaction of the corresponding bromide or iodide with alkyl or aryl Grignard reagents, although the direct metalation using magnesium turnings at higher temperatures can also be employed when no other functionalities are present, as the case of the recent use of 3-pyridylmagnesium bromide, generated at $70{ }^{\circ} \mathrm{C}$, for the preparation of aromatase inhibitors. ${ }^{187}$ However, the first method is more convenient due to the milder conditions employed, an example being the formation 5-bromopyridyl-2-magnesium chloride (90) from 5-bromo-2-iodopyridine (89) by iodine-magnesium exchange at $0{ }^{\circ} \mathrm{C}$, and its use as nucleophile in the reaction with the Weinreb amide 91 to give the ketone 92 (Scheme 27). ${ }^{188}$ In addition, 3-pyridylmagnesium reagents have been obtained similarly and used also in reactions with Weinreb amides ${ }^{189}$ and in additions to azo compounds. ${ }^{190}$ 


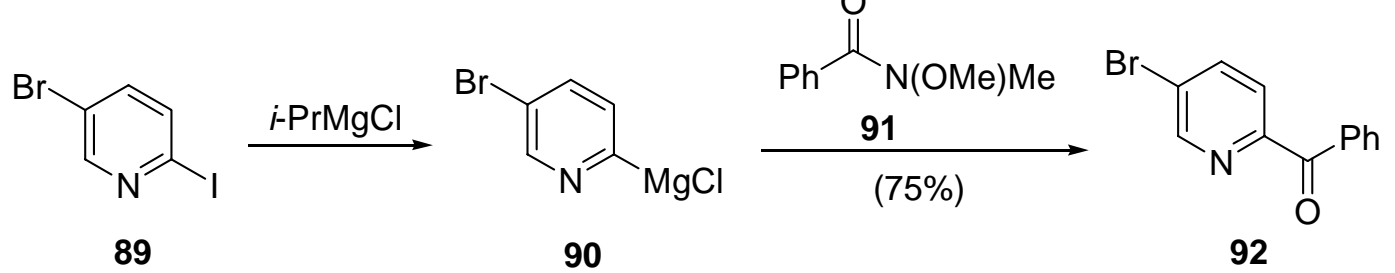

\section{Scheme 27}

The above mentioned use of lithium chloride to enhancing the reactivity of alkyl Grignards employed in metalation reactions has also been used for the generation of 2-magnesiated pyridines employed in addition reactions to aldehydes ${ }^{191 \mathrm{a}}$ and ketones, ${ }^{191 \mathrm{~b}}$ as well as in the preparation of 3-pyridylmagnesium reagents. ${ }^{192}$ Moreover, functionalized picolines have been recently obtained by using a bromine-magnesium exchange at C-3 employing an organomagnesium reagent generated by mixing $n$-butyllithium and isopropylmagnesium chloride and a subsequent reaction with electrophiles. ${ }^{193}$ Furthermore, 2-, 3- and 4-bromoquinolines such as compound 93 can be converted into the corresponding lithium tri(quinolinyl)magnesates such as $\mathbf{9 4}$ when exposed to $n$ - $\mathrm{Bu}_{3} \mathrm{MgLi}^{194}$ This organomagnesium compound $\mathbf{9 4}$ can be quenched with electrophiles ${ }^{194 \mathrm{~b}}$ or can be used in metal-catalyzed coupling reactions with heteroaryl halides ${ }^{194}$ to afford functionalized quinolines, as is the case of the palladium-catalyzed coupling with 2-bromopyridine to give the quinoline 95 (Scheme 28). ${ }^{194 a}$ Related lithium magnesate reagents have allowed the $o$-metalation of fluoropyridines, ${ }^{194 a}$ chloropyridines ${ }^{195 b}$ and 3 fluoroquinoline ${ }^{195 a}$ to give pyridyl- $^{195}$ and 2-quinolinylmagnesates. ${ }^{195 a}$ Finally, iodinated thioenopyrimidines and purines have been also transformed into magnesates for addition reactions to aldehydes. ${ }^{196}$

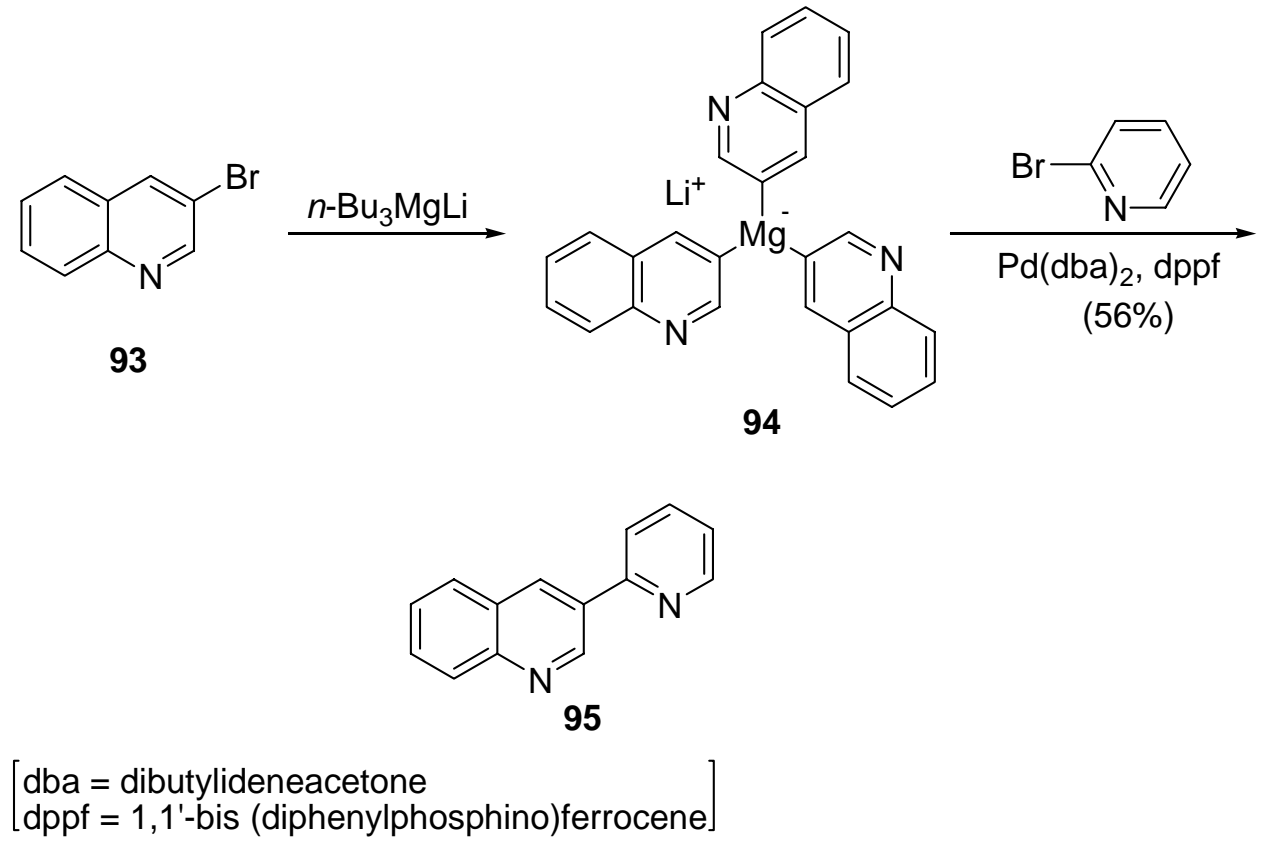

\section{Scheme 28}


The recently developed highly soluble mixed magnesium/lithium amide derived from 2,2,6,6-tetramethylpiperidine 97, which has high kinetic activity because of the presence on the lithium chloride salt (see above), has shown to be a quite efficient base for the regioselective generation of functionalized heteroaryl magnesium compounds. ${ }^{197}$ For example, treatment of 2chloropyrimidine (96) with this reagent 97 allowed the generation of the corresponding 4magnesiated derivative 98 at $-55^{\circ} \mathrm{C}$ which adds to $p$-bromobenzaldehyde to give the alcohol 99 (Scheme 29). When the isopropylmagnesium chloride/lithium chloride mixture was used, the bromo/magnesium exchange in 5-bromo-4-halogeno-2,6-dimethoxypyrimidines and also the successive one-pot bromo/magnesium exchange and difunctionalization on 4,5-dibromo-2,6dimethoxypyrimidine, was regioselectively achieved. ${ }^{198}$

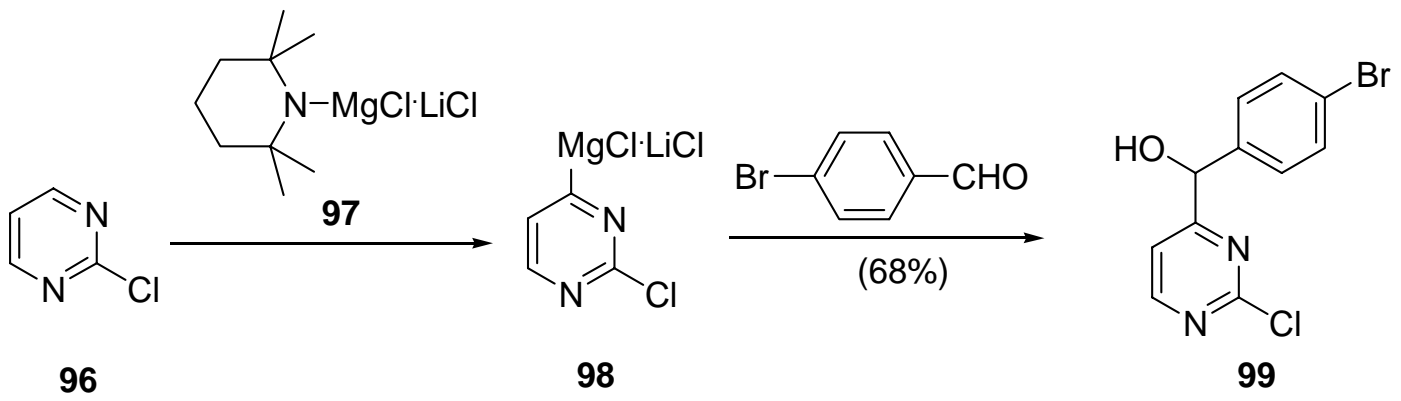

Scheme 29

\section{Group 3 Metalated Heterocycles}

\subsection{Boron Heterocycles}

Heterocyclic boronic acid derivatives are generally prepared by reaction of the corresponding organolithium derivatives with a trialkylborate, ${ }^{1,4,199}$ although there are examples of catalytic borylation of heteroarenes using iridium $^{200}$ and rhodium complexes. ${ }^{200,201}$ The formed organoboron derivatives are used mainly for palladium-catalyzed cross-coupling reactions (the so-called Suzuki-Miyaura reaction ${ }^{166}$ ).

\subsubsection{Aromatic five-membered rings}

N-Boc-protected pyrrole boronic acid 100, obtained by the typical borination of the directly 2lithiated species, has been recently employed in the palladium-catalyzed coupling reaction to the brominated pyrrole enamine 101 to give the bipyrrole aldehyde derivative 102, which is a precursor of polypyrrole natural products of the prodigiosin series (Scheme 30). ${ }^{202}$ Another member of this family of natural products has been obtained by palladium-catalyzed coupling of the boron derivative 100 with a pyrrolyl triflate. ${ }^{203}$ This pyrrole boronic acid compound has also been employed in other cross-coupling reactions, ${ }^{204}$ including progesterone receptor 
modulators ${ }^{205}$ and the total synthesis of ageladine $\mathrm{A} .{ }^{206}$ When the boronic acid functionality in the protected pyrrole is desired at $\mathrm{C}-3$, its preparation is achieved generally via a brominationlithiation-borination sequence, a recent example being the synthesis of a $N$-silyl-protected pyrrol3-ylboronic acid, which has been employed in the synthesis of conductive electrochromic polymers. $^{207}$

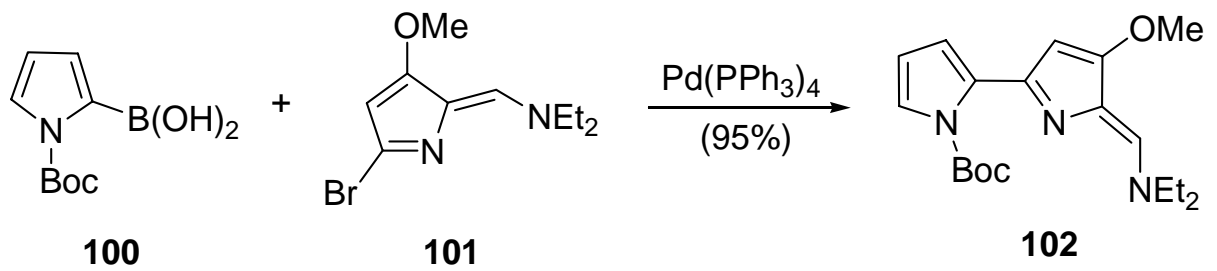

\section{Scheme 30}

As expected, indolylboronic acids can be prepared and behave similarly to pyrroles, being also mainly used in cross-coupling reactions. Thus, $N$-substituted indolyl-2-boronic acids are obtained from the corresponding indole by direct lithiation followed by treatment with trimethylborate and hydrolysis, ${ }^{208}$ examples of their use being a cross-coupling reaction driving to a indolocarbazole alkaloid. ${ }^{209}$ Indolyl-3-boronic acids can be obtained by the former bromation-lithiation-borination sequence, as shown in the generation of an indol-3yl(pinacolboronate), as Suzuki-Miyaura boronic acid counterpart in a total synthesis of the bisindole alkaloid (+)- and (-)-dragmacidin F. ${ }^{210}$ However, there are examples of preparation of indol-3-ylboronic acids using other methodologies, such as the mercury-boron exchange, as shown in Scheme 31, where the indolylboronic acid $\mathbf{1 0 4}$ is obtained after 3-mercuriation of the bromoindole 103, being employed for a double coupling to 2,5-dibromopyrazine giving compound 105 in a formal total synthesis of dragmacidin B, trans-dragmacidin $\mathrm{C}$ and cis and trans-dihydrohamacanthins A. ${ }^{211}$ The Suzuki-Miyaura coupling employing different nitrogenated five- and six-membered heteroaryl boronic acids has been efficiently performed very recently using $\mathrm{Pd}_{2}(\mathrm{dba})_{2}-\mathrm{PCy}_{3}$ as catalytic system in the presence of potassium phosphate. $^{212}$ 


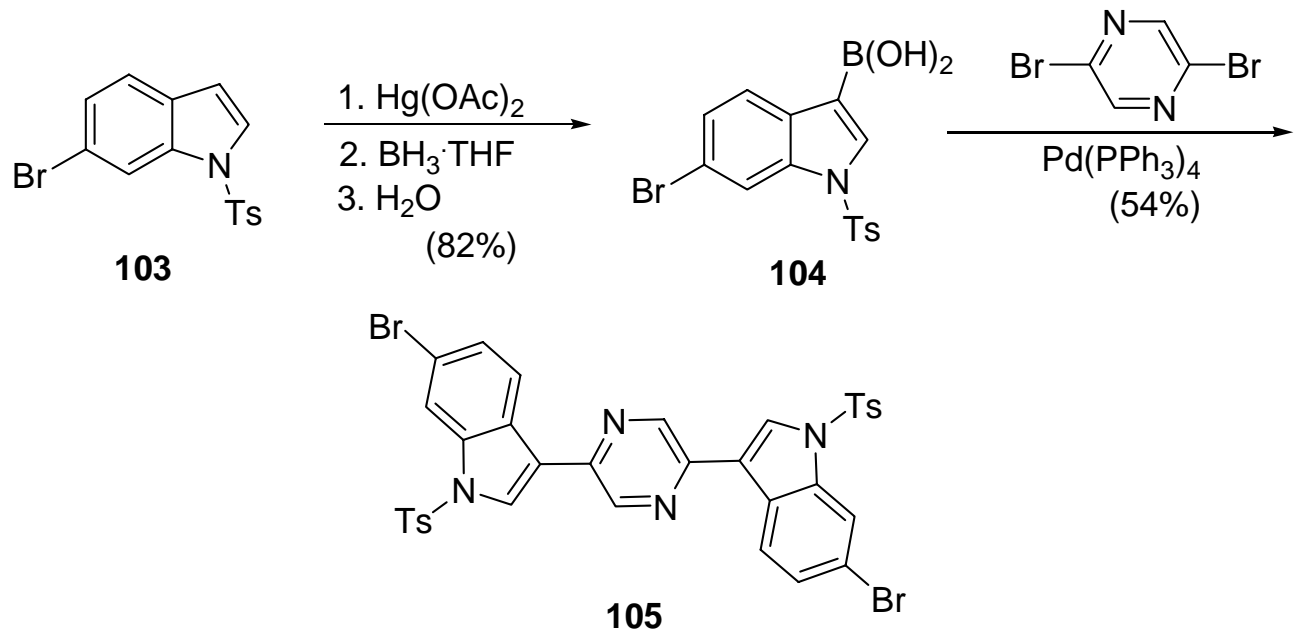

\section{Scheme 31}

Furylboronic acids were prepared similarly to pyrrole derivatives, recent examples of the use of fur-2-ylboronic acid in Suzuki-Miyaura cross-couplings being frequent. ${ }^{213}$ 3-Furylboronic acids have also been used in this type of reaction, for instance, in the coupling to a 6chloropurine ribonucleoside in the search for compounds with anti-HCV or cytostatic activity. ${ }^{214}$ In addition, benzofurylboronic acids behave similarly to their non-benzocondensated counterparts, some recent examples of their use in Suzuki-Miyaura couplings being the synthesis of a precursor of the antimalarial machaeriol $\mathrm{B},{ }^{215}$ sulfamide HIV-1 protease inhibitors, ${ }^{216}$ antifungal dihydrofuranones, ${ }^{217}$ heteroarylated azolopyrimidines ${ }^{218}$ or compound $\mathbf{1 0 8}$ from the coupling of benzofuran-2-ylboronic acid (106) and the bromonaphthalene 107 (Scheme 32). ${ }^{219}$ This compound $\mathbf{1 0 8}$ is an intermediate in the preparation of a potent inhibitor of plasminogen activator inhibitor-1.

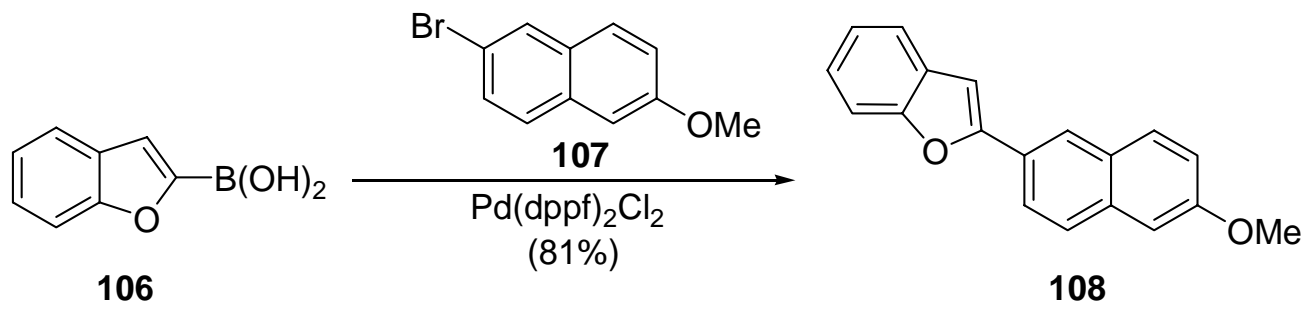

\section{Scheme 32}

Thien-2-ylboronic acids, prepared by lithium-boron exchange have been used recently in different Suzuki-Miyaura processes, being coupled to benzyl bromides, ${ }^{220}$ aryl halides, ${ }^{221}$ vinyl halides, ${ }^{222}$ or chloropyrimidones. ${ }^{223}$ Among these applications, those involving the preparation of highly conjugated systems involving the thiophene moiety with optoelectronic properties are particularly interesting. ${ }^{224}$ An illustrative example is the use of the thiophene boronic acid 109 (obtained by 2-lithiation of the corresponding 2,4-dibrominated derivative and further treatment 
with tri-n-butylborate) in the coupling to 1-bromo-4-fluorobenzene to give the brominated derivative 110 (Scheme 33). ${ }^{225}$ This compound has been used, after lithiation and coupling to octafluorocyclopentene, in the synthesis of dithienylethenes with photochromic properties. ${ }^{225}$ In addition, benzo[b]thiophenylboronic acids have been cross-coupled with 2-brominated dehydrophenylalanines. ${ }^{226}$ Moreover, copper-catalyzed cross-coupling reactions between an alkynyliodonium salt and thien-2-ylboronic acid has also been reported. ${ }^{227}$ Interestingly, substituted thien-2-ylboronic acids have been explored as inhibitors of hormone-sensitive lipase. $^{228}$

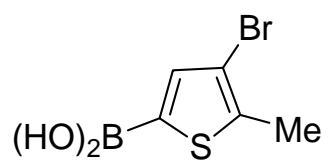

109

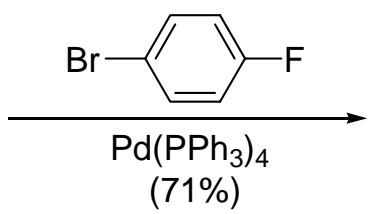

$(71 \%)$

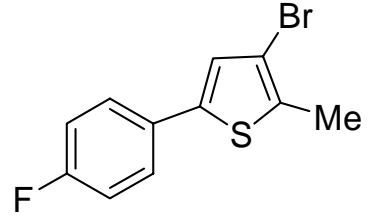

110

\section{Scheme 33}

Pinacole-derived thien-2-ylboronate derivative $\mathbf{1 1 2}$ has been recently obtained by copper(I)catalyzed cross-coupling reaction of 2-iodothiophene (111) with pinacolborane (Scheme X). ${ }^{229}$ This type of thienylboronates have also been prepared using palladium-catalysis, ${ }^{230}$ as well as by lithiation of the thiophene system and further reaction with 2-isopropoxy(pinacole)borane. ${ }^{231}$ These heteroaromatic pinacolboranes have been used in cross-coupling processes, ${ }^{230,232}$ but also in the Petasis reaction between boronates, aldehydes and primary and secondary amines, as illustrated in Scheme 34, where boronate 112, glyoxylic acid and benzylamine react to give the aminoacid derivative 113 . $^{233}$

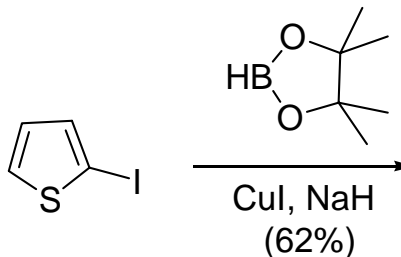

111<smiles>CC1(C)OB(c2cccs2)OC1(C)C</smiles>

112

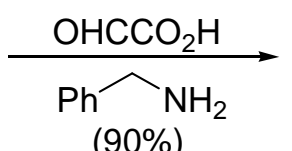

$(90 \%)$

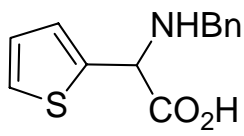

113

\section{Scheme 34}

Examples of the use of thien-3-ylboronic acid (114) in Suzuki-Miyaura coupling reactions are the synthesis of 2- and 5-thienylated pyrazinones from the corresponding chlorides, ${ }^{234}$ as well as the coupling to bromosulfonamide 115 to give compound 116 (Scheme 35), in the search of selective $\mathrm{EP}_{1}$ receptor antagonists. ${ }^{235}$ In addition, potassium 3-thiophenetrifluoroborate (117) (as well as their furane and pyridine analogues) have been prepared from the corresponding boronic 
acid by reaction with $\mathrm{KHF}_{2}$, and has been used in palladium-catalyzed coupling reactions with heteroaryl halides ${ }^{236}$ or triflates, as shown in the preparation of the heteroarylated anisole 118 (Scheme 35). ${ }^{237}$ This borate $\mathbf{1 1 7}$ has also been used in a copper(II)-catalyzed $O$-arylation of furfuryl alcohol. ${ }^{238}$

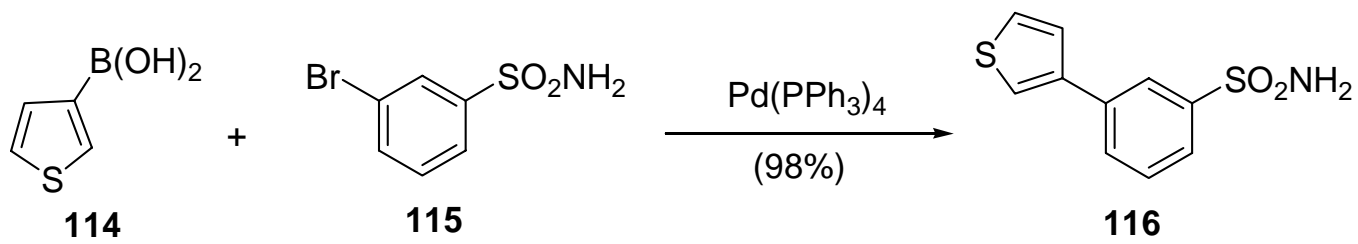<smiles>[Mg]C(Br)(Br)c1ccsc1</smiles>

117

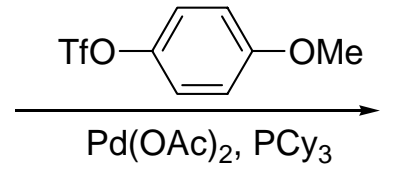

$(79 \%)$

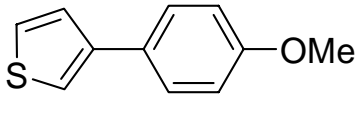

118

\section{Scheme 35}

3-Aryl-1-H-pyrazoles have been recently obtained from the corresponding pyrazolyl pinacolderived boronates by Suzuki-Miyaura coupling. Thus, silyl-protected boronate $\mathbf{1 2 0}$ has been prepared from the corresponding pyrazole 119 by successive lithiation, reaction with triisopropylborate and condensation with pinacol (Scheme 36). ${ }^{239}$ The obtained boronates can be cross-coupled with an aryl iodide or bromide such as phenyl iodide to give the coupled product 121. In addition, isoxazoles substituted with a pinacol-derived boronic esters at $\mathrm{C}-3$ have been obtained by [3+2] cycloaddition involving nitrile oxides and alkynylboronates. ${ }^{240}$ Moreover, 3benzyloxyisothiazole has been transformed into a isothiazo-5-yl boronic ester, intended to crosscoupling reactions, via direct lithiation using LDA followed by boronic ester formation and transesterification. ${ }^{241}$ However, the yield was very low, probably due to the limited stability of the 5-lithio-3-benzyloxyisothiazole intermediate.

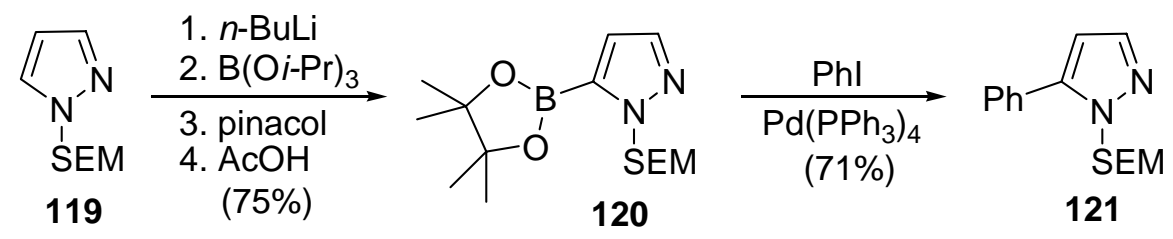

[SEM = 2-(trimethylsilyl)ethoxymethyl]

\section{Scheme 36}




\subsubsection{Aromatic six-membered rings}

Boronated pyridines are prepared normally via the usual lithium or magnesium transmetalation, frequently achieved by halogen-metal exchange or the DoM methodology. Among boronated pyridines, reports on the preparation of 2-pyridylboron species are rather sparse. ${ }^{199}$ However, 2pyridylboronic acid has been prepared in $70 \%$ yield from the corresponding 2-bromopyridine through initial reaction with isopropylmagnesium chloride and the usual metal-boron exchange. ${ }^{242}$ However, the lithium-boron transmetalation has been used in the case of the preparation of halopyrid-2-ylboronic acids and esters for palladium-catalyzed cross-couplings, ${ }^{243}$ whereas 2,2'-bipyridines have been metalated with pinacol-derived boronic acid esters using an iridium-catalyzed borylation. ${ }^{244}$

More stable 2-pyridylboron species, also suitable for cross-coupling reactions, are 2pyridinedioxazaborocanes such as $\mathbf{1 2 3}$, which can be prepared by esterification of the corresponding boronic acid with $N$-substituted diethanolamines ${ }^{243}$ or by reaction of the lithium boronate intermediate 122 with $\mathrm{N}$-phenyldiethanolamine (Scheme 37). ${ }^{245 a}$ This boronate 123 has been used in Suzuki-Miyaura reactions such as the coupling with 1-iodo-4-nitrobenzene to give the arylpyridine 124. An $N$-anchored diethanolamine has also been used in this process, the obtained supported 2-pyridylboron reagent being used for cross-couplings in combinatorial chemistry. ${ }^{245 b}$

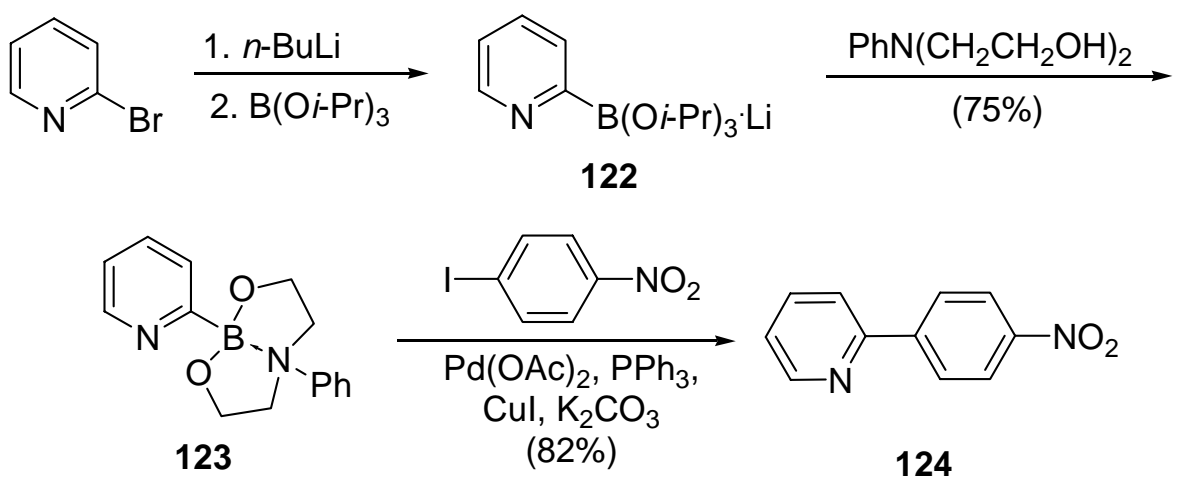

\section{Scheme 37}

3-Pyridylboron reagents have been employed more frequently than their 2-boronated counterparts in Suzuki-Miyaura cross-coupling reactions. Thus, examples of the use of 3pyridinboronic acids in the last years are common, ${ }^{246}$ as it is the case of 2-ethoxy-3pyridylboronic acid 126, obtained by a DoM reaction of 2-ethoxypyridine (125), which has been employed for the coupling reaction with heteroaryl bromides such as 5-bromo-2methoxypyrimidine (127), to give the corresponding coupled product 128 (Scheme 38). ${ }^{247}$ In addition, examples of the use 4-pyridylboronic acids for the preparation of 4,4'-bipyridyl systems can be recently found, ${ }^{248}$ as well as the use of $N$-alkyl-boronopyridinium salts as thermally stable and reusable amide condensation catalysts. ${ }^{249}$ Moreover, 2- and 3- 
pyridylboronic acids have shown an unusual behaviour in the above mentioned Petasis reaction, affording dioxaborolanones instead of amino acid derivatives. ${ }^{250}$

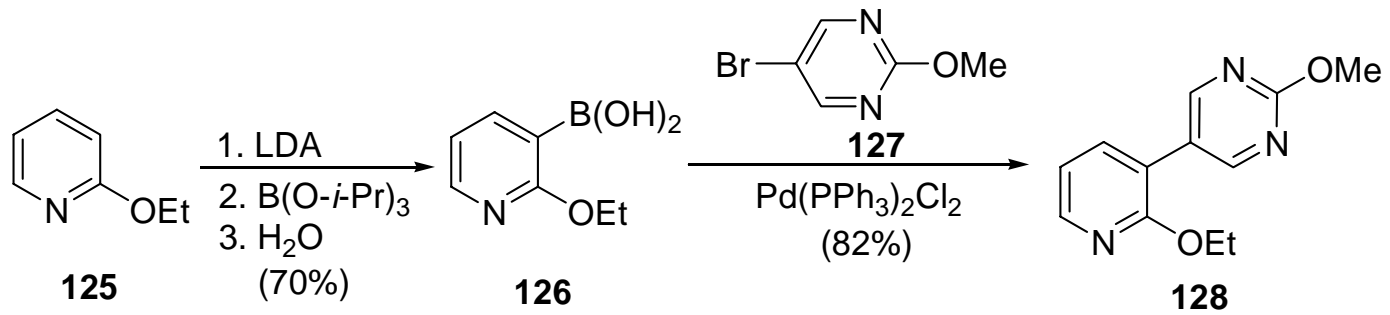

\section{Scheme 38}

Examples of the use of pinacol-derived 3-pyridylboronates in the Suzuki-Miyaura reaction have been recently reported. ${ }^{251}$ These pyridylboronates have also been used in copper-promoted $\mathrm{C}-\mathrm{N}^{252}$ and $\mathrm{C}-\mathrm{O}^{253}$ bond cross-coupling reactions, an example being shown in Scheme 39 for the coupling of the pyridine-derived dioxaborolane 129 with $p$-chlorophenol (130), to afford the oxybisarylated compound $\mathbf{1 3 1}$ in the search of building blocks in cholinergic medicinal chemistry. ${ }^{253}$ This reaction seems to depend strongly on the $\mathrm{pK}_{\mathrm{a}}$ of the hydroxy compound, the higher the value, the more efficient the coupling. There are also examples of the use of 3pyridylboroxin in the generation of 3-pyridyl biaryl systems by means of the palladium-catalyzed Suzuki-Miyaura reaction. ${ }^{254}$

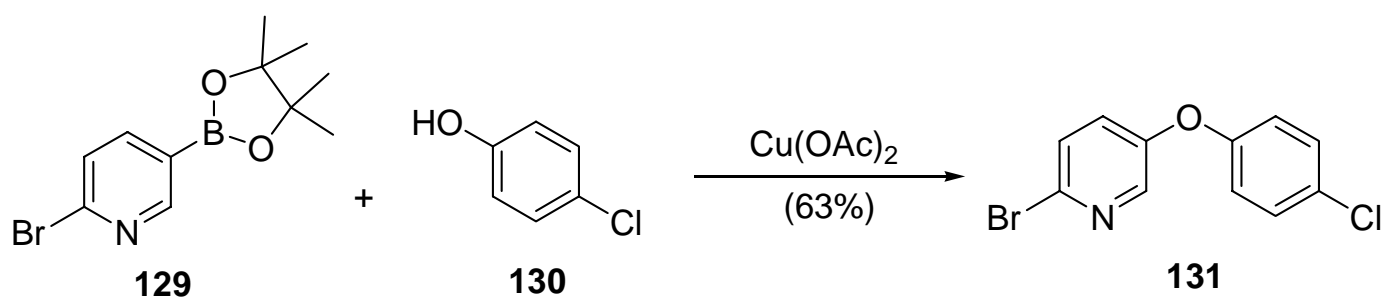

\section{Scheme 39}

Highly substituted pyridazines have been prepared by a sequence involving cycloaddition reactions of pinacol-derived alkynyl boronic esters with symmetrical tetrazines and subsequent cross-coupling reaction using the formed pyridazine boronic ester. ${ }^{255}$ An example of this methodology is the cycloaddition of the tetrazine 132 with the alkynylboronate $\mathbf{1 3 3}$ to give the boronic ester 134 after nitrogen extrusion (Scheme 40). Subsequent palladium-catalyzed crosscoupling with phenyl iodide gave the pyridazine 135. When the pyridazine boronic ester is treated with hydrogen peroxide, an oxidation to the $1 H$-pyridazin-4-ones takes place. ${ }^{255}$ In addition, 5-pyrimidylboronic acid and 2-methoxy-5-pyrimidylboronic acid, prepared by the typical halogen-lithium-boron exchange process, has been used for the synthesis of heteroarylpyrimidine derivatives via Suzuki-Miyaura cross-coupling reactions. ${ }^{256}$ 


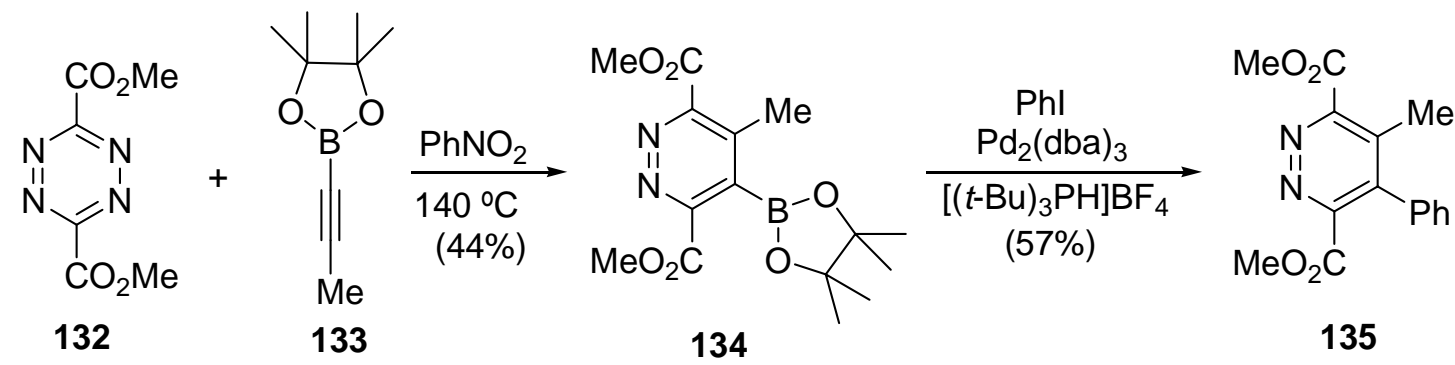

\section{Scheme 40}

\subsubsection{Nonaromatic heterocycles}

3-Boronic ester-substituted pyrrolidines have been prepared via 1,3-dipolar cycloaddition of azomethine ylides to alkenyl boronates. ${ }^{257}$ An example is shown in Scheme X, for the reaction of the vinylboronate 136 and $N$-benzylated glycine in the presence of formaldehyde, to give the 3boronic ester pyrrolidine 137 (Scheme 41). This type of pinacol-derived boronates can be converted into boronic acids by transesterification with phenylboronic acid, or can be oxidatively hydroxylated after treatment with triethylamine oxide affording 3-hydroxypyrrolidines.

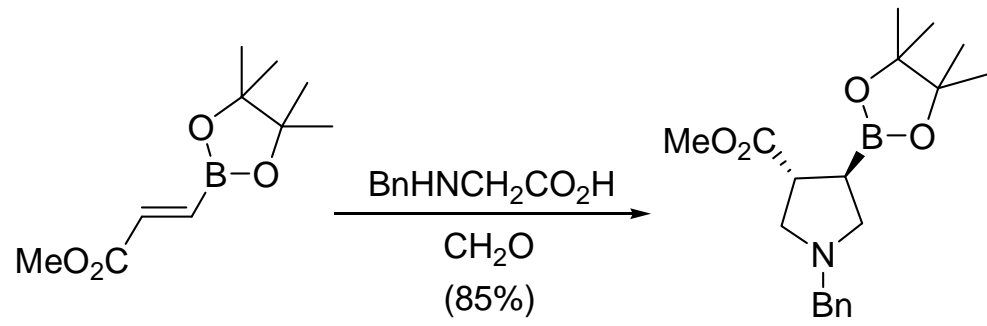

136

137

\section{Scheme 41}

\section{Group 4 Metalated Heterocycles}

\subsection{Silicon heterocycles}

Silylated heterocyclic systems are frequently prepared by reaction of the corresponding heterocyclic organolithiums with alkylhalosilanes. ${ }^{1,4}$ The introduction of a silylated group can be required for blocking determined ring positions towards further transformations, as well as for ipso-substitution reactions by electrophiles or for palladium-catalyzed cross-coupling reactions with organic halides (the so-called Hiyama coupling ${ }^{166}$ ). 


\subsubsection{Aromatic five-membered rings}

$N$-Boc-Protected 2-pyrrolyldimetylsilanols, ${ }^{258}$ as well as their indolyl, ${ }^{259}$ thienyl $^{258}$ and furyl ${ }^{1}$ analogues, have been obtained by 2-lithiation and trapping with dimethyldichlorosilane followed by hydrolysis, and have been used in palladium-catalyzed coupling reactions with aryl halides. An example of the use of this methodology is the coupling of the pyrrolylsilanol 138 with $p$ iodoanisole, where the starting silanol is treated previously with sodium hydride generating the corresponding sodium silanolate, which is the real species that couples with the aryl halide to give compound 139 (Scheme 42). ${ }^{258}$ A palladium-catalysis has also been used in a SuzukiMiyaura cross-coupling reactions involving an in situ ipso-borodesilylation of a $\mathrm{N}$-protected 2(trimethylsilyl)- $1 \mathrm{H}$-indole followed by coupling with aryl halides. ${ }^{260} \mathrm{In}$ addition, examples of the incorporation of a trimethylsilyl group at the 2-position of an indole, for protecting that position in further metalations, can be seen in the synthesis of some pyrrolophenanthridone alkaloids. ${ }^{261}$

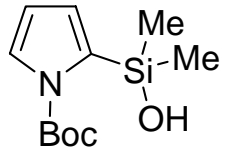

138

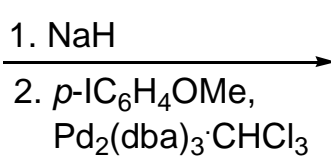

$(72 \%)$

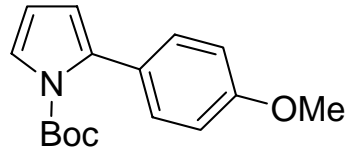

139

\section{Scheme 42}

2-Silylfuran derivatives substituted at the 3- or 4-positions are appropriate precursors of the corresponding regioisomeric $\gamma$-hydroxybutenolides, because they can be regiospecifically oxidized with singlet oxygen, thus the silyl group directing the formation of the carbonyl group. Applications of this methodology to the synthesis of natural products in the last years are frequent, ${ }^{262}$ as illustrated in Scheme 43 for the McMurry coupling of two molecules of 2silylated furan $\mathbf{1 4 0}$ to give the alkene $\mathbf{1 4 1}$ followed by photooxygenation in the presence of the sensitizer Rose Bengal, affording a mixture of diastereomeric bis-hydroxy butenolides 142. Subsequent dehydration using silica gel gave the bis-spiroketal 143, which is the spirocyclic core of prunolides, metabolites of static marine invertebrates. ${ }^{263}$ In addition, 2-trialkylsilyl furanes have been used in pericyclic reactions driving to the antibiotic viridin ${ }^{264}$ and the skeleton of the diterpene ingenane. ${ }^{265}$ Moreover, 3-silylated furans, obtained by halogen-lithium-silicon exchanges or by DoM-directed lithiation-silylation have been used in an ipso-boroxine formation, ${ }^{266}$ and in a reductive benzylation in a total synthesis of secosyrin $1,{ }^{267}$ respectively. 

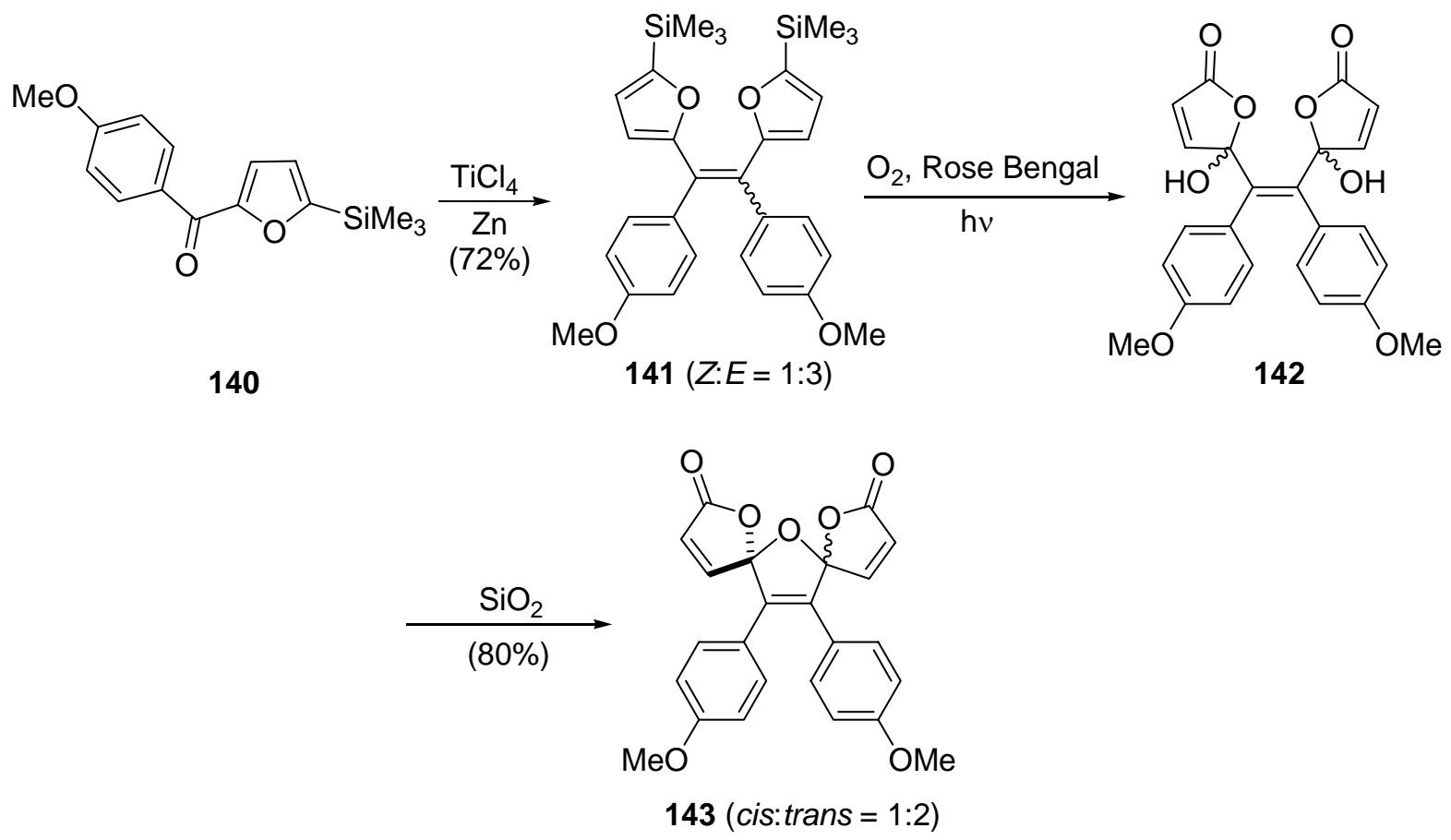

\section{Scheme 43}

Thiophene derivatives containing a silyl group at the 2-position have been used in the preparation of $\pi$-conjugated thiophene-derived compounds with possible applications for electronic devices. ${ }^{268}$ For instance, the dithienophosphole $144^{269}$ has been used for a platinumcatalyzed hydrosilation reaction with diphenylacetylene affording the diphenylethylenesubstituted species 145, which shows blue light-emitting properties (Scheme 44). ${ }^{270}$ The 2lithiation-silylation with tetramethydisiloxane sequence (employed for the introduction of the dimethylsilyl group in the synthesis of the former compound 144) has also been used for the preparation of polymer supported 2-silylated thiophenes, as well as trialkylsilanes when using trialkylsilyl chlorides as electrophiles. ${ }^{271}$ Moreover, when 2,5-bis(trialkylsilyl)thiophenes are intended, the thionation of bis(acylsilanes) with hexamethyldisilathiane under cobalt(II) chloride is a feasible route, ${ }^{272}$ and 2-thienylsilanols can be prepared by oxidation of the corresponding dialkyl- or diarylsilanes under iridium catalysis. ${ }^{273}$

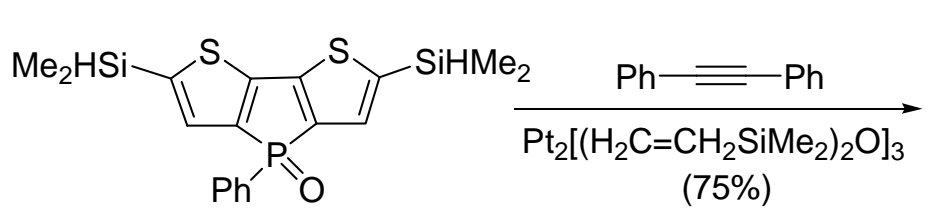

144<smiles>C[Si](C)(/C(=C/c1ccccc1)c1ccccc1)c1cc2c(s1)-c1sc([Si](/C(=C/c3ccccc3)c3ccccc3)(c3ccccc3)c3ccccc3)cc1P2(=O)c1ccccc1</smiles>

145

\section{Scheme 44}


Although $N$-substituted 5-silylpyrazoles can be obtained by the usual lithium-silicon exchange, another method consisting of the reaction of silyl $\beta$-enaminones with alkyl and aryl hydrazines has been recently developed. Using this methodology, $N$-methyl-3-silylpyrazoles have also been obtained, their regioselectivity depending on the employed hydrazine, as all hydrazines except methylhydrazine led to the 5-silylated pyrazoles. ${ }^{274}$ In addition, 3trimethylsilylindazoles, which are in fact benzocondensed counterparts of the corresponding pyrazoles, can be prepared by [3+2] cycloaddition reaction of lithium trimethylsilyldiazomethane with benzynes. ${ }^{275}$ These silylated indazoles can be used as nucleophilic precursors in the cesium(I) fluoride-promoted addition to aldehydes affording 3-substituted indazoles, although variable amounts of desilylated indazole are also obtained. ${ }^{276}$ This process is illustrated in Scheme 45, where 3-trimethylsilylindazole (146) is mixed with benzaldehyde in the presence of cesium(I) fluoride, which act as a base. The formed silicon-stabilized carbanion $\mathbf{1 4 7}$ adds to the carbonyl group to give the silylated species 148, which suffers a Brook rearrangement to give the O-silyl intermediate 149 which affords the 3 -substituted indazole 150. ${ }^{276}$ These 3trimethylsilylindazoles can be regioselectively $N$-arylated using arylboronic acids under copper(II)-catalysis. ${ }^{277}$

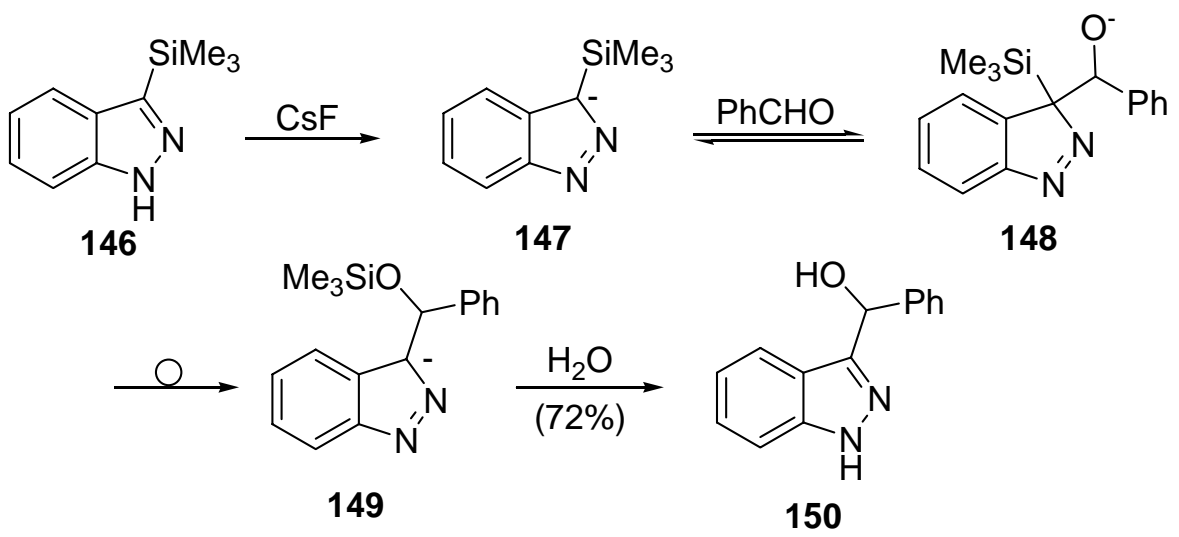

\section{Scheme 45}

Imidazoles have been silylated at C-2 using the conventional lithium-silicon exchange, although it has been observed that 2-tert-butyldimethylsilylimidazole can be obtained by reaction of O-tert-butyldimethylsilylimidazolyl aminals with organolithium reagents through a retro$[1,4]$-Brook rearrangement. ${ }^{278}$ Usually, 2-silylimidazoles are used a subsequent lithiation at the 3 -position and further reaction with electrophiles such as aldehydes ${ }^{279}$ or tosyl azide. ${ }^{280}$ Similarly, 2-silylated oxazoles $^{281}$ and thiazoles ${ }^{282}$ have been used performing a 4-lithiation followed by reaction with electrophiles. ${ }^{281}$ Their preparation by the typical lithium-silicon exchange is straightforward, although 2-trimethylsilyloxazoles, as well as other 2-silylated 1,3azoles have also been prepared by reaction with trimethylsilylbromide in the presence of triethylamine. ${ }^{283}$ In addition, 2-methylthiazole can be trimethylsilylated at C-5 by lithium-silicon 
exchange, the resulting 2-methyl-5-silylthiazole permitting therefore a subsequent lithiation at the 2-methyl substituent. ${ }^{284}$ Furthermore, 2-trimethylsilylbenzothiazol has been directly 2acylated after treatment with an acyl chloride, ${ }^{285}$ and a 2-nucleophilic position for addition reactions can also be created by treatment with a phosphazene base. ${ }^{286}$

\subsubsection{Aromatic six-membered rings}

Chloro-, fluoro- and methoxypyridyltrimethylsilanes have been explored recently for a room temperature access to arylic heterocycles by means of a palladium catalyzed Hiyama crosscoupling reaction. ${ }^{287}$ The presence of the pyridine nitrogen $\alpha$ to the trimethylsilyl group was a requisite to achieve the cross-coupling, as illustrated in the palladium-catalyzed reaction of 2trimethylsilylchloropyridine $\mathbf{1 5 1}$ with $p$-iodoanisole in the presence of tetra- $n$-butylammonium fluoride (TBAF), which afforded the corresponding arylated pyridine 152 (Scheme 46).<smiles>CSc1ncccc1Cl</smiles>

151

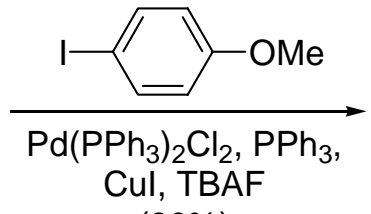

$(80 \%)$

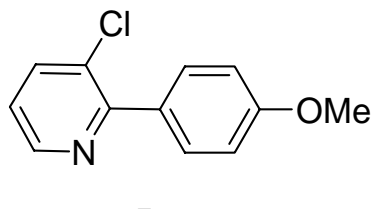

152

\section{Scheme 46}

The 2-pyridylsilyl group has shown to be an interesting removable directing group for organometallic reactions, specially when alkenyl(2-pyridyl)silanes are involved, a very recent review covering this topic. ${ }^{288}$ Examples of these uses are the copper-catalyzed allylation of carbonyl derivatives using allyl(2-pyridyl)silanes as the allyl source, ${ }^{289}$ and a regioselective Mizoroki-Heck reaction on vinyl(2-pyridyl)silane for the synthesis of triarylene-based extended $\pi$-systems. ${ }^{289 \mathrm{~b}}$ (2-Pyridyl)allyldimethylsilanes such as compound $\mathbf{1 5 3}$ have also been employed recently in palladium-catalyzed cross-coupling reactions with aryl iodides such phenyl iodide in the presence of silver(I) oxide as an activator, to give the corresponding 2-phenylpyridine (154) (Scheme 47). ${ }^{290}$ In this process the effect of the allyl substituent on silicon was crucial, vinyl or benzyl groups resulting in much lower yields, whereas a 2-trimethylsilylpyridine gave no reaction.

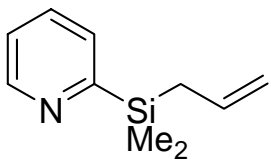

153

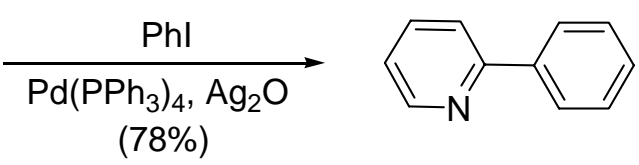

154

\section{Scheme 47}


A trialkylsilyl group in a pyridine ring can be used for rerouting nucleophilic substitution reactions on di-, tri- and tetra-halopyridines. Thus, 2,4-difluoro, 2,4,6-trifluoro and 2,3,4,6tetrafluoropyridine, as well as their chlorinated analogues, undergo nucleophilic substitution preferentially at the 4-position, whereas the halogen at the 6- or 2-position is displaced selectively if a trialkylsilyl group is introduced at C-3 or C-5, respectively. ${ }^{291}$ In addition, a silyl group on a pyridine ring can be employed for the generation of a nucleophilic species when treated with fluoride, as shown in an internal cyclization driving to the total synthesis of the alkaloid louisianin $\mathrm{C}^{292}$

There are also recent examples of the use of the ipso-substitution reaction, such as the ipsoiodination, applied to 3-trimethylsilylpyridine derivatives, as in the case of the reaction of the silylated pyridine 155 with iodine to give the 3-iodopyridine 156, which is a key compound for the synthesis of pyridoxine (vitamin $\mathrm{B}_{6}$ ) (Scheme 48). ${ }^{293}$

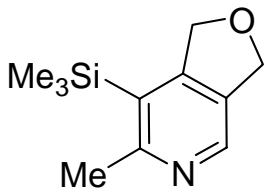

155

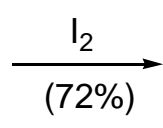

$(72 \%)$

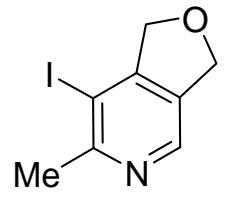

156

\section{Scheme 48}

Chiral 1-acylpyridinium salts, prepared by reaction of 4-methoxy-3-(triisopropylsilyl)pyridine with an enantiomerically pure chloroformate, has been used for the diastereomeric addition of zinc enolates at $\mathrm{C}-2$ of the pyridinium cation, driving to intermediates in the total synthesis of (+)-cannabisativine ${ }^{294}$ and (+)-hyperaspine. ${ }^{295}$ Another chiral 1-acylpyridinium salt from a 3-methoxycarbonylated 4-silylpyridine has been used for the addition of functionalized Grignard derived cuprates in the preparation of 6-substituted nipecotic acid derivatives. ${ }^{296}$

\subsubsection{Nonaromatic heterocycles}

Although silylated aziridines have been obtained by lithiation-silylation of the corresponding aziridines, other procedures have been developed more recently. Thus, silyl aziridines can be prepared by reaction of silyldibromomethylithiums with aromatic imines followed by in situ treatment of the bromo aziridine intermediate with Grignard reagents. ${ }^{297}$ In addition, 2phosphono-3-(trimethylsilyl)aziridines have been synthesized by the aziridination of 1phosphono-2-aza-1,3-dienes with (trimethylsilyl)diazomethane. ${ }^{298}$

Epoxysilanes, ${ }^{299,300}$ as well as epoxydisilanes ${ }^{300,301}$ can be prepared from oxiranylithiums (see Section 2.1.3), although when synthetically useful functionalized silylated epoxides are intended, probably the more convenient route is the epoxidation of vinyl silanes. ${ }^{302}$ Thus, this methodology has been used for the synthesis of epoxysilanes useful in $\alpha$-lithiation reactions, ${ }^{303}$ generation of vinyl siloxanes under basic conditions ${ }^{304}$ [which give a formyl group after 
treatment with fluoride $\mathrm{e}^{304 \mathrm{c}}$ or palladium $(0)^{304 \mathrm{f}}$ ] and also in ring-opening reactions using lithium diphenylphosphide, ${ }^{305}$ Grignards $^{306}$ or hidrides. ${ }^{307}$ Silyl epoxides, preapared by epoxidation, have also been used in oxidation reactions to give aldehydes, ${ }^{308}$ and $\mathrm{S}_{\mathrm{N}} 2$ ' reactions in the case of silylated vinyloxiranes. ${ }^{309}$ Trimethylsilylated epoxides bearing a three methylene-containing tethered hydroxy group have been used in boron trifluoride-promoted internal cyclizations driving to tetrahydropyrans. ${ }^{310}$ Interestingly, when this Lewis acid is used with the diepoxyde 157, the 5-exo-ditetrahydrofuran 158 is obtained in a ladder polyether fashion, whereas the more interesting natural product-containing tetrahydropyrane dyad 159 is generated after treatment of compound 157 with cesium carbonate (Scheme 49). ${ }^{311}$ The boron-trifluoride epoxide oxacyclization has also applied to triepoxides, leading to bisoxepanes. ${ }^{312}$

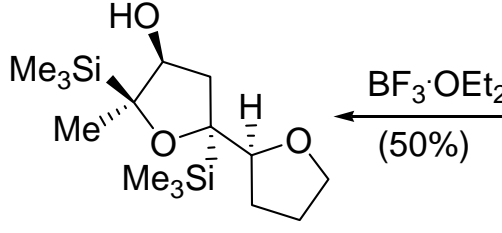

158

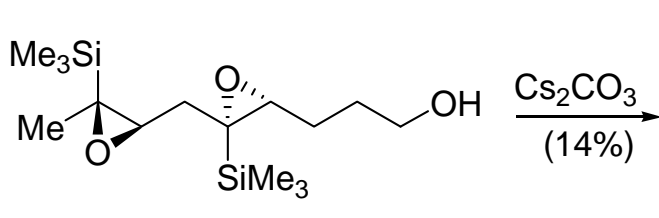

157

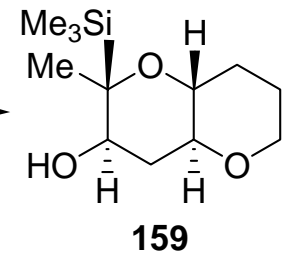

\section{Scheme 49}

The trimethylsilyl group has been enantioselectively introduced at C-2 of $N$-Boc-pyrrolidine by direct lithiation using sec-butyllithium in the presence of sparteine or sparteine-like chiral diamines and further reaction with trimethylsilyl chloride. ${ }^{149-151}$ This silyl group in related $N$ methoxycarbonylated pyrrolidines has been removed by electrochemical oxidation giving an $N$ acyliminium cation, which suffers addition of an alkyl radical generated by reaction of alkyl halides and hexa- $n$-butylditin, affording alkylated pyrrolidines. ${ }^{313}$ In addition, silylated pyrazolines and indazolines have been regioselectively prepared from the corresponding pyrazolium and imidazolium salts, respectively, with silyllithium reagents. ${ }^{314}$

Examples of the synthesis of 3-silylated tetrahydrofurans by cyclization of silyl alcohols can be found. ${ }^{315 a}$ In addition, treatment of cyclopropyl silyl ketones such as $\mathbf{1 6 0}$ with trimethylsilyl trifluoromethanesulfonate gave the corresponding 5-silyl-2,3-dihydrofuran 161. These type of compounds exhibited both reactivity of the vinylsilane and the cyclic enol ether in the reactions with electrophilic reagents such as $N$-bromosuccinimide (NBS), affording the 4-bromo-2,3dihydrofuran 163 through the intermediate 162, or the $\alpha$-silylated $\gamma$-lactone 165 (through species 164) when working under basic aqueous conditions (Scheme 50). ${ }^{54}$ The same dual behavior was observed in Heck-type reactions. ${ }^{315 b}$ 


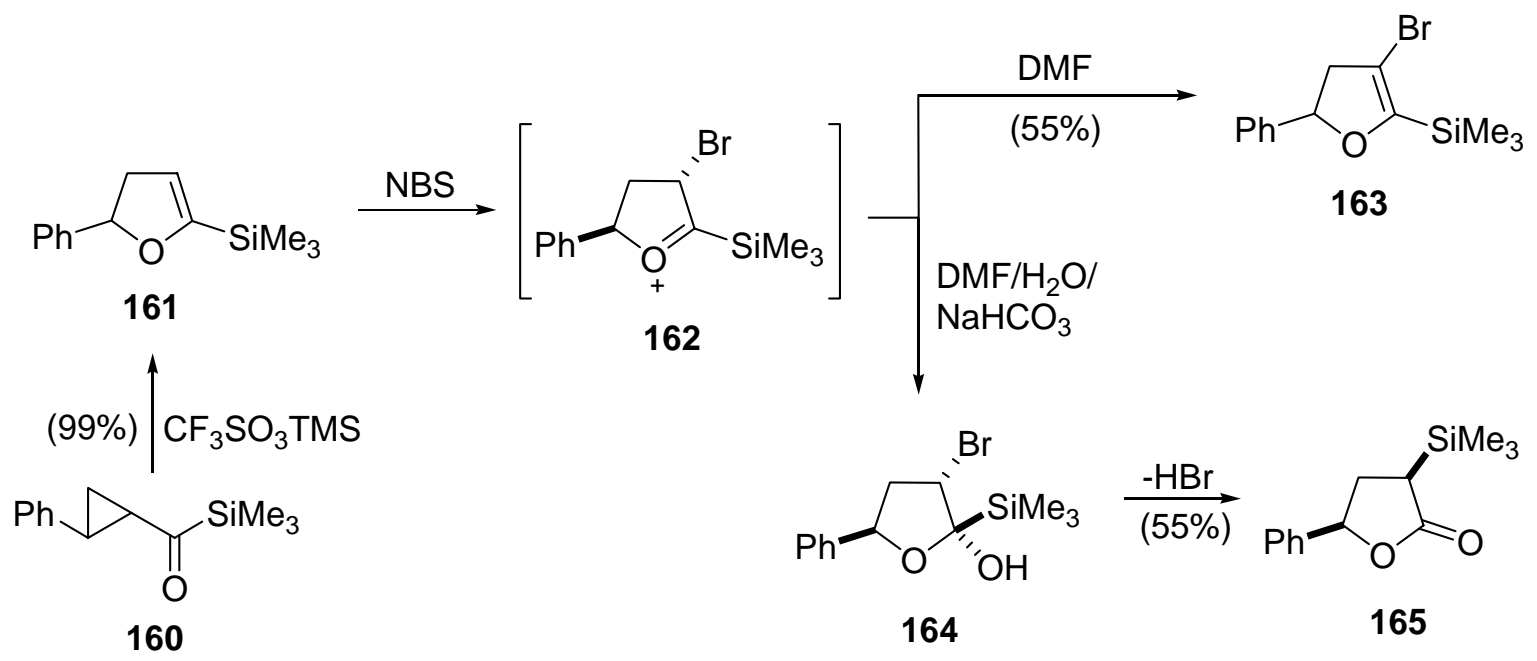

\section{Scheme 50}

The disilylated 1,4-dihydropyridine 166, generated by reductive disilylation of (S)-nicotine after treatment with lithium powder and trimethylsilyl chloride, has allowed the addition of aldehydes in the presence of a catalytic amount of TBAF to give C-5 substituted nicotines. ${ }^{316} 2$ Silylated 5,6-dihydro-4H-pyranes such as 167 have been obtained by ruthenium-catalyzed cycloisomerization of diynes containing one silyl alkyne and one propargyl alcohol, and have been elaborated to give tetrahydropyran-2-ones using aqueous basic hydrogen peroxide, or desilylated by using TBAF. ${ }^{317}$

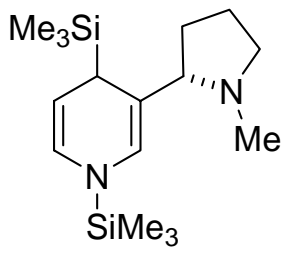

166

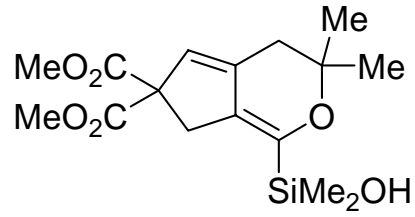

167

\subsection{Germanium heterocycles}

Tri(2-furyl)germane has found recent applications in the radical-mediated germyldesulfonylation of vinyl and ( $\alpha$-fluoro)vinyl sulfones. Upon oxidative treatment with basic hydrogen peroxide, the resulting vinyl germane underwent palladium-catalyzed cross-coupling reactions with aryl halides. ${ }^{318}$ In addition, a dichlorogermanium-based linker for the solid-phase iterative synthesis of oligothiophenes has been developed, the oligothiophene being finally dettached from the solid fase by ipso-degermylation using trifuoroacetic acid. ${ }^{319}$ A related soluble thienylgermanium 
species 168 has been used for a Friedel-Crafts acyldegermylation process leading to acylthiophene 169 (Scheme 51). ${ }^{320}$

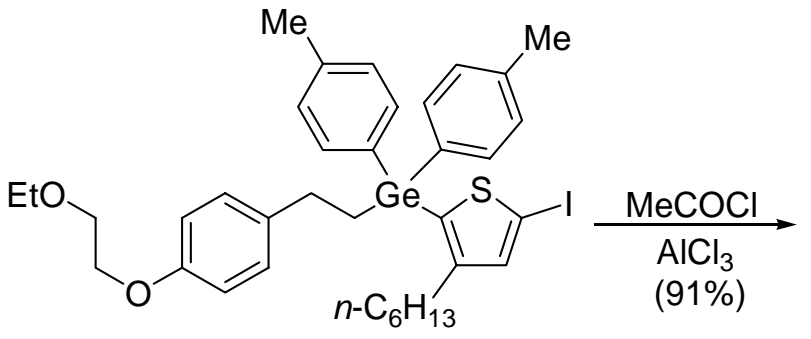

168

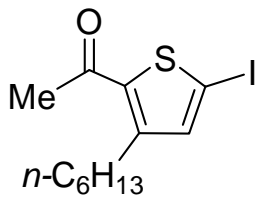

169

\section{Scheme 51}

\subsection{Tin heterocycles}

Heterocyclic stannanes are mainly obtained by reaction of the corresponding lithiated species with halostannanes, ${ }^{1,4}$ being mainly used in palladium-catalyzed cross-coupling reactions (the socalled Stille-Migita coupling ${ }^{166}$ ).

\subsubsection{Aromatic five-membered rings}

2-Stannylpyrroles, prepared by direct 2-lithiation of the corresponding $N$-protected heterocycles and reaction with a chlorostannane, have been employed recently for cross-coupling reactions with aryl halides in the synthesis of stilbenylpyrroles, ${ }^{321}$ calixpyrroles, ${ }^{322}$ pyrrole-based polymers, ${ }^{323}$ compounds against cocaine abuse ${ }^{324}$ and fluorescence indicators. ${ }^{325}$ An example of generation and use of this stannylated pyrroles is shown in Scheme 52, with the $N$-lithium2,2,6,6-tetramethylpiperidine-promoted lithiation of $N$-Boc-pyrrole, followed by stannylation to give 2-stannylpyrrole 170. Subsequent double Stille coupling with dibrominated azulene 171 gave the bis(pyrrolyl)azulene 172, which, once deprotected, is an efficient luminescent probe for fluoride. ${ }^{326}$ When 3-stannylated pyrrole are desired, a halogen-lithium exchange is usually performed, a recent example being the preparation and use of a 3-trimethylstannylated $\mathrm{N}-$ tosylated pyrrole in the generation of a stannylated Diels-Alder adduct for a copper-promoted trimerization. $^{327}$ 
<smiles>O=C(Oc1ccccc1)n1cccc1</smiles>

1.

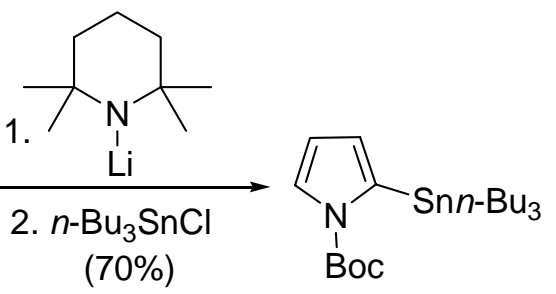

170

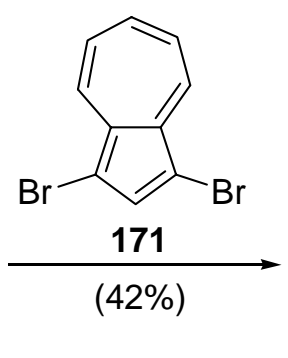

$42 \%)$

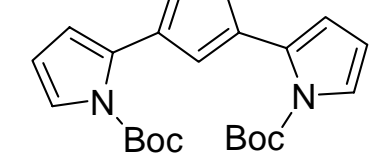

172

\section{Scheme 52}

$\mathrm{N}$-Substituted indoles behave similarly to pyrroles, and can be 2 -stannylated by direct lithiation followed by stannylation, these tin derivatives being used in Stille cross-coupling reactions. ${ }^{328}$ However, examples of the preparation of 2-stannylated indoles by bromo-lithium-tin exchanges can be recently found, for instance, in the preparation of inhibitors of the viral NS5B polymerase using the Stille coupling. ${ }^{329}$ As in the pyrrole case, 3-stannylated indoles can be prepared by the halogen-lithium-tin procedure, as well as related 7-azaindoles, also employed in palladium-catalyzed cross coupling reactions. ${ }^{330}$ In addition, palladium-catalyzed stannylation of 3-iodinated 5-azaindoles using hexamethylditin has been used for the synthesis of the corresponding organostannanes. ${ }^{331}$

2-Stannylated furans are prepared generally by the usual direct lithiation-stannylation procedure, recent examples of their use in Stille cross-couplings being frequent. ${ }^{332}$ In addition, tributyl(furan-2-yl)stannane has been used in a carbonylative Stille coupling reaction for the construction of the core structure of manzamine A. ${ }^{333}$ However, when labile group-substituted furans are the starting materials, some protective strategies must be developed, as in the recent case of the stannylation of 3-methylfurfural (173). Thus, in situ protection of the aldehyde 173 as the lithio-hemiaminal adduct followed by deprotonation of the furan nucleus gave intermediate 174 (Scheme 53). Lithium-tin exchange afforded the stannyl furfural 175, which has been coupled with the vinyl iodide $\mathbf{1 7 6}$ affording compound 177, an intermediate in the total synthesis of the gorgonian coral metabolite $( \pm)$-bipinnatin $\mathrm{J}^{334}$ 


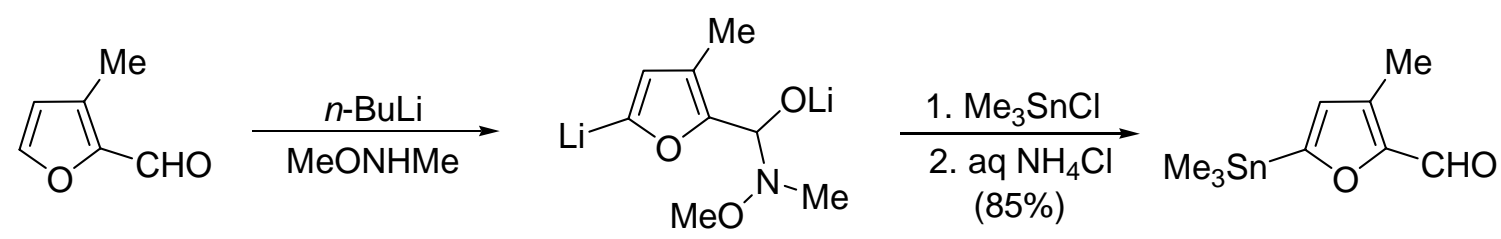

173

174

175<smiles>C/C(=C/CCC1=CC(C/C(C)=C/c2cc(C)c(C=O)o2)CC1=O)CC/C=C(\C)CO</smiles>

\section{Scheme 53}

As expected, the synthesis of 3-stannylated furans is usually carried out by halogen-lithiumtin exchange procedures and their main use is in the Stille coupling reaction, as it was recently reported in the preparation of a 12-acetoxyazadiranone analogue of a limonoid triterpene. ${ }^{335}$ However, when the synthesis of 3,4-distannylated furan 180 is intended, an efficient procedure consisting of palladium-catalyzed addition of hexa- $n$-butylditin to the alkyne $\mathbf{1 7 8}$ to give compound 179, followed by iodoxybenzoic acid (IBX) oxidative cyclization, has been developed (Scheme 54). ${ }^{336}$ This distannylated furan $\mathbf{1 8 0}$ has been employed in a double Stille coupling with the iodoarylated derivative 181 to give the disubstituted furan 182, which is a precursor of a potent antioxidant found in beet root. ${ }^{337}$

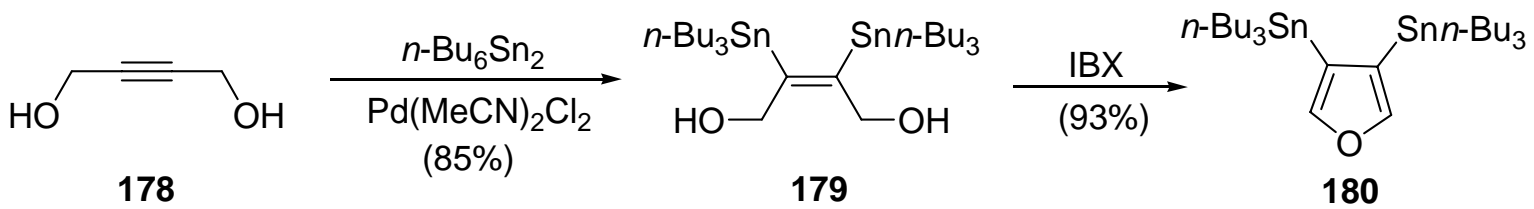

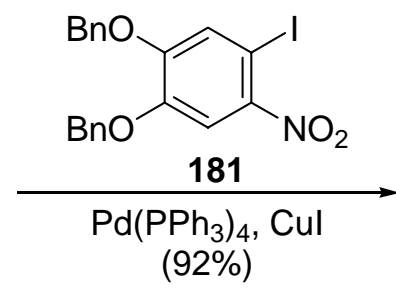<smiles>O=[N+]([O-])c1cc(OCc2ccccc2)c(OCc2ccccc2)cc1-c1cocc1OCc1ccccc1</smiles>

182

\section{Scheme 54}


Probably, the most frequently employed 5-membered tin heterocycles are 2-stannylated thiophenes, prepared as usually by lithiation and further stannylation. These compounds have been used profusely in the last years for Stille cross-coupling reactions in the preparation of many oligo- and polythiophenes, ${ }^{338}$ as well as for other highly conjugated thiophene-containing oligo- and polymers, ${ }^{339}$ many of them with potentially useful electronic and electrooptical properties. Other molecules with interesting optical properties have been prepared using 2stannylated thiophenes, such as the bithiophene 186, which is a fluorescent marker by in vivo optical imaging of amyloid aggregates in brain (Scheme 55). ${ }^{340}$ This compound is obtained by Stille coupling of the stannylated bithiophene 183 and the $O$-silylated iodophenol 184 giving compound 185. Formylation of $\mathbf{1 8 5}$, followed by Knoevenagel condensation with malononitrile and final desilylation gave the final product 186. In addition, ligands for the dopamine D3 receptor, ${ }^{341}$ organic dyes, ${ }^{342}$ acene-thiophene molecules for transistor applications, ${ }^{343}$ fluorescent $\mathrm{Ca}(\mathrm{II})$-indicators, ${ }^{344}$ luminescent europium(III) chelates, ${ }^{345}$ as well as thienylated benzodiazepins ${ }^{346}$ and other heterocycles, ${ }^{347}$ have also been obtained recently by Stille coupling using 2-stannylated thiophenes. Finally, an example of a useful 3-stannylated thiophene is compound 187, which has been prepared from its brominated derivative by bromo-lithium exchange, and has been used in a cross-coupling reaction for the preparation of ${ }^{14} \mathrm{C}$-labeled angiotensin-(1-7)-receptor agonist AVE 0991. ${ }^{348}$

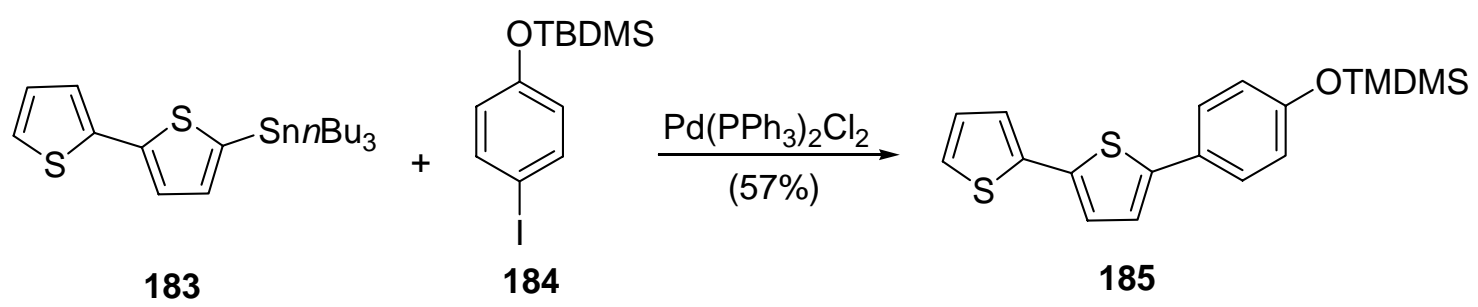
1. $n$-BuLi
2. DMF
3. $\mathrm{CH}_{2}(\mathrm{CN})_{2}$, piperidine
4. $\mathrm{HCl}$

(65\%)<smiles>N#CC(C#N)=Cc1ccc(-c2ccc(-c3ccc(O)cc3)s2)s1</smiles>

186

\section{Scheme 55}<smiles>CCNC(=O)NSc1sc(CC(C)C)cc1[Sn]S(=O)(=O)c1ccccc1</smiles> 
Trifluoromethylated 5-(tri-n-butylstannyl)pyrazole 189, has been obtained recently by reaction of the propynylstannane 188 with diazomethane (Scheme 56), ${ }^{349}$ other stannylated triazoles and isoxazoles, ${ }^{28}$ as well as a 4-fluorinated pyrazole, ${ }^{350}$ being prepared by related dipolar cycloaddition reactions. After $N$-methylation of pyrazole 189 and tin-lithium exchange followed by addition to benzaldehyde, compound 190 was obtained. Subsequent $O$-alkylation under phase-transfer conditions gave pyrazole 191, which is a trifluoromethylated analogue of the analgesic cizolirtine. ${ }^{351}$ In addition, recent examples of the use of $\mathrm{N}$-protected $2-{ }^{352}$ and 3 stannylated imidazoles, ${ }^{353}$ obtained by conventional lithium-tin exchange, in Stille crosscouplings have been reported.

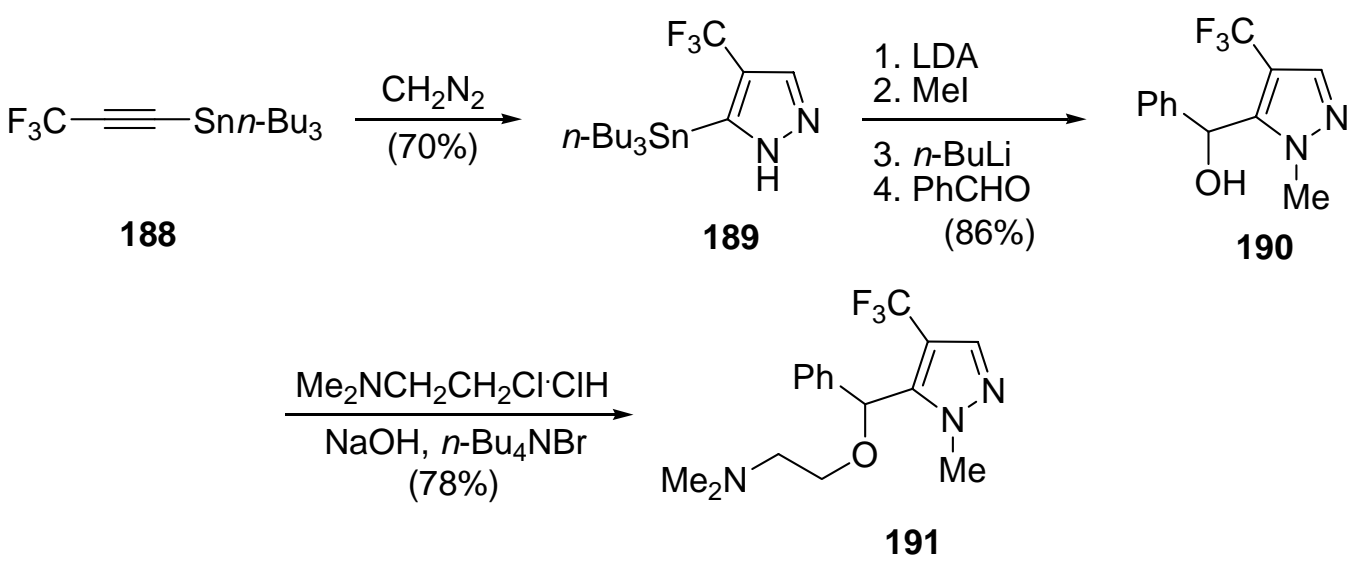

\section{Scheme 56}

Isoxazoles stannylated at C-4- and C-5 have been obtained via a [2+3] cycloaddition reaction between substituted chloro oximes and tri- $n$-butylethynyltin, and used in cross-coupling reactions for the preparation of antibacterial agents. ${ }^{354}$ When 2-oxazolylstannanes are intended, the direct lithiation-stannylation methodology is usually employed, a recent synthetic example being the use of 2-(tri-n-butylstannyl)oxazole (193) and the vinyl iodide 192 in a Stille reaction driving to the polyene derivative 194, an intermediate in the synthesis of the eastern portion of the mycobacteria metabolite ajudazol A (Scheme 57). ${ }^{355}$ When 4-stannylated oxazoles bearing labile groups are required, the palladium-catalyzed stannylation using appropriately 4-substituted oxazoles and bis(trimethyltin) is a feasible methodology, an application of these tin-heterocycles being reported in the total synthesis of $(+)$-phorboxazole $\mathrm{A},{ }^{356}$ and some phorboxazole $\mathrm{C}$ analogues. $^{357}$ 


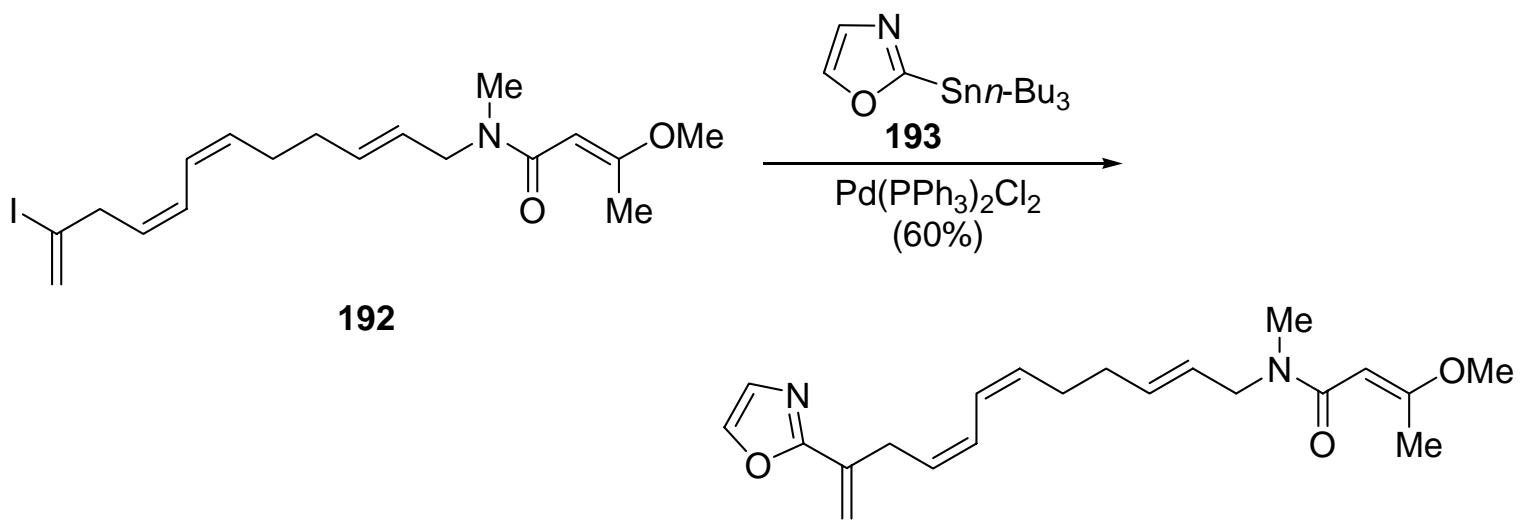

194

\section{Scheme 57}

2-Stannylthiazoles, generated by direct lithiation-stannylation, have been employed in palladium-catalyzed cross-couplings, examples being the coupling to aryl iodides in the development of matrix metalloproteinase inhibitors, ${ }^{358}$ or to aryl triflates for the synthesis of canine COX-2-inhibitors. ${ }^{359}$ In addition, thiazoles stannylated at C-4 are usually obtained by sequential halogen-lithium-tin exchange, and have been used for instance in Stille couplings for the synthesis of epothilone B analogues, ${ }^{360}$ as well as the total synthesis of the antifungal agents cystothiazoles $\mathrm{A}$ and $\mathrm{B}^{361}$ and the fermentation broth metabolite WS75624 $\mathrm{B}^{362}$ In some cases, 4-stannylthiazoles are prepared by palladium-catalyzed cross-coupling of the corresponding bromide using bis(trimethyltin), as in the synthesis of the heterocyclic core of the GE2270 antibiotic, a Stille coupling being a key step. ${ }^{363}$ Finally, 5-stannylated thiazoles can be prepared by direct lithiation-stannylation if a substituent blocks the 2-position, an example of their use in a Stille coupling being reported in the design of artificial nucleobases for molecular recognition. ${ }^{364}$

\subsubsection{Aromatic six-membered rings}

Stannylpyridines, generally obtained by reaction of a pyridyllithium with a halostannane, have been employed almost exclusively in the palladium-catalyzed Stille coupling reaction. Thus, 2stannylated and 2,6-distannylated pyridines have been frequently cross-coupled with halogenated or tosylated pyridines in the synthesis of bi- ${ }^{365}$ and terpyridines ${ }^{366}$ compounds with interesting metal-complexating or electrooptical properties. Supramolecular self-assemblies, ${ }^{367}$ as well as receptors for monosaccharides ${ }^{368}$ have also been recently prepared via cross-coupling reactions involving 2-stannylpyridines. Moreover, natural products such as several lupine alkaloids ${ }^{369}$ and (-)-7-demethylpiericidin $\mathrm{A}_{1}{ }^{370}$ have been obtained using cross-coupling reactions involving 2stannylated pyridines. Scheme 58 shows the use of the 2-stannylpyridine 196 (prepared by direct lithiation and reaction with trimethyltin chloride) in the cross-coupling with the heteroaromatic thioether 195. The resulting compound $\mathbf{1 9 7}$ is a pyridinyl analogue of the gram-positive antibacterial boxazomycin C. ${ }^{371}$ 


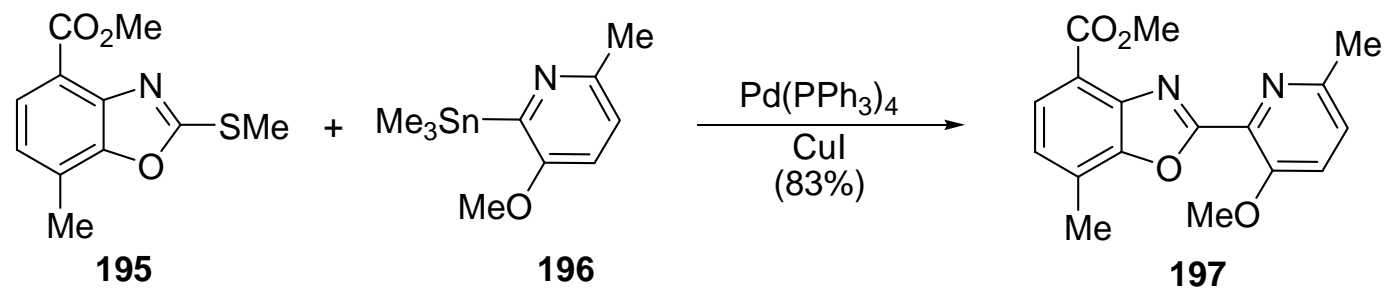

\title{
Scheme 58
}

3-(Trialkylstannyl)pyridines have been used in palladium-catalyzed Stille cross-coupling reactions, recent examples being the reaction with halogenated pyridines for the synthesis of metal-complexating molecular suprastructures ${ }^{372}$ or nicotinic ligands, ${ }^{373}$ as well as the coupling with a vinyl bromide in the total synthesis of the epiphytic marine bacterium strain metabolite ent-thallusin. ${ }^{374}$ There are also examples of ipso-substitution of 3-stannylpyridines using an electrophilic reagent such as the generated by radioactive iodide in the presence of an oxidant, affording radiolabelled 3-iodopyridines. ${ }^{375}$ In addition, a recent example of the synthetic use of a 4-pyridylstannane is the generation of the stannylated chloropyridine 199 by lithium-tin exchange from the iodopyridine 198 (Scheme 59). This heteroaromatic tin derivative has been used as Stille metalated counterpart in the coupling with the starting iodopyridine 198 giving 4,4'-bipyridine 200, which has been used as a key precursor of selective inhibitors of c-Jun $N$ terminal kinase- $3 .^{376}$<smiles>Clc1cc(I)ccn1</smiles>

198

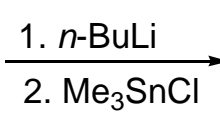$$
\text { (1) }
$$

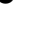

\section{Scheme 59}

The 4-(trimethylstannyl)quinoline 201, obtained by iodo-lithium-tin exchange, has been used for a double Stille coupling with 1,8-dibromonaphthalene to give the highly constrained (4,4'diquinolyl)naphthalene 202, which has been employed as fluorosensor (Scheme 60), ${ }^{377}$ similar systems with other alkyl substituents being also prepared. ${ }^{378}$ Moreover, related 1,8diacrydylnaphthalenes have been obtained employing Stille couplings involving the 5stannylated acridine 203, ${ }^{379}$ as well as $1-^{380}$ and 2-substituted analogues. ${ }^{381}$ 


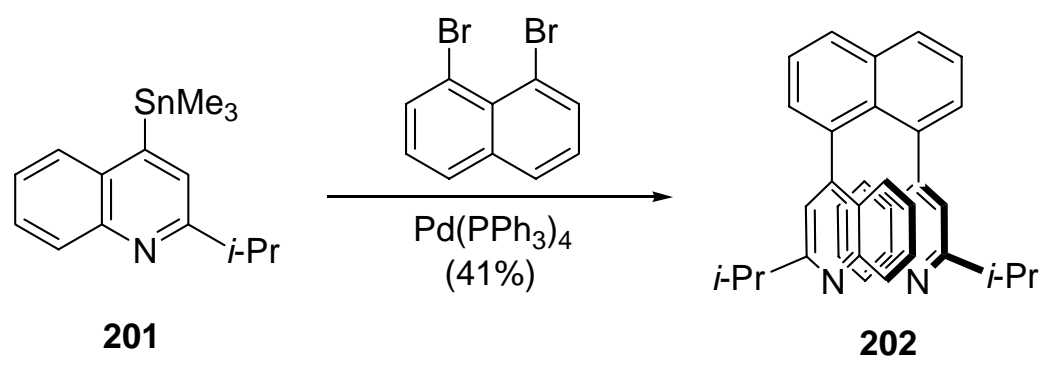

\section{Scheme 60}

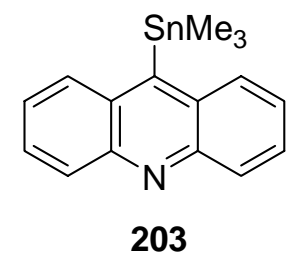

4-Stannylpyridazines can be obtained by [4+2] cycloaddition of 1,2,4,5-tetrazines with ethynyltributyltin followed by molecular nitrogen extrusion. These compounds have been employed, for instance, in Stille reactions affording $\mathrm{GABA}_{\mathrm{A}} \alpha 5$ ligands, as well as in ipsoiodination reactions. ${ }^{382}$ In addition, pyrimidinylstannanes have been prepared using the lithiumtin exchange methodology, although 2-stannylated pyrimidine 205 can also be prepared by reaction of the corresponding chloropyrimidine 204 with (tri-n-butylstannyl)lithium (Scheme 61). This organotin species can be employed as a source of the corresponding organolithium (see Section 2.1.3) in an addition reaction to $N$-Boc-4-piperidone affording the alcohol 206, a precursor in the synthesis of selective $5-\mathrm{HT}_{1 \mathrm{~A}}$ agonists with anti-ischemic effects. ${ }^{383}$

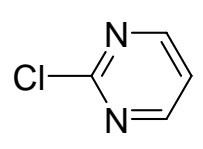

204

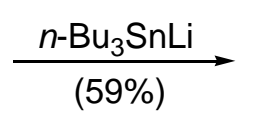

$(59 \%)$

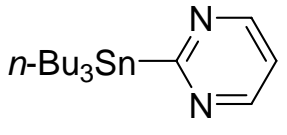

205

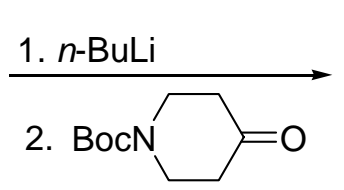

(61\%)

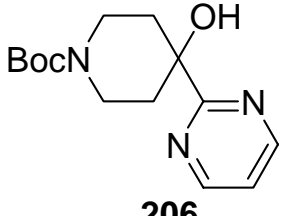

206

\section{Scheme 61}

However, most of the stannylated pyrimidines have been dedicated to Stille reactions, as it can be seen in the coupling of the 4-stannylpyrimidine 207 (Scheme 62). This organotin compound was obtained by palladium-catalyzed halogen-tin exchange employing hexamethylditin and cross-coupled with the brominated tricyclic compound 208 to give the corresponding derivative 209, which is related to variolin marine alkaloids. ${ }^{384}$ Similar 4stannylpyrimidines have been used in the total synthesis of variolin $\mathrm{B}^{385}$ and deoxyvariolin $\mathrm{B}^{385 \mathrm{~b}}$ Moreover, 5-stannylated pyrimidines have been used in palladium-catalyzed couplings to give 
iodoimidazole-containing nucleosides for new base pairing motifs, ${ }^{386}$ and also in the preparation of structures for supramolecular assemblies, after double coupling to 5,10dibromoanthracenes. ${ }^{387}$

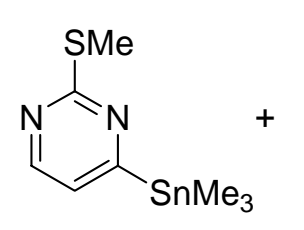

207

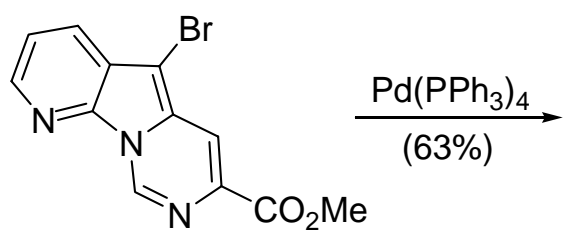

208

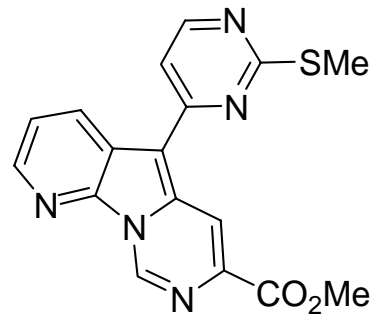

209

\section{Scheme 62}

Pyrazines stannylated at C-2 have been obtained by a direct lithiation-stannylation sequence and used recently in cross-coupling reactions with aryl halides for the synthesis of liquid crystal diazines, ${ }^{388}$ or with aroyl chlorides in the preparation of pyrazine alkaloids. ${ }^{389}$ This type of heteroaryl stannanes have been also obtained by halogen-lithium-tin exchange, and dedicated to Stille reactions in the synthesis of cyclin-dependant kinase inhibitors, ${ }^{390}$ and also from 2chloropyrazines by reaction with (tri-n-butylstannyl)lithium in the synthesis of polynuclear polyaza heterocycles. ${ }^{391}$ In addition, 2-stannylpurines, generated by direct 2-lithiation followed by reaction with a trialkylstannyl chloride, have also been used in Stille reactions, for instance, in the synthesis of adenosine derivatives. ${ }^{392}$ 2-Stannylated purines have been also employed in the ipso-iodination reaction, thus creating a template for further functionalization, ${ }^{393}$ as illustrates Scheme 63 for the iodination of the stannyl purine ring of nucleoside derivative 210 affording the iodinated purine 211. ${ }^{394}$ Furthermore, the nitration of heteroaryltrimethyltins derived from pyridine, purine and even 1,3,5-triazine with nitrometane and dinitrogen tetroxide has been investigated in the search of improvements in conventional explosives. ${ }^{395}$

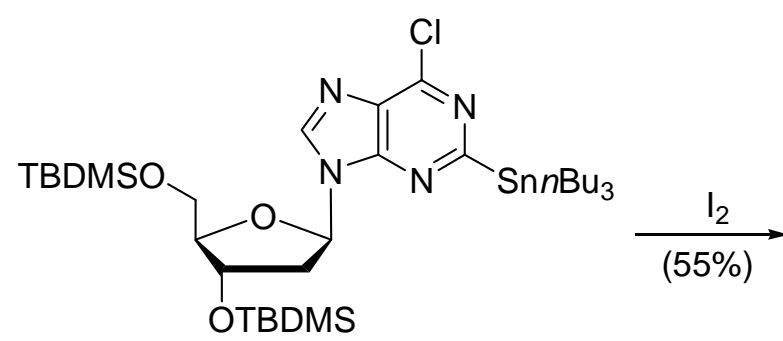

210

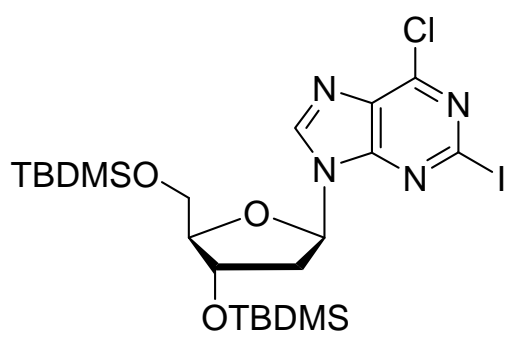

211

\section{Scheme 63}




\subsubsection{Nonaromatic heterocycles}

Differently $O$-substituted cis-stannyl aziridines, such as 212, have been prepared by addition of (tri-n-butylstannyl)lithium to $\alpha$-aminated aldehydes, followed by intramolecular cyclization of the resulting aminoalcohol. These stannylated systems have been used as reagents for the generation of the corresponding aziridinyllithium species after treatment with methyllithium. ${ }^{396}$ Stannylated epoxides such as the enantiomerically enriched derivative 213 (79\% ee) have been obtained by (-)-sparteine-induced enantioselective $\alpha$-deprotonation of the corresponding achiral epoxides (see Section 2.1.3) followed by reaction with tri- $n$-butylstannyl chloride having been also used for the generation of the corresponding oxiranyllithiums. ${ }^{397}$ Terminal epoxides can also be transformed into racemic $\alpha, \beta$-epoxystannanes using a diamine-assisted direct lithiationstannylation procedure. ${ }^{398}$

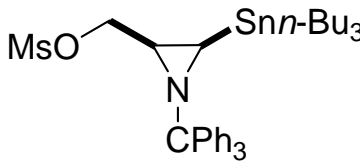

212

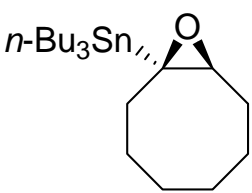

213

$N$-Boc-Protected 2-(tri- $n$-butylstannyl)pyrrolidine has been obtained by $\alpha$-lithiation followed by reaction with tri-n-butylstannyl chloride, a procedure which can be rendered enantioselective if (-)-sparteine is added (see Section 2.1.3) thus driving to the synthesis of the (S)- stannylated enantiomer, as confirmed recently by anomalous dispersion X-ray analysis. ${ }^{399}$ In addition, enantiopure $N$-methyl-2-(tri- $n$-butylstannyl)pyrrolidine and its piperidine analogue have been prepared by a chiral trans-cumylcyclohexanol-induced stereoselective addition of (tri- $n$ butylstannyl)lithium to an $N$-acylpyrrolidinium or piperidinium ion. ${ }^{400}$ However, racemic $N$ alkylated 2-(tri-n-butylstannyl)pyrrolidines have been transformed into enantiomerically enriched 2-substituted pyrrolidines via dynamic resolution of the corresponding 2lithiopyrrolidine generated by tin-lithium transmetalation in the presence of $(-)$-sparteine and subsequent quenching with electrophiles (see Section 2.1.3). Furthermore, $N$-methyl-2-(tri- $n$ butylstannyl)pirimidines have been studied in solution using NMR techniques showing distortion of the equatorial conformer to a half chair in some cases, something that could influence tinlithium transmetalation reactions. ${ }^{401}$

5-Stannylated $\mathrm{N}$-Boc-protected 2,3-dihydro-1 $\mathrm{H}$-pyrrole $\mathbf{2 1 4}$ has been recently obtained by direct lithiation-stannylation of the corresponding $N$-Boc-pyrroline, and has been used in a Stille cross-coupling reaction with the vinyl triflate 215 to give the trienecarbarbamate 216. This compound has been heated to effect an electrocyclic ring closure and oxidized in situ with manganese(IV) oxide to give the marine sponge metabolite ( \pm )-cis-trikentrin A (217) after Bocdeprotection and aromatization (Scheme 64 ). ${ }^{402}$ Starting from a related stannylated pyrroline, $( \pm)$-cis-trikentrin B has been obtained. ${ }^{402}$ 


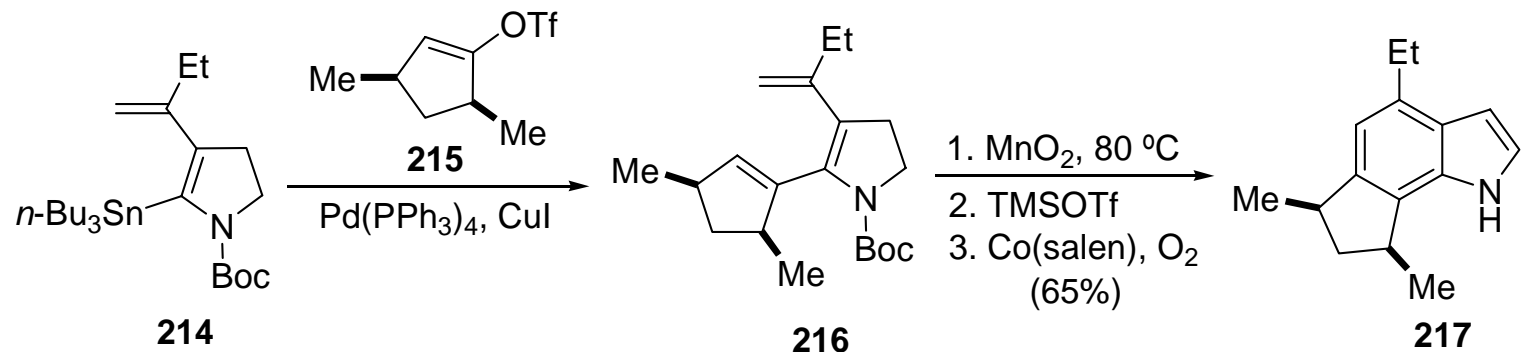

\section{Scheme 64}

Tetrahydrofurans stannylated at C-2, such as compound 218, have been employed for a cerium ammonium nitrate (CAN)-mediated oxidative acetal forming reaction through capture of the oxonium ion intermediate 219, thus driving to furo[2,3-b]pyrans such as the bicycle 220 (Scheme 65). ${ }^{403}$ In addition, 5-tri-n-butylstannylated 2,3-dihydrofuran, prepared by stannylation of the corresponding dihydrofuryllithium, has been attempted in a palladium-catalyzed coupling with benzoyl chloride, although serious problems arising in the final separation of the benzoylated product from the resulting tri- $n$-butylstannyl chloride occurred. ${ }^{404}$ Moreover, 3-and 4-stannylated furan-2(5H)-ones have been used for introducing the furanone moiety by means of the Stille reactions, examples involving furan-2-ones stannylated at C-3, ${ }^{405} \mathrm{C}-4,{ }^{406}$ or both positions ${ }^{407}$ having been reported in the last years.

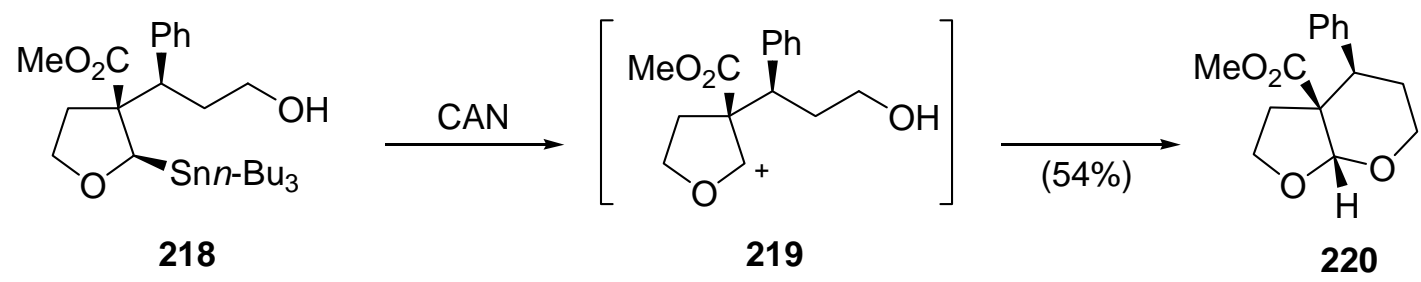

\section{Scheme 65}

Tetrahydropyrans have been recently stannylated at the anomeric position by a reductive lithiation of the corresponding phenylthio acetals followed by a subsequent reaction with a trialkylstannyl chloride, the obtained 2-stannylated systems being used for tin-lithium transmetalation in an approach to the central core of amphidinol $3 .^{408}$ However, a direct lithiation followed by a reaction with trialkylstannyl halides has been employed when the preparation of (5,6-dihydro-4H-pyran-2-yl)trialkylstannane is intended. An example can be seen in the synthesis of the stannylated glycal 221, which has been employed for a Stille crosscoupling reaction with $\alpha$-iodostyrene affording compound 222 (Scheme 66), an intermediate in the synthesis of the branched $C$-glycoside substructure of pluramycin antibiotic altromycin B. ${ }^{409}$ Other 6-stannylated 3,4-dihydro-2H-pyrans have also been used recently in Stille couplings, as in the total synthesis of the neurotoxin azaspirazid $-1^{410}$ or in the synthesis of spiroketals. ${ }^{411}$ These 
organotin derivatives have also been employed as a source of organolithiums in a total synthesis of the marine sponge metabolite $(+)$-mycalamide $\mathrm{A},{ }^{412}$ as well as in desulfitative Stille reactions $^{413}$
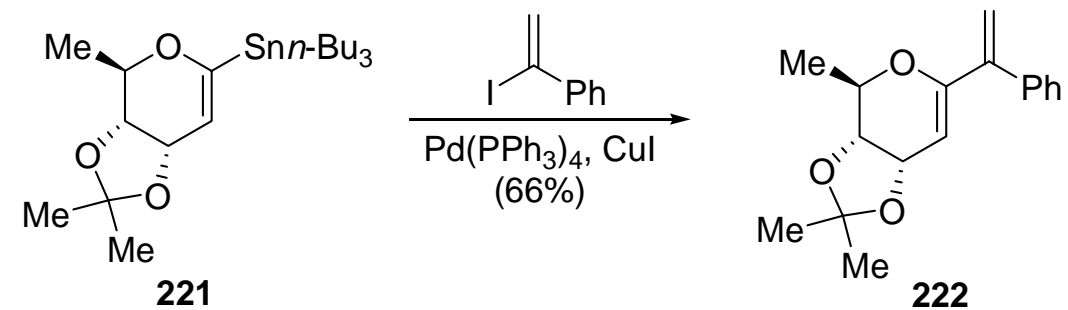

\section{Scheme 66}

\section{Group 5 Metalated Heterocycles}

\subsection{Selenium heterocycles}

Selanylated heteroaromatic compounds are tipycally prepared from their organolithium counterparts by reaction with a selenylating agent. However, procedures such as the phenylselenenyl chloride-induced electrophilic cyclization of 2-alkynylated enones or 2alkynylated anisoles, have also been employed for the synthesis of 3-selanylated furans ${ }^{414}$ or benzo[b]furans, ${ }^{415}$ respectively. In the case of selanylated pyridines, another synthetic method is the use of selenoates in a substitution reaction starting from halopyridines. ${ }^{416}$ Procedures such as the copper(I)-catalyzed arylselanylation of pyridyl bromides using tri- $n$-butyltin aryl selenides have also been applied. ${ }^{417}$

Selanylated tetrahydrofurans have been employed mainly in carbohydrate synthesis an can be obtained by addition of a selanylating agent to a 2,3-dihydrofuran, something that has been achieved photochemically, ${ }^{418}$ of via a selenonium cation. ${ }^{419}$ However, the most frequently employed selanylated systems in carbohydrate chemistry are $\alpha$-selanylated tetrahydro- $2 \mathrm{H}$ pyrans. Thus, these selenoglycosides have found many applications in this field as effective and stable glycosyl donors. They can be obtained by reaction of acetylated sugars with phenylselenol (obtained by reduction of diphenyldiselenide) and have been employed in elimination reactions to give 3,4-dihydro-2H-pyrans, ${ }^{420}$ or attached to diol linkers. ${ }^{421}$ Selenoglycosides have also been obtained from their corresponding glycosyl bromides by substitution reactions using selenoates, ${ }^{422}$ selenocarboxylic acids ${ }^{423}$ or their salts. ${ }^{424}$ and. An example of this latter methodology is the reaction of the glycosyl bromide 223 with potassium $p$ methylselenobenzoate (224) to give the $\beta$-selenoglycoside 225, which can react with an electrophile such as iodide 226, in the presence of an amine and cessium carbonate, to give the selenoglycosyl serine derivative 227 through an anomeric selenoate anion (Scheme 67). ${ }^{424 a}$ 


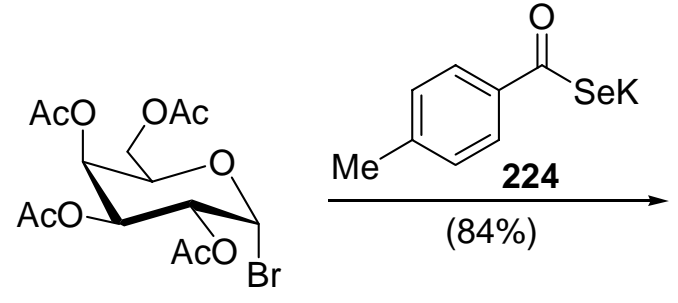

223

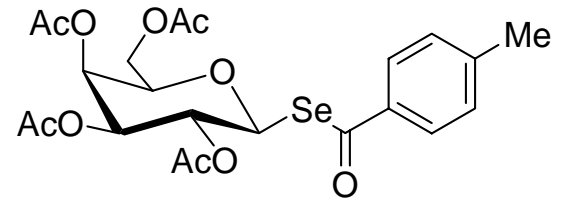

225

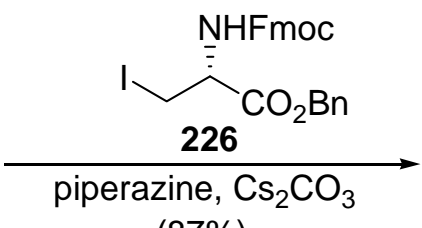

(87\%)

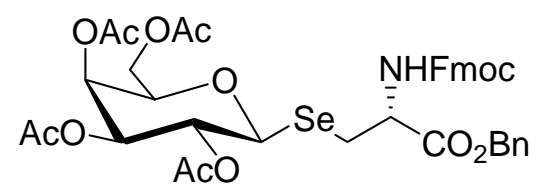

227

\section{Scheme 67}

Glycosyl bromides have also been used in the preparation of selenoglycosides after reaction with bis(phenylselanyl)zinc ${ }^{425}$ or after indium(I)-mediated cleavage of diselenides and further susbtitution reaction. ${ }^{426}$ In addition, the azidophenylselenylation of glycals has also been used for the synthesis of selenoglycosides, ${ }^{427}$ as well as the ring opening of epoxides with phenylselanol. $^{428}$

A recent synthetic application of one of these selanylated systems is the treatment of the selenoglycoside 228 with allyldimethylchlorosilane to give the 6-O-allylsilyl ether 229. Radicalmediated cyclization of this compound gave the product 230, which was ring-opened via oxidative Si-C bond fission affording the $\beta$-C-glucoside 231 (Scheme 68). ${ }^{429}$

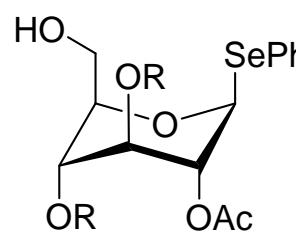

228

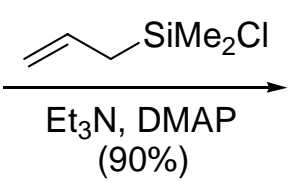

(90\%)

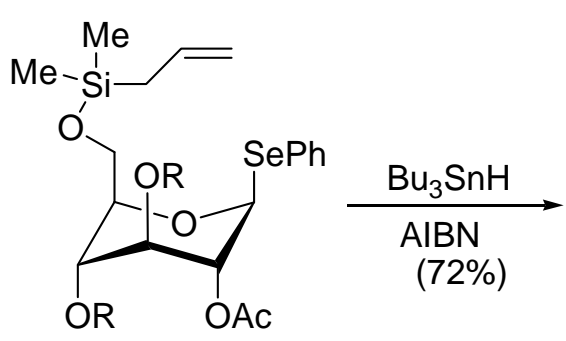

229

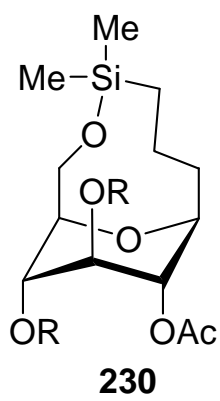

230

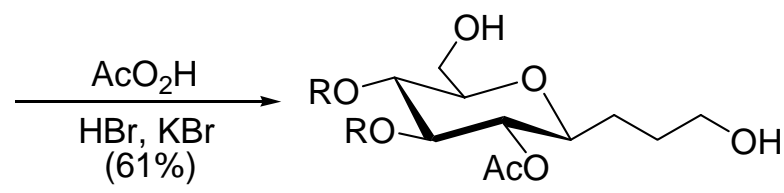

$\left[\mathrm{R}=\mathrm{Sit}-\mathrm{BuMe}_{2}\right]$

231

\section{Scheme 68}


$\beta$-Organoselenium-substituted butenolides have been obtaines from 2,3-allenoates and phenylselenenyl chloride, the presence of water being crucial for this electrophilic cyclization. ${ }^{430}$ A particular example of this methodology is shown in the cyclization of the ethyl allenoate 232 to give the corresponding selanylated butenolide 233 in quantitative yield (Scheme 69). ${ }^{430 \mathrm{~b}}$

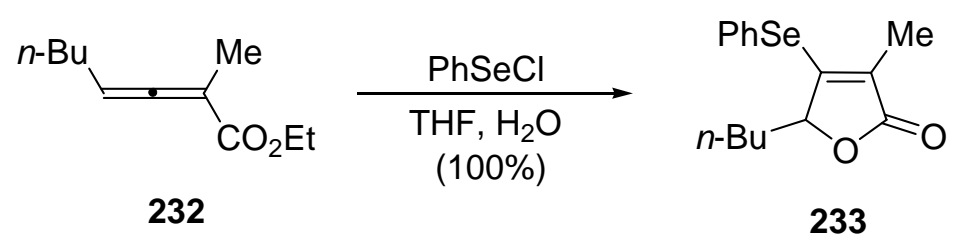

\section{Scheme 69}

\subsection{Tellurium heterocycles}

Heteroaryl tellurides are usually prepared from the corresponding heteroaryllithium reagents after reaction with elemental tellurium an subsequent reaction with an alkyl halide, ${ }^{431}$ although a method consisting of microwave-assisted copper-catalyzed coupling of diaryl dichalcogenides and aryl halides has been recently developed. ${ }^{432}$ These tellurides have been found as suitable counterparts for some palladium-catalyzed cross-coupling reactions. ${ }^{433}$ An example is 2-(nbutyltelluro)furan 234, obtained from furan following the usual method, which has been employed in a Suzuki-Miyaura cross-coupling reaction with potassium phenyltrifluoroborate, affording 2-phenylfuran (235) (Scheme 70). ${ }^{434}$ Similarly 2-tellurothiophene and 3-telluropyridine derivatives have also been used in this reaction. ${ }^{434}$ The process has also been performed using $E$ vinylic trifluoroborates under ultrasound conditions, affording stilbene derivatives. ${ }^{435}$

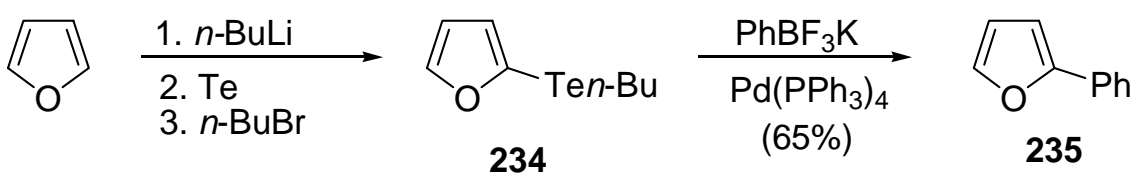

\section{Scheme 70}

Symmetrical and unsymmetrical 2- and 3-pyridyltellurium compounds have been obtained from the corresponding pyridylmagnesium chlorides after treatment with elemental tellurium, dimerization achieved upon aerial oxidation. ${ }^{436}$ Other tellurium-substituted heterocycles have been obtained by a $S_{N} A r$ reaction using sodium arenetellurate ions, generated in situ by the reduction of diarylditelluride with sodium borohydride, as it is the case of the triazine 236, prepared by this method from 2,4,6-trichloro-1,3,5-triazine. ${ }^{437}$ In addition, $\beta$ organotellurobutenolides, such as compound 237, have been prepared by electrophilic tellurolactonization of $\alpha$-allenoic acids, and have been used in both substitution reaction with cuprates or in palladium-catalyzed Sonogashira cross-coupling reactions. ${ }^{438}$ 
<smiles>Brc1nc(Br)nc([Al-]c2nc(Br)nc(C[Te])n2)n1</smiles>

236

$\left[\mathrm{Ar}=4-\mathrm{FC}_{6} \mathrm{H}_{4}\right]$

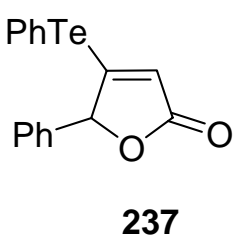

\section{Transition Metal-Substituted Heterocycles}

\subsection{Titanium heterocycles}

Heteroaryltitanium reagents are usually prepared by lithium-titanium exchange, examples of their synthetic applications being rather limited in spite of their good reactivity and selectivity. A recent example of their use is the (silyloxyfuranyl)titanium reagent 238, generated by bromolithium exchange from the corresponding silylated bromofuran followed by reaction with triisopropoxytitanium(IV) chloride. Addition reaction to the aldehyde 239 afforded the corresponding alcohol $\mathbf{2 4 0}$ mainly with a $(R)$ stereochemistry at the newly created stereocenter (Scheme 71). ${ }^{439}$ Interestingly, an opposite stereoselection was achieved when the addition reaction was performed with the lithiated silyloxyfuran analogue. The alcohol $\mathbf{X}$ was used as an intermedite in the total synthesis of the antitumor diterpenoid (+)-zerumin $\mathrm{B}$. The same organotitanium reagent $\mathbf{X}$ has also been used in other addition to a chiral aldehyde in the total synthesis of the furanosesquiterpe lactones (+)-ricciocarpins A and B. ${ }^{440}$

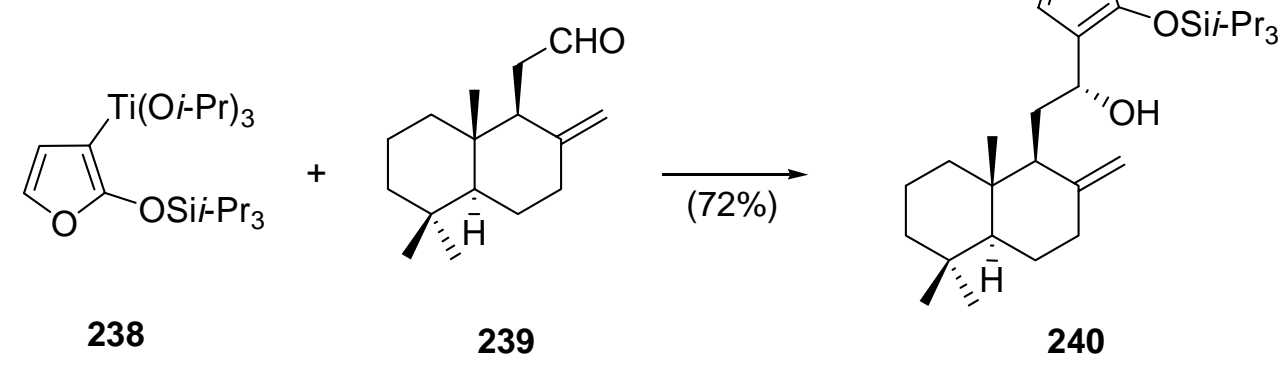

\section{Scheme 71}




\subsection{Copper heterocycles}

Heteroaryl copper reagents are usually obtained from the corresponding organolithium reagents ( 2 equivalents) by reaction with a copper(I) salt. ${ }^{1,4}$ However, other transmetalation procedures have been used, as in the case of furylcopper reagent 241 which has been prepared by mixing 2lithiofuran and magnesium(II) bromide followed by transmetalation with the complex copper(I) bromide-dimethylsulfide. The high order thiophene-derived cuprate 242 has been prepared by transmetalation of (benzyloxymethyl)tri- $n$-butylstannane with $n$-butyllithium and addition of the Lipshutz reagent (2-thienyl) $\mathrm{Cu}(\mathrm{CN}) \mathrm{Li}$. Both reagents have been used in addition reactions of 2furyl and benzyloxymethyl groups, respectively, to $\mathrm{C}-4$ of $\mathrm{N}$-acylpyridinium salts derived from (S)-nicotine. ${ }^{441}$

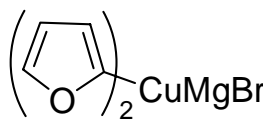

241

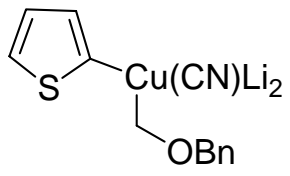

242

The former mixed high-order cyanocuprates of the type $\mathrm{R}$ (2-thienyl) $\mathrm{Cu}(\mathrm{CN}) \mathrm{Li}_{2}$, obtained as above from organolithium reagents, which bear non-transferable 2-thienyl ligand are very reactive and have shown high thermal stability and selectivity, being therefore used frequently as nucleophiles. Thus, these reagents have been employed recently, for instance, in Michael addition reactions, ${ }^{442}$ an example being the transfer of a butadienyl moiety to the unsaturated aldehyde 244 by means of the organocuprate 243 to give mainly the cis-product 245 (Scheme 72). ${ }^{442 \mathrm{e}}$ The ring-opening of aziridines ${ }^{443}$ and epoxides, ${ }^{444}$ as well as $\mathrm{S}_{\mathrm{N}} 2$ ' reactions, ${ }^{445}$ have also been performed using this copper-derived reagents.

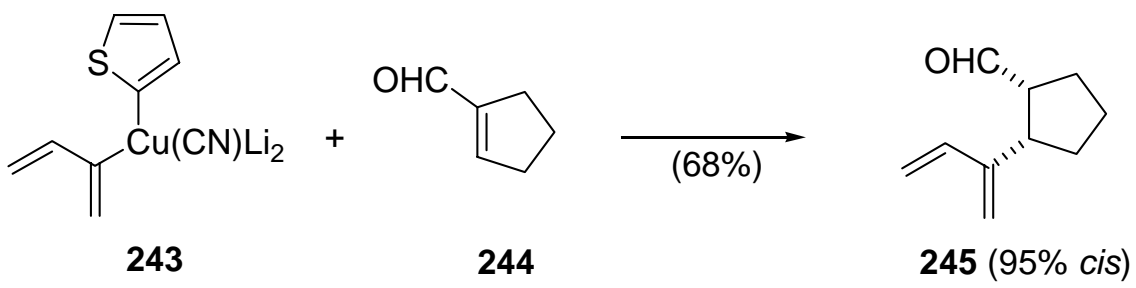

\section{Scheme 72}

The $\mathrm{N}$-substituted 4,5-diiodoimidazole $\mathbf{2 4 6}$ has been regioselectively transformed into the 5cuprated imidazole 247 after reaction with $\left(\mathrm{PhMe}_{2} \mathrm{CCH}_{2}\right)_{2} \mathrm{CuLi}$. These organocopper reagents reacted with electrophiles such as allyl bromide to give the corresponding 5-functionalized imidazole 248 (Scheme 73). ${ }^{446}$ Examples of high order 5-oxazolyl cuprates in allylation and propargylation reactions, ${ }^{447}$ as well as 4-pyridinyl cuprates in allylation reactions ${ }^{448}$ have also been reported. 


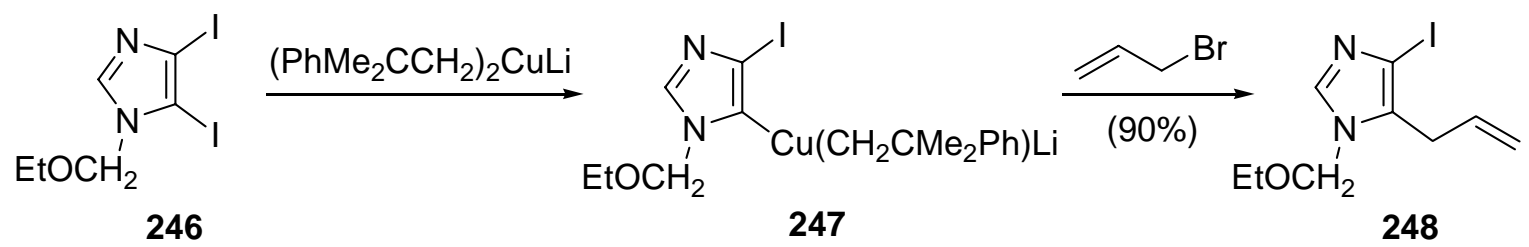

\section{Scheme 73}

The scalemic 2-pyrrolidinylcuprate 249, generated via asymmetric lithiation of $N$-Bocpyrrolidine in the presence of (-)-sparteine (see Section 2.1.3) and further treatment with $\mathrm{CuCN} \cdot 2 \mathrm{LiCl}$ (1 equiv.), reacted with $\omega$-functionalized vinyl halides, such as iodide $\mathbf{2 5 0}$, to give the corresponding enantiomerically enriched substituted pyrrolidine 251 (Scheme 74). ${ }^{449}$ When the starting scalemic lithiated species whas treated with 0.5 equiv. of $\mathrm{CuCN} \cdot 2 \mathrm{LiCl}$, the resulting cuprate of the type $\mathrm{R}_{2} \mathrm{CuLi}$ gave a slightly lower enantioselection (74\% ee). This organocupratebased methodology has been applied to the synthesis of some alkaloids, ${ }^{449}$ such as the pyrrolizidine alkaloid (-)-pyrrolam $\mathrm{A}^{450}$ and the indolizidine alkaloid (+)-elaeokanine $\mathrm{A} .{ }^{451}$ The $\mathrm{N}$-Boc-protected 2-pyrrolidinyl-based scalemic cuprate of the type $\mathrm{R}_{2} \mathrm{CuLi}$ has also been used in iodine-promoted dimerization reactions. ${ }^{452}$

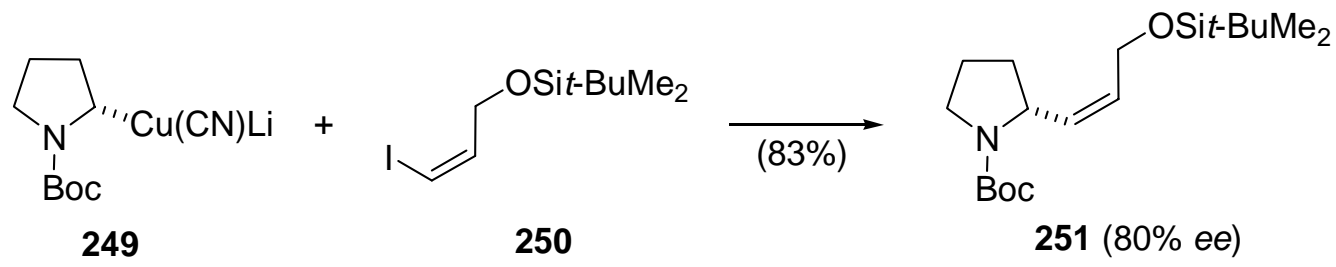

\section{Scheme 74}

\subsection{Zinc heterocycles}

Heterocyclic zinc species are usually prepared from their corresponding organolithium or organomagnesium counterparts by transmetalation with a zinc dihalide, the ratio of these reagents allowing to generate organozinc halides of diorganozincs. Organozincs are stable at higher temperatures than their precursors and frequently tolerate the presence of other functionalities. $^{1,4} \mathrm{~A}$ frequent use of these zinc-derived reagents is in transition-metal-catalyzed cross-coupling reactions such as the palladium-catalyzed coupling with unsaturated halides (the so-called Negishi coupling ${ }^{166}$ ).

\subsubsection{Aromatic five-membered rings}

2-Indolylzinc chlorides have been used for a Negishi coupling with brominated 2azabicyclo[2.2.2] octenes in the preparation of analogues of the cocaine-intake reductor ibogaine. ${ }^{453}$ The nickel(II) chloride-diethyl phosphite system has been used as catalyst in cross- 
coupling reactions or organozincs, such as the coupling of (1-methylpyrrol-2-yl)zinc bromide with 3-bromopyridine. ${ }^{454}$ Iron trichloride has also been used as catalyst in the cross-coupling reaction of some heteroarylzincs with alkyl halides, the reaction occurring probably through radical intermediates. Thus, $N$-methylated 2 -indolylzinc derivative 253, bearing a nontransferable (trimethylsilyl)methyl group, was generated upon treatment of the organozinc reagent 252 with [(trimethylsilyl)methyl]magnesium chloride, and reacted with cyclohexylchloride in the presence of catalytic amount of iron trichloride to give the corresponding 2-substituted indole 254 (Scheme 75). ${ }^{455}$

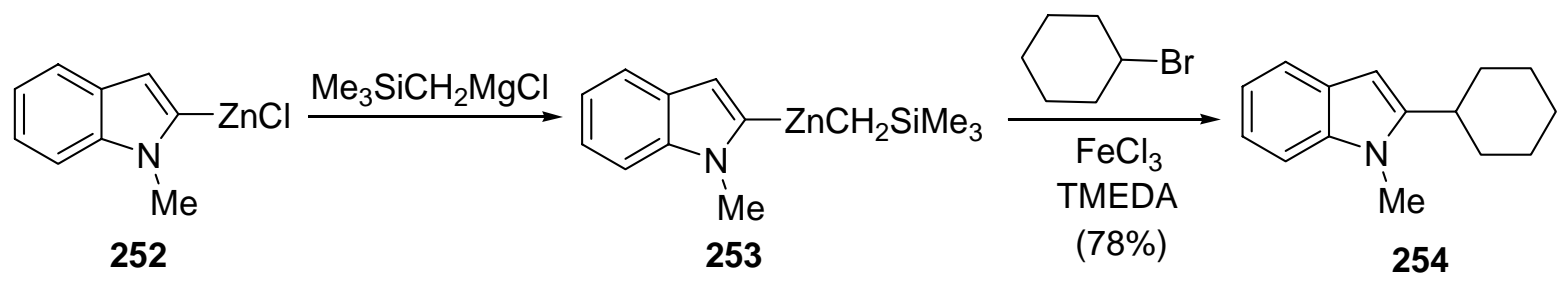

\section{Scheme 75}

Di(furan-2-yl)zinc has been used as nucleophile in the ring opening of glycal epoxides to achieved the corresponding $\alpha$-glycoside with high $\alpha$-selectivity, similar results being obtained when using the furylzinc reagent generated by reaction of 2-furyllithium with zinc chloride. ${ }^{456} \mathrm{In}$ addition, functionalized heteroaryl disulfides have been obtained by reaction of the corresponding functionalized zinc organometallics (such as 2-furylzinc and 3-indolylzinc bromides prepared by magnesium-zinc exchange) with sulfur monochloride. ${ }^{457}$

Thienylzinc compounds have been prepared under cobalt catalysis from thienyl chlorides and zinc metal, ${ }^{458}$ or from thienyl iodides using a zinc-copper couple in a microwave environment. ${ }^{459}$ This direct insertion of zinc into organic iodides and bromides has been performed very recently adding lithium chloride, a methodology similar to the acceleration of the bromo-magnesium exchange observed after addition of this salt (see Section 3.1.1). ${ }^{460}$ An example of the application of this methodology is the transformation of 2,5-diiodothiophene (255) into the thienylzinc-lithium chloride species 256 (after addition of 1.4 equivalents of zinc metal and lithium chloride) which afforded to ketone 257 after copper(I)-catalyzed acylation with benzoyl chloride (Scheme 76). Moreover, functionalized iodinated systems such as an acetylated 2-iodothiophene can be converted into diaryl zinc compounds after an iodo-zinc exchange using diisopropylzinc in the presence of a catalytic amount of nickel acetylacetonate to accelerate the otherwise slow halogen-zinc exchange. The obtained functionalized diorganozincs have been used for palladium-catalyzed Negishi couplings. ${ }^{461}$ 


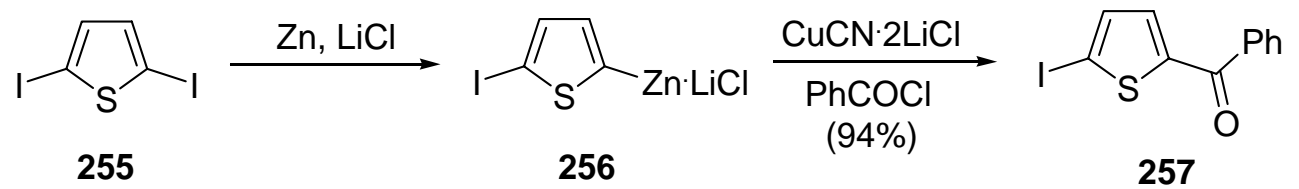

\section{Scheme 76}

As commented before, organozincs have been used mainly for palladium catalyzed crosscoupling reactions, something that for thienylzinc reagents is specially more frequent. Thus, examples of the use of thiophene-derived organozincs in a Negishi reaction for the preparation of 2,2'-dithienylated 1,1'-binaphthyls, ${ }^{462} 2,5$-diarylheteropentalenes, ${ }^{463}$ susbtituted azulenes, ${ }^{464}$ analogues of tropane, ${ }^{465}$ carborane derivatives, ${ }^{466}$ 2-pyrimidyl-5-amidothiophenes as inhibitors for $\mathrm{AKT},{ }^{467}$ 4-thienylated quinolinones ${ }^{468}$ or multi[60]fullerenes with heterojunctions ${ }^{469}$ have been recently reported. In addition, thien-2-ylzinc iodide has been employed in a new rhodiumcatalyzed coupling reaction with (iodomethyl)trimethylsilane. ${ }^{470}$

2-Thiazolylzinc reagents have also been used in Negishi cross-coupling reactions, ${ }^{471}$ as illustrated in Scheme 77 with the coupling of the organozinc reagent 258 with the dibromopyridine 259 to give compound 260, which is an intermediate in the synthesis of the heterocyclic core of the GE 2270 antibiotic. $^{472}$

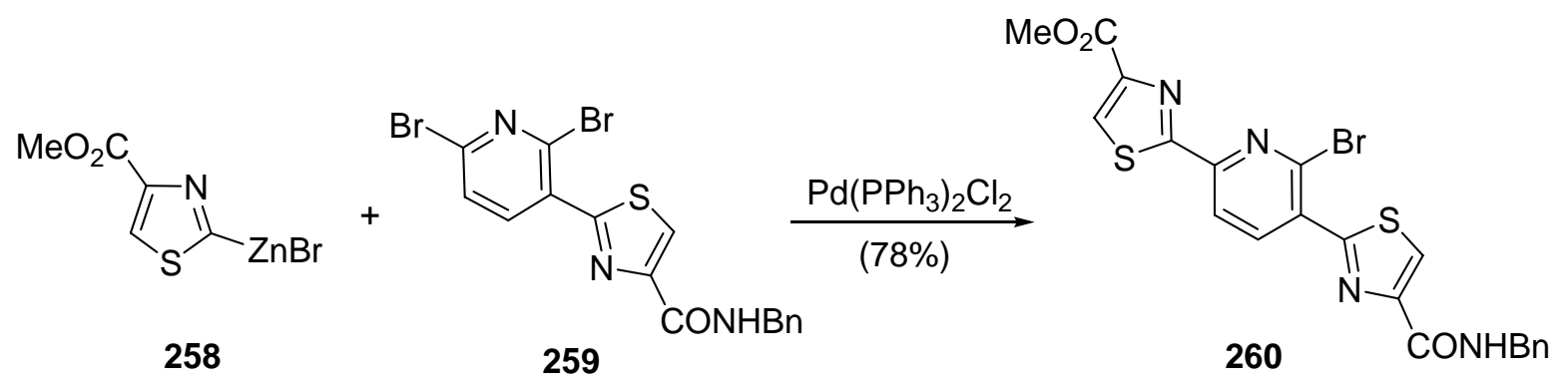

\section{Scheme 77}

\subsubsection{Aromatic Six-Membered Rings}

Pyridylzincs are usually prepared by the typical lithium-zinc transmetalation, and have been employed mostly in palladium-catalyzed Negishi cross-coupling reactions for introducing a pyridine nucleus. Thus, recent examples of the use of 2-pyridylzinc bromides and chlorides as metalated counterpart in this coupling process are common, ${ }^{473}$ as in the case of the coupling of 2pyridylzinc bromide (261) with the chlorinated 2'-deoxyribosylpurine 262, affording compound 263 in a synthesis of a purine-like nickel(II) base pair for DNA (Scheme 78). ${ }^{474 a}$ A similar process has been followed in the preparation of a related pirimidine-like system. ${ }^{474 \mathrm{~b}}$ 


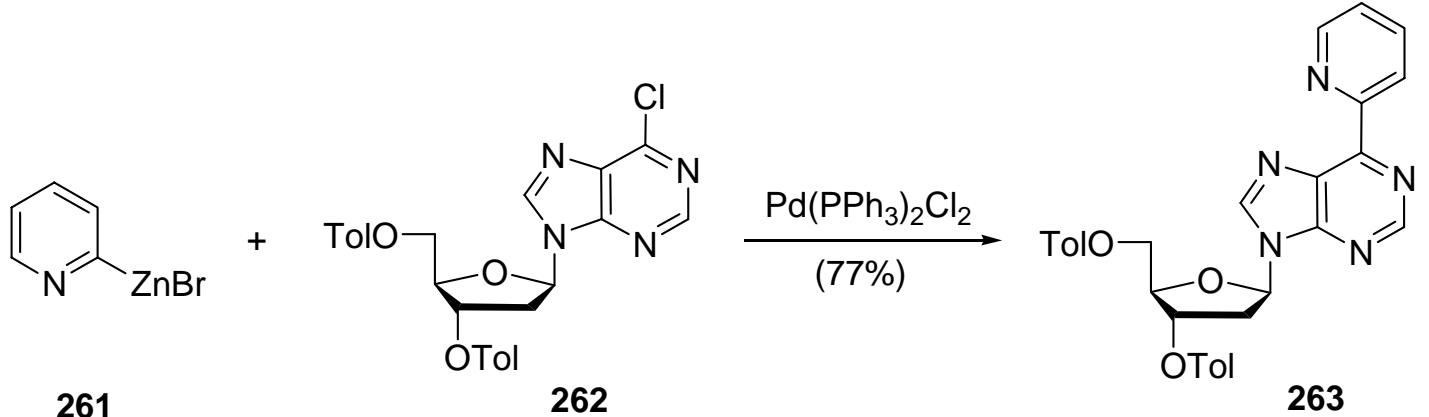

262

263

$\left[\mathrm{Tol}=4-\mathrm{MeC}_{6} \mathrm{H}_{4} \mathrm{CO}\right]$

\section{Scheme 78}

2-Fluorinated 4-pyridylzinc halides have also been used in palladium-catalyzed crosscoupling reactions for the synthesis of pyridinyl-pyrimidines ${ }^{475}$ and analogues of the phenylamino-pyrimidine type protein kinase C inhibitor CGP $60474 .{ }^{476}$ In addition, dipyridin-2ylzinc has been used as nucleophile in a copper-catalyzed electrophilic amination using $O$ acyl $^{477 a}$ and $O$-benzoyl hydroxylamines ${ }^{477 b}$ has nitrogen sources.

\subsubsection{Nonaromatic heterocycles}

Thermally stable oxyranylzinc compounds have been obtained from optically pure trifluoromethyl oxiranes by a conventional low temperature lithiation, followed by metal exchange with zinc dichloride, being employed in Negishi couplings. ${ }^{132 b}$ This palladiumcatalyzed cross-coupling reaction has also been performed using pyran-2-ylzinc chloride (264), generated similarly by lithium-zinc transmetalation, and the racemic vinyl iodide $\mathbf{2 6 5}$ to give the alcohol 266 (Scheme 79). This compound can be cyclized under acid catalysis using camphorsulfonic acid (CSA) to spiroketal 267, a model for more complex systems present in a number of natural products. ${ }^{478}$

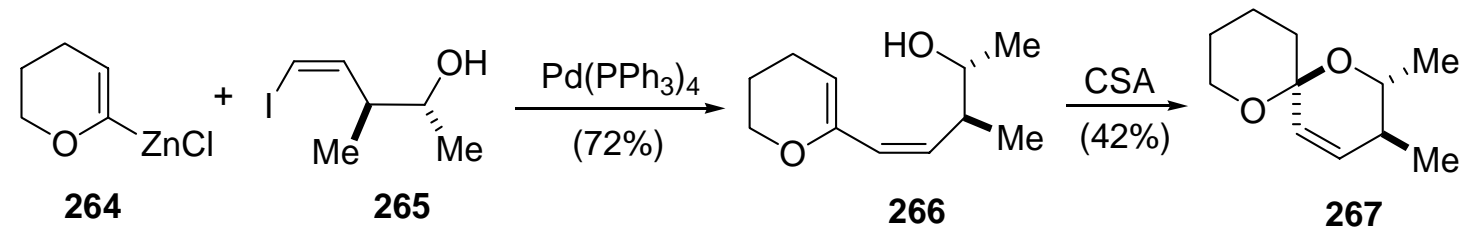

\section{Scheme 79}

\subsection{Mercury heterocycles}

3-Mercuriated furans have recently been obtained regioselectively from propargylic dithioacetals, an example being shown in Scheme 80. Thus, treatment of the dithioacetal 268 with $n$-butyllithium and benzaldehyde gave the allenyl species 269 which was allowed to react 
with mercury(II) acetate to afford the corresponding organomercury derivative 271 through the dihydrofuran intermediate 270. This compound can be employed for the preparation of the 3iodofuran 272 upon reaction with iodine. ${ }^{479}$ This mercury-iodo exchange reaction has also been employed in a 2,5-bis(acetoxymercury)thiophene, obtained by reaction of the corresponding dilithiated compound with mercury(II) acetate, giving a 2,5-diiodothiophene useful in the solidstate synthesis of conducting polythiophenes. ${ }^{480}$

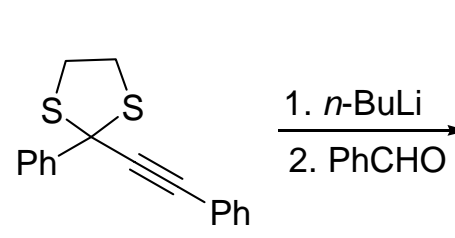

268

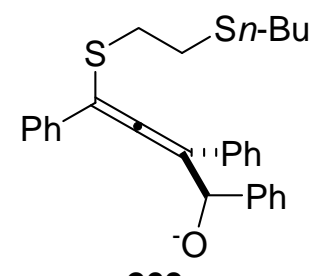

269

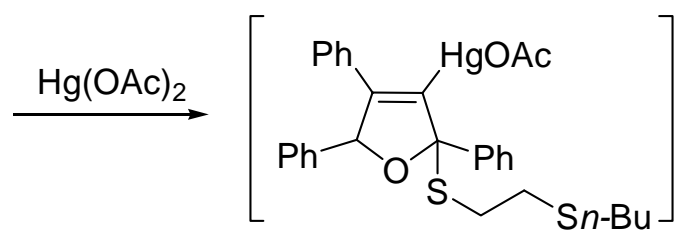

270
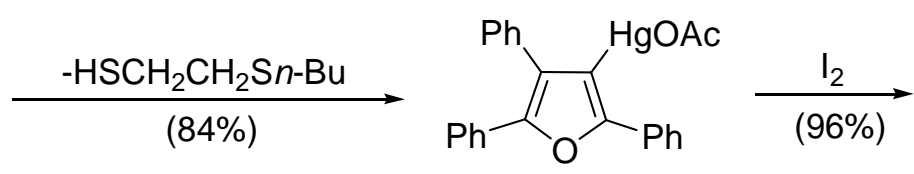

271

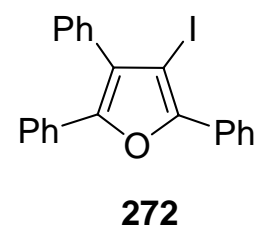

\section{Scheme 80}

\section{Conclusions}

From the reading of this review, not totally comprehensive although extensive enough, it is easy to realize the large amount of synthetic work that has been carried out with of all kind of metalated heterocycles in only three and a half years. That shows the key role that metalated heterocycles continue to play in synthetic organic chemistry. Starting from the quite frequent lithiated species, which are still the subject of many developments and studies, many other organometals with plenty of applications in transition-metal cross-coupling reactions for the preparation of nowadays interesting compounds have been obtained. Other metalated systems, such as organomagnesiums and organozincs have shown interesting developments in the very last years. It is sure that, as it has been until now, the use of metalated heterocycles will show a continuous flow of applications in the next years and will continue to be an indispensable synthetic tool in organic chemistry. 


\section{Acknowledgements}

The Spanish Ministerio de Educación y Ciencia, the Generalitat Valenciana and the Universidad de Alicante are aknowledged for their continuous financial support.

\section{References}

1. Chinchilla, R.; Nájera, C.; Yus, M. Chem. Rev. 2004, 104, 2667.

2. The Chemistry of Organolithium Compounds, Vols 1 and 2; Rappoport, Z., Marek, I., Eds.; John Wiley \& Sons: Chichester, 2004 and 2006.

3. Gribble, G. W. Science of Synthesis 2006, 8a, 357.

4. Handbook of Functionalized Organometallics; Knochel, P., Ed.; Wiley-VCH: Weinheim 2005.

5. Nájera, C.; Sansano, J. M.; Yus, M. Tetrahedron 2003, 59, 9255.

6. (a) Garg, N. K.; Caspi, D. D.; Stolz, B. M. J. Am. Chem. Soc. 2004, 126, 9552. (b) Garg, N. K.; Caspi, D. D.; Stolz, B. M. J. Am. Chem. Soc. 2005, 127, 5970.

7. Bergauer, M.; Hübner, H.; Gmeiner, P. Tetrahedron 2004, 60, 1197.

8. Donohoe, T. J.; Sintim, H. O.; Hollinshead, J. J. Org. Chem. 2005, 70, 7297.

9. Shionhara, T.; Suzuki, K. Synthesis 2003, 141.

10. Roy, S.; Gribble, G. W. Tetrahedron Lett. 2005, 46, 1325.

11. Wynne, J. H.; Stalick, W. M. J. Org. Chem. 2003, 68, 4845.

12. Rawat, M.; Wulff, W. D. Org. Lett. 2004, 6, 329.

13. (a) Fall, Y.; Vidal, B.; Alonso, D.; Gómez, G. Tetrahedron Lett. 2003, 44, 4467. (b) Pérez, M.; Canoa, P.; Gómez, G.; Terán, C.; Fall, Y. Tetrahedron Lett. 2004, 45, 5207. (c) Selander, N.; Sebelius, S.; Estay, C.; Szabó, K. J. Eur. J. Org. Chem. 2006, 4085.

14. (a) Rao, S. V.; Puranik, V. G.; Kumar, P. Tetrahedron Lett. 2003, 44, 5015. (b) Bartlett, S.; Hodgson, R.; Holland, J. M.; Jones, M.; Kilner, C.; Nelson, A.; Warriner, S. Org. Biomol. Chem. 2003, 1, 2393. (c) Pawlicki, M.; Latos-Grazyński, L. Chem. Eur. J. 2003, 9, 4650. (d) Krishna, U. M.; Deodhar, K. D.; Trivedi, G. K. Tetrahedron 2004, 60, 4829. (e) Li, M.; O’Doherty, G. A. Tetrahedron Lett. 2004, 45, 6407. (f) Takao, K.; Yasui, H.; Yamamoto, S.; Sasaki, D.; Kawasaki, S.; Watanabe, G.; Tadano, K. J. Org. Chem. 2004, 69, 8789. (g) Yin, B.-L.; Hu, T.-S.; Yue, H.-J.; Gao, Y.; Wu, W.-M.; Wu, Y.-L. Synlett 2004, 306. (h) Harmata, M.; Wacharasindhu, S. J. Org. Chem. 2005, 70, 725. (i) Li, H.; Procko, K.; Martin, S. F. Tetrahedron Lett. 2006, 47, 3485.

15. Fuller, A. A.; Chen, B.; Minter, A. R.; Mapp, A. K. J. Am. Chem. Soc. 2005, 127, 5376.

16. Alphonse, F.-A.; Suzenet, F.; Keromnes, A.; Lebret, B.; Guillaumet, G. Synthesis 2004, 2893.

17. Krishna, U. M.; Srikanth, G. S. C.; Trivedi, G. K.; Deodhar, K. D. Synlett 2003, 2383.

18. Kraus, G. A.; Wei, J. Tetrahedron Lett. 2005, 46, 7511. 
19. Yim, H.-K.; Wong, H. N. C. J. Org. Chem. 2004, 69, 2892.

20. Kurata, H.; Oki, Y.; Matsumoto, K.; Kawase, T.; Oda, M. Chem. Lett. 2005, 34, 910.

21. (a) Gupta, I.; Ravikanth, M. Tetrahedron 2003, 59, 6131. (b) Gupta, I.; Hung, C.-H.; Ravikanth, M. Eur. J. Org. Chem. 2003, 4392.

22. Tofi, M.; Geourgiou, T.; Montagnon, T.; Vassilikogiannakis, G. Org. Lett. 2005, 7, 3347.

23. Stanetty, P.; Kolodziejczyk, K.; Roiban, G.-D.; Mihovilovic, M. D. Synlett 2006, 789.

24. (a) Hughes, C. C.; Kennedy-Smith, J. J.; Trauner, D. Org. Lett. 2003, 5, 4113. (b) Miyaoka, H.; Yamanishi, M.; Kajiwara, Y.; Yamada, Y. J. Org. Chem. 2003, 68, 3476. (c) Marcos, I. S.; Pedrero, A. B.; Sexmero, M. J.; Diez, D.; Basabe, P.; Garcia, N. Moro, R. F.; Broughton, H. B.; Mollinedo, F.; Urones, J. G. J. Org. Chem. 2003, 68, 7496. (d) Pihko, A. J.; Lundell, K.; Kanerva, L.; Koskinen, A. M. P. Tetrahedron: Asymmetry 2004, 15, 1637.

25. Toró, A.; Deslongchamps, P. J. Org. Chem. 2003, 68, 6847.

26. Paintner, F. F.; Allmendinger, L.; Bauschke, G. Synlett 2005, 2735.

27. Yamaguchi, T.; Irie, M. J. Org. Chem. 2005, 70, 10323.

28. Sato, N.; Yue, Q. Tetrahedron 2003, 59, 5831.

29. Jantzi, K. L.; Puckett, C. L.; Guzei, I. A.; Reich, H. J. J. Org. Chem. 2005, 70, 7520.

30. Peyron, C.; Navarre, J.-M.; Van Craynest, N.; Benhida, R. Tetrahedron Lett. 2005, 46, 3315.

31. Izumi, T.; Kobashi, S.; Takimiya, K.; Aso, Y.; Otsubo, T. J. Am. Chem. Soc. 2003, 125 , 5286.

32. Noack, A.; Schöder, A.; Hartmann, H.; Rohde, D.; Dunsch, L. Org. Lett. 2003, 5, 2393.

33. (a) You, Y.; Gibson, S. L.; Hilf, R.; Davies, S. R.; Oseroff, A. R.; Roy, I.; Ohulchanskyy, T. Y.; Bergey, E. J.; Detty, M. R. J. Med. Chem. 2003, 46, 3734. (b) Gupta, I.; Ravikanth, M. J. Org. Chem. 2004, 69, 6796. (c) Punidha, S.; Agarwal, N.; Ravikanth, M. Eur. J. Org. Chem. 2005, 2500.

34. Song, M.-Y.; Na, H.-K.; Kim, E.-Y.; Lee, S.-J.; Kim, K. I.; Baek, E.-M.; Kim, H.-S.; An, D. K.; Lee, C.-H. Tetrahedron Lett. 2004, 45, 299.

35. Wex, B.; Kaafarani, B. R.; Neckers, D. C. J. Org. Chem. 2004, 69, 2197.

36. Gunn, D.; Akuche, C.; Baryza, J.; Blue, M.-L.; Brennan, C.; Campbell, A.-M.; Choi, S.; Cook, J.; Conrad, P.; Dixon, B.; Dumas, J.; Ehrlich, P.; Gane, T.; Joe, T.; Johnson, J.; Jordan, J.; Kramss, R.; Liu, P.; Levy, J.; Lowe, D.; McAlexander, I.; Natero, R.; Redman, A. M.; Scott, W.; Seng, T.; Sibley, R.; Wang, M.; Wang, Y.; Wood, J.; Zhang, Z. Bioorg. Med. Chem. Lett. 2005, 15, 3053.

37. Ammann, M.; Bäuerle, P. Org. Biomol. Chem. 2005, 3, 4143.

38. Leroy, J.; Levin, J.; Sergeyev, S.; Geerts, Y. Chem. Lett. 2006, 35, 166.

39. (a) Maiorana, S.; Papagni, A.; Licandro, E.; Annunziata, R.; Paravidino, P.; Perdicchia, D.; Giannini, C.; Bencini, M.; Clays, K.; Persoons, A. Tetrahedron 2003, 59, 6481. (b) Raposo, M. M. M.; Sousa, A. M. R. C.; Fonseca, A. M. C.; Kirsch, G. Tetrahedron 2006, 62, 3493.

40. Wagner, P.; Ballantyne, A. M.; Jolley, K. W.; Officer, D. L. Tetrahedron 2006, 62, 2190.

41. Sotgiu, G.; Favaretto, L.; Barbarella, G.; Antolini, L.; Gigli, G.; Mazzeo, M.; Bongini, A. Tetrahedron 2003, 59, 5083. 
42. Nanajdenko, V. G.; Sumerin, V. V.; Chernichenko, K. Y.; Balenkova, S. S. Org. Lett. 2004, $6,3437$.

43. Kenny, R. S.; Mashelkar, U. C.; Rane, D. M.; Bezawada, D. K. Tetrahedron 2006, 62, 9280.

44. Artemova, N. V.; Chevykalova, M. N.; Luzikov, Y. N.; Nifant'ev, I. E.; Nifant'ev, E. E. Tetrahedron 2004, 60, 10365.

45. Anderson, T. F.; Statham, M. A. J.; Carroll, M. A. Tetrahedron Lett. 2006, 47, 3353.

46. Frigoli, M.; Mehl, G. H. Chem. Commun. 2004, 818.

47. Bonini, C.; Funicello, M.; Scialpi, R.; Spagnolo, P. Tetrahedron 2003, 59, 7515.

48. Tatsumi, R.; Seio, K.; Fujio, M.; Katayama, J.; Horikawa, T.; Hashimoto, K.; Tanaka, H. Bioorg. Med. Chem. Lett. 2004, 14, 3781.

49. Zeni, G. Tetrahedron Lett. 2005, 46, 2647.

50. Nishida, J.; Miyagawa, T.; Yamashita, Y. Org. Lett. 2004, 6, 2523.

51. Ali, A.; Thompson, C. F.; Balkovec, J. M.; Graham, D. W.; Hammond, M. L.; Quraishi, N.; Tata, J. R.; Einstein, M.; Ge, L.; Harris, G.; Kelly, T. M.; Mazur, P.; Pandit, S.; Santoro, J.; Sitlani, A.; Wang, C.; Williamson, J.; Miller, D. K.; Thompson, C. M.; Zaller, D. M.; Forrest, M. J.; Carballo-Jane, E.; Luell, S. J. Med. Chem. 2004, 47, 2441.

52. Pepitone, M. F.; Eaiprasertsak, K.; Hardaker, S. S.; Gregory, R. V. Org. Lett. 2004, 6, 3229.

53. Locatelli, M.; Cozzi, P. G. Angew. Chem. Int. Ed. 2003, 42, 4928.

54. Balle, T.; Begtrup, M.; Jaroszewski, J. W.; Liljefors, T.; Norrby, P.-O. Org. Biomol. Chem. 2006, 4, 1261.

55. (a) Pettersen, D.; Dinér, P.; Amedjkouh, M.; Ahlberg, P. Tetrahedron: Asymmetry 2004, 15, 1607. (b) Dinér, P.; Pettersen, D.; Lill, S.O.N.; Ahlberg, P. Tetrahedron: Asymmetry 2005, $16,2665$.

56. (a) Montagne, C.; Fournet, G.; Joseph, B. Synlett 2003, 1533. (b) Richardson, T. I.; Ornstein, P. L.; Briner, K.; Fisher, M. J.; Backer, R. T.; Biggers, C. K.; Clay, M. P.; Emmerson, P. J.; Hertel, L. W.; Hsiung, H. M.; Husain, S.; Kahl, S. D.; Lee, J. A.; Lindstrom, T. D.; Martinelli, M. J.; Mayer, J. P.; Mullaney, J. T.; O'Brien, T. P.; Pawlak, J. M.; Revell, K. D.; Shah, J.; Zgombick, J. M.; Herr, R. J.; Melekhov, A.; Sampson, P. B.; King, C.-H. R. J. Med. Chem. 2004, 47, 744.

57. Janssens, F.; Leenaerts, J.; Diels, G.; De Boeck, B.; Megens, A.; Langlois, X.; van Rossem, K.; Beetens, J.; Borgers, M. J. Med. Chem. 2005, 48, 2154.

58. Chittiboyina, A. G.; Reddy, C. R.; Watkins, E. B.; Avery, M. A. Tetrahedron Lett. 2004, 45, 1869.

59. Wang, L.; Wang, G. T.; Wang, X.; Tong, Y.; Sullivan, G.; Park, D.; Leonard, N. M.; Li, Q.; Cohen, J.; Gu, W.-Z.; Zhang, H.; Bauch, J. L.; Jakob, C. G.; Hutchins, C. W.; Stoll, V. S.; Marsh, K.; Rosenberg, S. H.; Sham, H. L.; Lin, N.-H. J. Med. Chem. 2004, 47, 612.

60. Feldman, K. S.; Skoumbourdis, A. P. Org. Lett. 2005, 7, 929.

61. Jalil, M. A.; Hui, E. B. Tetrahedron Lett. 2006, 47, 1473. 
62. Asakawa, K.; Dannenberg, J. J.; Fitch, K. J.; Hall, S. S.; Kadowaki, C.; Karady, S.; Kii, S.; Maeda, K.; Marcune, B. F.; Mase, T.; Miller, R. A.; Reamer, R. A.; Tschaen, D. M. Tetrahedron Lett. 2005, 46, 5081.

63. Yus, M. In Ref. 2, Vol 1, Chapter 11, pp 647-747.

64. Torregrosa, R.; Pastor, I.M.; Yus, M. Tetrahedron 2005, 61, 11148.

65. Montagne, C.; Fournat, G.; Joseph, B. Synthesis 2005, 136.

66. (a) Lin, N.-H.; Wang, L.; Cohen, J.; Gu, W.-Z.; Frost, D.; Zhang, H.; Rosenberg, S.; Sham, H. Bioorg. Med. Chem. Lett. 2003, 13, 3821. (b) de Solms, S. J.; Ciccarone, T. M.; MacTough, S. C.; Shaw, A. W.; Buser, C. A.; Ellis-Hutchings, M.; Fernandes, C.; Hamilton, K. A.; Huber, H. E.; Kohl, N. E.; Lobell, R. B.; Robinson, R. G.; Tsou, N. N.; Walsh, E. S.; Graham, S. L.; Beese, L. S.; Taylor, J. S. J. Med. Chem. 2003, 46, 2973.

67. Karusawa, S.; Araki, L.; Terashima, H.; Kawamura, M.; Takashima, S.; Sakamoto, Y.; Hashimoto, T.; Yamamoto, Y.; Yamatodani, A.; Kurihara, T. Chem. Pharm. Bull. 2003, 51, 832.

68. Di Nunno, L.; Scilimati, A.; Vitale, P. Tetrahedron 2005, 61, 2623.

69. Vogensen, S. B.; Clausen, R. P.; Greenwood, J. R.; Johansen, T. N.; Pickering, D. S.; Nielsen, B.; Ebert, B.; Krogsgaard-Larsen, P. J. Med. Chem. 2005, 48, 3438.

70. Bayh, O.; Awad, H.; Mongin, F.; Hoarau, C.; Bischoff, L.; Trecourt, F.; Queguiner, G.; Marsais, F.; Blanco, F.; Abarca, B.; Ballesteros, R. J. Org. Chem. 2005, 70, 5190.

71. Pirrung, M. C.; Ghorai, S. J. Am. Chem. Soc. 2006, 128, 11772.

72. Stanetty, P.; Spina, M.; Mihovilovic, M. D. Synlett 2005, 1433.

73. (a) Elgazwy, A.-S. S. H. Tetrahedron 2003, 59, 7445. (b) Busscher, G. F.; Rutjes, F. P. J. T.; van Delft, F. L. Tetrahedron Lett. 2004, 45, 3629. (c) Dondoni, A.; Catozzi, N.; Marra, A. J. Org. Chem. 2004, 69, 5023.

74. Dondoni, A.; Marra, A. Chem. Rev. 2004, 104, 2557.

75. Cooper, T. S.; Larigo, A. S.; Laurent, P.; Moody, C. J.; Takle, A. K. Org. Biomol. Chem. 2005, 3, 1252.

76. Dondoni, A.; Catozzi, N.; Marra, A. J. Org. Chem. 2005, 70, 9257.

77. Swanson, D. M.; Dubin, A. E.; Shah, C.; Nasser, N.; Chang, L.; Dax, S. L.; Jetter, M.; Breitenbucher, J. G.; Liu, C.; Mazur, C.; Lord, B.; Gonzales, L.; Hoey, K.; Rizzolio, M.; Bogenstaetter, M.; Codd, E. E.; Lee, D. H.; Zhang, S.-P.; Chaplan, S. R.; Carruthers, N. I. J. Med. Chem. 2005, 48, 1857.

78. Chen, C.; Reamer, R. A.; Hilenski, J. R.; McWilliams, C. J. Org. Lett. 2003, 5, 5039.

79. Stanetty, P.; Schnürch, M.; Mereiter, K.; Mihovilovic M. D. J. Org. Chem. 2005, 70, 567.

80. Le Flohic, A.; Meyer, C.; Cossy, J. Org. Lett. 2005, 7, 339.

81. Gros, P.; Fort, Y. Eur. J. Org. Chem. 2002, 3375.

82. Kaminski, T.; Gros, P.; Fort, Y. Eur. J. Org. Chem. 2003, 3855.

83. Martineau, D.; Gros, P.; Fort, Y. J. Org. Chem. 2004, 69, 7914.

84. Février, F. C.; Smith, E. D.; Comins, D. L. Org. Lett. 2005, 7, 5457.

85. Parmentier, M.; Gros, P.; Fort, Y. Tetrahedron 2005, 61, 3261. 
86. Comoy, C.; Banaszak, E.; Fort, Y. Tetrahedron 2006, 62, 6036.

87. Doudouh, A.; Gros, P. C.; Fort, Y.; Woltermann, C. Tetrahedron 2006, 62, 6166.

88. Rebstock, A.-S.; Mongin, F.; Trécourt, F.; Quéguiner, G. Org. Biomol. Chem. 2003, 1, 3064.

89. Emerson, K. M.; Wilson, R. D.; Ashwood, M. S.; Kennedy, D. J.; Hands, D.; Brands, K. M. J.; Cottrell, I. F.; Dolling, U.-H. Synth. Commun. 2003, 33, 4235.

90. (a) Cottet, F.; Schlosser, M. Tetrahedron 2004, 60, 11869. (b) Cottet, F.; Marull, M.; Mongin, F.; Espinosa, D.; Schlosser, M. Synthesis 2004, 1619. (c) Cottet, F.; Schlosser, M. Eur. J. Org. Chem. 2004, 3793. (d) Marzi, E.; Bobbio, C.; Cottet, F.; Schlosser, M. Eur. J. Org. Chem. 2005, 2116. (e) Bobbio, C.; Schlosser, M. J. Org. Chem. 2005, 70, 3039.

91. Wang, X.-Y.; Shi, H.-C.; Sun, C.; Zhang, Z.-G. Tetrahedron 2004, 60, 10993.

92. Rahm, F.; Fischer, A.; Moberg, C. Eur. J. Org. Chem. 2003, 4205.

93. Kotschy, A.; Faragó, J.; Csámpai, A.; Smith, D. M. Tetrahedron 2004, 60, 3421.

94. Ishii, T.; Fujioka, S.; Sekiguchi, Y.; Kotsuki, H. J. Am. Chem. Soc. 2004, 126, 9558.

95. Khanapure, S. P.; Garvey, D. S.; Young, D. V.; Ezawa, M.; Earl, R. A.; Gaston, R. D.; Fang, X.; Murty, M.; Martino, A.; Shumway, M.; Trocha, M.; Marek, P.; Tam, S. W.; Janero, D. R.; Letts, L. G. J. Med. Chem. 2003, 46, 5484.

96. (a) Charbonnière, L. J.; Ziessel, R. Tetrahedron Lett. 2003, 44, 6305. (b) Charbonnière, L. J.; Ziessel, R. 2003, Helv. Chim. Acta 2003, 86, 3402.

97. Rajadurai, C.; Ivanova, A.; Enkelmann, V.; Baumgarten, M. J. Org. Chem. 2003, 68, 9907.

98. Denmark, S. E.; Fan, Y.; Eastgate, M. D. J. Org. Chem. 2005, 70, 5235.

99. Gotchev, D. B.; Comins, D. L. Tetrahedron 2004, 60, 11751.

100.(a) Lefebvre, O.; Marull, M.; Schlosser, M. Eur. J. Org. Chem. 2003, 2115. (b) Marull, M.; Lefebvre, O.; Schlosser, M. Eur. J. Org. Chem. 2004, 54.

101.Ruiz, J.; Lete, E.; Sotomayor, N. Tetrahedron 2006, 62, 6182.

102. Meana, A.; Rodríguez, J. F.; Sanz-Tejedor, M. A.; García-Ruano, J. L. Synlett 2003, 1678.

103.Shaw, S. A.; Aleman, P.; Vedejs, E. J. Am. Chem. Soc. 2003, 125, 13368.

104.Irlapati, N. R.; Adlington, R. M.; Conte, A.; Pritchard, G. J.; Marquez, R.; Baldwin, J. E. Tetrahedron 2004, 60, 9307.

105. Myśliborski, R.; Latos-Grazyński, L. Eur. J. Org. Chem. 2005, 5039.

106.Pierrat, P.; Gros, P.; Fort, Y. Synlett 2004, 2319.

107.Tchabanenko, K.; Taylor, M. G. O.; Adlington, R. M.; Baldwin, J. E. Tetrahedron Lett. 2006, 47, 39.

108.(a) Saitton, S.; Kihlberg, J.; Luthman, K. Tetrahedron 2004, 60, 6113. (b) Saitton, S.; Del

Tredici, A. L.; Mohell, N.; Vollinga, R. C.; Boström, D.; Kihlberg, J.; Luthman, K. J. Med. Chem. 2004, 47, 6595.

109.Chang, C.-Y.; Liu, H.-M.; Chow, T. J. J. Org. Chem. 2006, 71, 6302.

110.Connon, S. J.; Hegarty, A. F. Eur. J. Org. Chem. 2004, 3477.

111.Rebstock, A.-S.; Mongin, F.; Trécourt, F.; Quéguiner, G. Tetrahedron 2004, 60, 2181.

112.Rebstock, A.-S.; Mongin, F.; Trécourt, F.; Quéguiner, G. Org. Biomol. Chem. 2004, 2, 291. 113. Cailly, T.; Fabis, F.; Lemaître, S.; Bouillon, A.; Rault, S. Tetrahedron Lett. 2005, 46, 135. 
114. Audoux, J.; Plé, N.; Turck, A.; Quéguiner, G. Tetrahedron 2004, 60, 4107.

115.Gros, P. C.; Doudouh, A.; Woltermann, C. Chem. Commun. 2006, 2673.

116.Li, X.; Yin, W.; Sarma, P. V. V. S.; Zhou, H.; Ma, J.; Cook, J. M. Tetrahedron Lett. 2004, 45, 8569 .

117.Dishington, A. P.; Johnson, P. D.; Kettle, J. G. Tetrahedron Lett. 2004, 45, 3733.

118. Yang, X.; Luo, S.; Fang, F.; Liu, P.; Lu, Y.; He, M.; Zhai, H. Tetrahedron 2006, 62, 2240.

119.Lazaar, J.; Hoarau, C.; Mongin, F.; Trécourt, F.; Godard, A.; Quéguiner, G.; Marsais, F. Tetrahedron Lett. 2005, 46, 3811.

120.Ondi, L.; Volle, J.-N.; Schlosser, M. Tetrahedron 2005, 61, 717.

121. Grig-Alexam I.-C.; Finaru, A.-L.; Caubère, P.; Guillaumet, G. Org. Lett. 2006, 8, 4187.

122. Weymeels, E.; Awad, H.; Bischoff, L.; Mongin, F.; Trécourt, F.; Quéguiner, G.; Marsais, F. Tetrahedron 2005, 61, 3245.

123.Comins, D. L.; Nolan, J. M.; Bori, I. D. Tetrahedron Lett. 2005, 46, 6697.

124.Berghian, C.; Darabantu, M.; Turck, A.; Plé, N. Tetrahedron 2005, 61, 9637.

125. Schlosser, M.; Lefebvre, O.; Ondi, L. Eur. J. Org. Chem. 2006, 1593.

126. Rahier, N. J.; Cheng, K.; Gao, R.; Eisenhauer, B. M.; Hecht, S. M. Org. Lett. 2005, 7, 835.

127.Hanessian, S.; Machaalani, R. Tetrahedron Lett. 2003, 44, 8321.

128.Gridney, I. D.; Serafimov, J. M.; Quiney, H.; Brown, J. M. Org. Biomol. Chem. 2003, 1, 3811.

129. White, J. D.; Hansen, J. D. J. Org. Chem. 2005, 70, 1963.

130. Satoh, T.; Fukuda, Y. Tetrahedron 2003, 59, 9803.

131.Kim, M.; Vedejs, E. J. Org. Chem. 2004, 69, 7262.

132.(a) Yamauchi, Y.; Kawate, T.; Itahashi, H.; Katagiri, T.; Uneyama K. Tetrahedron Lett. 2003, 44, 6319. (b) Yamauchi, Y.; Kawate, T.; Katagiri, T.; Uneyama, K. Tetrahedron 2003, $59,9839$.

133.Hodgson, D. M.; Humphreys, P. G.; Ward, J. G. Org. Lett. 2005, 7, 1153.

134. Montagne, C.; Prévost, N.; Shiers, J. J.; Prié, G.; Rahman, S.; Hayes, J. F.; Shipman, M. Tetrahedron 2006, 62, 8447.

135.Hayes, J. F.; Prévost, N.; Prokeš, I.; Shipman, M.; Slawin, A. M. Z.; Twin, H. Chem. Commun. 2003, 1344.

136.(a) Luisi, R.; Capriati, V.; Florio, S.; Ranaldo, R. Tetrahedron Lett. 2003, 44, 2677. (b) Luisi, R.; Capriati, V. Florio, S.; Di Cunto, P.; Musio, B. Tetrahedron 2005, 61, 3251. (c) Troisi, L.; Granito, C.; Carlucci, C.; Bona, F.; Florio, S. Eur. J. Org. Chem. 2006, 775.

137.Vedejs, E.; Prasad, A. S. B.; Kendall, J. T.; Russel, J. S. Tetrahedron 2003, 59, 9849.

138.(a) Concellón, J. M.; Suárez, J. R.; García-Granda, S.; Díaz, M. R. Angew. Chem. Int. Ed. 2004, 43, 4333. (b) Concellón, J. M.; Bernard, P. L.; Suárez, J. R. Chem. Eur. J. 2005, 11, 4492.

139.(a) Chemla, F.; Vranken, E. In Ref. 2, Vol 1, Chap 18, pp 1165. (b) Capriati, V.; Florio, S.; Luisi, R. Synlett 2005, 1359.

140.Capriati, V.; Florio, S.; Luisi, R.; Perna, F. M.; Barluenga, J. J. Org. Chem. 2005, 70, 5852. 
141.Capriati, V.; Degennaro, L.; Florio, S.; Luisi, R.; Punzi, P. Org. Lett. 2006, 8, 4803.

142.(a) Organolithiums in Enantioselective Synthesis; Hodgson, D. M., Ed; Springer-Verlag: Heidelberg, 2003. (b) Gawley, R. E.; O’Connor, S.; Klein, R. Science of Synthesis 2006, 8a, 677.

143. Schütz, T. Synlett 2003, 901.

144. Ashweek, N. J. Coldham, I.; Haxell, T. F. N.; Howard, S. Org. Biomol. Chem. 2003, 1, 1532.

145.Deng, X.; Mani, N. S. Tetrahedron: Asymmetry 2005, 16, 661.

146.Hermet, J.-P.; Porter, D. W.; Dearden, M. J.; Harrison, J. R.; Koplin, T.; O’Brien, P.; Parmene, J.; Tyurin, V.; Whitwood, A. C.; Gilday, J.; Smith, N. M. Org. Biomol. Chem. 2003, 1, 3977.

147.McGrath, M. J.; Bilke, J. L.; O’Brien, P. Chem. Commun. 2006, 2607.

148. Morita, Y.; Tokuyama, H.; Fukuyama, T. Org. Lett. 2005, 7, 4337.

149.Phuan, P.-W.; Ianni, J. C.; Kozlowski, M. C. J. Am. Chem. Soc. 2004, 126, 15473.

150.O'Brien, P.; Wilberg, K. B.; Bailey, W. F.; Hermet, J.-P.; McGrath, M. J. J. Am. Chem. Soc. 2004, 126, 15480.

151.McGrath, M. J.; O’Brien, P. J. Am. Chem. Soc. 2005, 127, 16378.

152.Ashweek, N. J.; Brandt, P.; Coldham, I.; Dufour, S.; Gawley, R. E.; Haeffner, F.; Klein, R.; Sanchez-Jimenez, G. J. Am. Chem. Soc. 2005, 127, 449.

153. (a) Coldham, I.; Patel, Sanchez-Jimenez, G. Chem. Commun. 2003, 3083. (b) Coldham, I.; Dufour, S.; Haxell, T. F. N.; Vennall, G. P. Tetrahedron 2005, 61, 3205. (c) Coldham, I.; Dufour, S.; Haxell, T. F. N.; Patel, J. J.; Sanchez-Jimenez, G. J. Am. Chem. Soc. 2006, 128, 10943.

154.Gawley, R. E.; Klein, R.; Ashweek, N. J.; Coldham, I. Tetrahedron 2005, 61, 3271.

155.Friesen, R. W.; Sturino, C. F. Science of Synthesis 2006, 8a, 841.

156.Koh, J. H.; Mascarenhas, C.; Gagné, M. R. Tetrahedron 2004, 60, 7405.

157.Jones, S.; Norton, H. C. Synlett 2004, 338.

158. Stead, D.; O’Brien, P.; Sanderson, A. J. Org. Lett. 2005, 7, 4459.

159.Xiao, D.; Lavey, B. J.; Palani, A.; Wang, C.; Aslanian, R. G.; Kozlowski, J. A.; Shih, N.-Y.; McPhail, A. T.; Randolph, G. P.; Lachowicz, J. E.; Duffy, R. A. Tetrahedron Lett. 2005, 46, 7653.

160.Kaufman, T. S. Tetrahedron: Asymmetry 2004, 15, 1203.

161.Azzena, H.; Pisano, L.; Pittalis, M. Heterocycles 2004, 63, 401.

162.Pandey, G.; Banerjee, P.; Kumar, R.; Puranik, V. G. Org. Lett. 2005, 7, 3713.

163.Nájera, C.; Yus, M. Science of Synthesis 2006, 8a, 813.

164.(a) Zenouz, A. M. Tetrahedron Lett. 2004, 45, 2967. (b) Fargeas, V.; Baalouch, M.; Metay, E.; Baffreau, J.; Ménard, D.; Gosselin, P.; Bergé, J.-P.; Barthomeuf, C.; Lebreton, J. Tetrahedron 2004, 60, 10359. (c) Arai, N.; Ui, H.; Omura, S.; Kuwajima, I. Synlett 2005, 1691. (d) Leung, L. M. H.; Boydell, A. J.; Gibson, V.; Light, M. E.; Linclau, B. Org. Lett. 2005, 7, 5183. (e) Otero, J. M.; Fernández, F.; Estévez, J. C.; Estévez, R. J. Tetrahedron: 
Asymmetry 2005, 16, 4045. (f) Allin, S. M.; Khera, J. S.; Thomas, C. I.; Witherington, J.; Doyle, K.; Elsegood, M. R. J.; Edgar, M. Tetrahedron Lett. 2006, 47, 1961. (g) Davis, F. A.; Ramachandar, T.; Chai, J.; Skucas, E. Tetrahedron Lett. 2006, 47, 2743. (h) Kikelj, V.; Plantier-Royon, R.; Portella, C. Synthesis 2006, 1200.

165.(a) Knochel, P.; Dohle, W.; Gommermann, N.; Kneisel, F. F.; Kopp, F.; Korn, T.; Sapountzis, I.; Vu, V. A. Angew. Chem. Int. Ed. 2003, 42, 4302. (b) Ila, H.; Baron, O.; Wagner, A. J.; Knochel, P. Chem. Lett. 2006, 35, 2. (c) Ila, H.; Baron, O.; Wagner, A. J.; Knochel, P. Chem. Commun. 2006, 583.

166. Metal-Catalyzed Cross-Coupling Reactions, 2nd Edition; Diederich, F.; de Meijere, A., Eds.; Wiley-VCH: Weinheim, 2004.

167.Kuethe, J. T.; Comins, D. L. J. Org. Chem. 2004, 69, 2863.

168. Sapountzis, I.; Knochel, P. Angew. Chem. Int. Ed. 2004, 43, 897.

169.Ainai, T.; Wang, Y.-G.; Tokoro, Y.; Kobayashi, Y. J. Org. Chem. 2004, 69, 655.

170.Focken, T.; Charette, A. B. Org. Lett. 2006, 8, 2985.

171.Duplais, C.; Bures, F.; Sapountzis, I.; Korn, T. J.; Cahiez, G.; Knochel, P. Angew. Chem. Int. Ed. 2004, 43, 2968.

172.Wang, X.; Sun, X.; Zhang, L.; Xu, Y.; Krishnamurthy, D.; Senanayake, C. H. Org. Lett. 2006, 8, 305.

173.Graham, D. V.; Hevia, E.; Kennedy, A. R.; Mulvey, R. E.; O’Hara, C. T.; Talmard, C. Chem. Commun. 2006, 417.

174.Christoffers, J.; Scharl, H.; Frey, W.; Baro, A. Org. Lett. 2004, 6, 1171.

175.Kamijo, S.; Dudley, G. B. J. Am. Chem. Soc. 2006, 128, 6499.

176. Mohanakrishnan, A. K.; Amaladass, P. Tetrahedron Lett. 2005, 46, 4225.

177.Gómez Arrayás, R.; Cabrera, S.; Carretero, J. C. Org. Lett. 2005, 7, 219.

178.(a) Ohmiya, H.; Yorimitsu, H.; Oshima, K. J. Am. Chem. Soc. 2006, 128, 1886. (b) Ohmiya, H.; Wakabayashi, K.; Yorimitsu, H.; Oshima, K. Tetrahedron 2006, 62, 2207.

179.Peters, A.; Branda, N. R. Chem. Commun. 2003, 954.

180.(a) Collis, G. E.; Burrell, A. K.; Scott, S. M.; Officer, D. L. J. Org. Chem. 2003, 68, 8974.

(b) Satou, T.; Sakai, T.; Kaikawa, T.; Takimiya, K.; Otsubo, T.; Aso, Y. Org. Lett. 2004, 6, 997. (c) Liu, X.-M.; Xu, J.; He, C. Tetrahedron Lett. 2004, 45, 1507.

181.(a) Yokoyama, A.; Miyakoshi, R.; Yokozawa, T. Macromolecules 2004, 37, 1169. (b) Yokoyama, A.; Miyakoshi, R.; Yokozawa, T. J. Am. Chem. Soc. 2005, 127, 17542.

182.Pepitone, M. F.; Eaiprasertsak, K.; Hardaker, S. S.; Gregory, R. V. Tetrahedron Lett. 2004, 45, 5637.

183.Reigenbach, C.; De Nicola, A.; Ziessel, R. J. Org. Chem. 2003, 68, 4708.

184.Krasovskiy, A.; Knochel, P. Angew. Chem. Int. Ed. 2004, 43, 3333.

185.Spieß, A.; Heckmann, G.; Bach, T. Synlett 2004, 131.

186.Bekish, A. V.; Isakov, V. E.; Kulinkovich, O. G. Tetrahedron Lett. 2005, 46, 6979.

187.Reza Saberi, M.; Vinh, T. K.; Yee, S. W.; Griffiths, B. J. N.; Evans, P. J.; Simons, C. J. Med. Chem. 2006, 49, 1016. 
188.Song, J. J.; Yee, N. K.; Tan, Z.; Xu, J.; Kapadia, S. R.; Senanayake, C. H. Org. Lett. 2004, 6, 4905.

189.Ferraris, D.; Ko, Y.-S.; Calvin, D.; Chiou, T.; Lautar, S.; Thomas, B.; Wozniak, K.; Rojas, C.; kalish, V.; Belyakov, S. Bioorg. Med. Chem. Lett. 2004, 14, 5579.

190. Tšubrik, O.; Sillard, R.; Mäeorg, U. Synthesis 2006, 843.

191.(a) Kopp, F.; Krasovskiy, A.; Knochel, P. Chem. Commun. 2004, 2288. (b) Krasovskiy, A.; Kopp, F.; Knochel, P. Angew. Chem. Int. Ed. 2006, 45, 497.

192.Ren, H.; Knochel, P. Chem. Commun. 2006, 726.

193.Kii, S.; Akao, A.; Iida, T.; Mase, T.; Yasuda, N. Tetrahedron Lett. 2006, 47, 1877.

194.(a) Dumouchel, S.; Mongin, F.; Trécourt, F.; Quéguiner, G. Tetrahedron Lett. 2003, 44, 3877. (b) Dumouchel, S.; Mongin, F.; Trécourt, F.; Quéguiner, G. Tetrahedron 2003, 59, 8629.

195.(a) Awad, H.; Mongin, F.; Trécourt, F.; Quéguiner, G.; Marsais, F.; Blanco, F.; Abarca, B.; Ballesteros, R. Tetrahedron Lett. 2004, 45, 6697. (b) Awad, H.; Mongin, F.; Trécourt, F.; Quéguiner, G.; Marsais, F. Tetrahedron Lett. 2004, 45, 7873.

196. Therkelsen, F. D.; Rottländer, M.; Thorup, N.; Pedersen, E. B. Org. Lett. 2004, 6, 1991.

197. Krasovskiy, A.; Krasovskaya, V.; Knochel, P. Angew. Chem. Int. Ed. 2006, 45, 2958.

198. Boudet, N.; Knochel, P. Org. Lett. 2006, 8, 2727.

199. Tyrrel, E.; Brookes, P. Synthesis 2003, 469.

200.(a) Ishiyama, T.; Takagi, J.; Yonekawa, Y.; Hartwig, J. F.; Miyaura, N. Adv. Synth. Catal. 2003, 345, 1103. (b) Chotana, G. A.; Rak, M. A.; Smith, III, M. R. J. Am. Chem. Soc. 2005, $127,10539$.

201.Mertins, K.; Zapf, A.; Beller, M. J. Mol. Catal. A: Chem. 2004, 207, 21.

202.Dairi, K.; Tripathy, S.; Attardo, G.; Lavallée, J.-F. Tetrahedron Lett. 2006, 47, 2605.

203.Fürstner, A.; Radkowski, K.; Peters, H. Angew. Chem. Int. Ed. 2005, 44, 2777.

204. Billingsley, K. L.; Anderson, K. W.; Buchwald, S. L. Angew. Chem. Int. Ed. 2006, 45, 3438.

205.Collins, M. A.; Hudak, V.; Bender, R.; Fensome, A.; Zhang, P.; Miller, L.; Winneker, R. C.;

Zhang, Z.; Zhu, Y.; Cohen, J.; Unwalla, R. J.; Wrobel, J. Bioorg. Med. Chem. Lett. 2004, 14, 2185.

206. Meketa, M. L.; Weinreb, S. M. Org. Lett. 2006, 8, 1443.

207.Nadeau, J. M.; Swager, T. M. Tetrahedron 2004, 60, 7141.

208.de Koning, C. B.; Michael, J. P.; Pathak, R.; van Otterlo, W. A. L. Tetrahedron Lett. 2004, 45, 1117.

209.Cai, X.; Snieckus, V. Org. Lett. 2004, 6, 2293.

210.Garg, N. K.; Caspi, D. D.; Stoltz, B. M. J. Am. Chem. Soc. 2005, 127, 5970.

211.Garg, N. K.; Stoltz, B. M. Tetrahedron Lett. 2005, 46, 2423.

212.Kudo, N.; Perseghini, M.; Fu, G. C. Angew. Chem. Int. Ed. 2006, 45, 1282.

213.(a) Beletskaya, I. P.; Ganina, O. G.; Tsvetkov, A. V.; Fedorov, A. Y.; Finet, J.-P. Synlett 2004, 2797. (b) Alphonse, F.-A.; Suzenet, F.; Keromnes, A.; Lebret, B.; Guillaumet, G. Synthesis 2004, 2893. (c) Kohyama, N.; Katashima, T.; Yamamoto, Y. Synthesis 2004, 
2799. (d) Yu, C.-M.; Kweon, J.-H.; Ho, P.-S.; Kang, S.-C.; Lee, G. Y. Synlett 2005, 2631. (e) El Kazzouli, S.; Bouissane, L.; Khouili, M.; Guillaumet, G. Tetrahedron Lett. 2005, 46, 6163. (f) Korolev, D. N.; Bumagin, N. A. Tetrahedron Lett. 2006, 47, 4225.

214.Hocek, M.; Nauš, P.; Pohl, R.; Votruba, I.; Furman, P. A.; Tharnish, P. M.; Otto, M. J. J. Med. Chem. 2005, 48, 5869.

215. Chittiboyina, A. G.; Reddy, C. R.; Watkins, E. B.; Avery, M. A. Tetrahedron Lett. 2004, 45, 1689.

216.Ax, A.; Schaal, W.; Vrang, L.; Samuelsson, B.; Hallberg, A.; Karlén, A. Bioorg. Med. Chem. Lett. 2005, 13, 755.

217.Mathews, C. J.; Taylor, J.; Tyte, M. J.; Worthington, P. A. Synlett 2005, 538.

218.Mendiola, J.; Castellote, I.; Alvarez-Builla, J.; Fernández-Gadea, J.; Gómez, A.; Vaquero, J. J. J. Org. Chem. 2006, 71, 1254.

219.Wang, Z.; Elokdah, H.; McFarlane, G.; Pan, S.; Antane, M. Tetrahedron Lett. 2006, 47, 3365 .

220.Langel, S.; Abarbri, M.; Duchêne, A. Tetrahedron Lett. 2003, 44, 9255.

221.(a) Vachal, P.; Toth, L. M. Tetrahedron Lett. 2004, 45, 7157. (b) Kondolff, I.; Doucet, H.; Santelli, M. Synlett 2005, 2057.

222.(a) Felpin, F.-X. J. Org. Chem. 2005, 70, 8575. (b) Lukashev, N. V.; Latyshev, G. V.; Donez, P. A.; Skryabin, G. A.; Beletskaya, I. P. Synthesis 2006, 533.

223. Colarusso, S.; Girardin, M.; Conte, I.; Narjes, F. Synthesis 2006, 1343.

224.(a) Kotha, S.; Kashinath, D.; Lahiri, K.; Sunoj, R. B. Eur. J. Org. Chem. 2004, 4003. (b) Masui, K.; Mori, A.; Okano, K.; Takamura, K.; Kinoshita, M.; Ikeda, T. Org. Lett. 2004, 6, 2011. (c) Mulder, A.; Jukovič, A.; Huskens, J.; Reinhoudt, D. N. Org. Biomol. Chem. 2004, 2, 1748. (d) Melucci, M.; Barbarella, G.; Zambianchi, M.; Di Pietro, P.; Bongini, A. J. Org. Chem. 2004, 69, 4821.

225.(a) Pu, S.; Yang, T.; Xu, J.; Shen, L.; Li, G.; Xiao, Q.; Chen, B. Tetrahedron 2005, 61, 6623.

(b) Pu, S.; Yang, T.; Li, G.; Xu, J.; Chen, B. Tetrahedron Lett. 2006, 47, 3167.

226.Abreu, A. S.; Ferreira, P. M. T.; Monteiro, L. S.; Queiroz, M.-J. R. P.; Ferreira, I. C. F. R.; Calhella, R. C.; Estevinho, L. M. Tetrahedron 2004, 60, 11821.

227.Yu, C.-M.; Kweon, J.-H.; Ho, P.-S.; Kang, S.-C.; Lee, G. Y. Synlett 2005, 2631.

228. Ebdrup, S.; Jacobsen, P.; Farrington, A. D.; Vedsø, P. Bioorg. Med. Chem. 2005, 13, 2305.

229.Zhu, W.; Ma, D. Org. Lett. 2006, 8, 261.

230.Christophersen, C.; Begtrup, M.; Ebdrub, S.; Petersen, H.; Vedsø, P. J. Org. Chem. 2003, $68,9513$.

231.Neumann, T.; Dienes, Y.; Baumgartner, T. Org. Lett. 2006, 8, 495.

232.Herland, A.; Nilsson, K. P. R.; Olsson, J. D. M.; Hammarström, P.; Konradsson, P.; Inganäs, O. J. Am. Chem. Soc. 2005, 127, 2317.

233.Jourdan, H.; Gouhier, G.; Van Hijfte, L.; Angibaud, P.; Piettre, S. R. Tetrahedron Lett. 2005, 46, 8027. 
234.Azzam, R.; De Borggraeve, W.; Compernolle, F.; Hoornaert, G. J. Tetrahedron Lett. 2004, $45,1885$.

235.Ducharme, Y.; Blouin, M.; Carrière, M.-C.; Chateauneuf, A.; Côté, B.; Denis, D.; Frenette, R.; Greig, G.; Kargman, S.; Lamontagne, S.; Martins, E.; Nantel, F.; O’Neill, G.; Sawyer, N.; Metters, K. M.; Friesen, R. W. Bioorg. Med. Chem. Lett. 2005, 15, 1155.

236. Molander, G. A.; Biolatto, B. J. Org. Chem. 2003, 68, 4302.

237. Molander, G. A.; Petrillo, D. E.; Landzberg, N. R.; Rohanna, J. C.; Biolatto, B. Synlett 2005, 1763.

238. Quach, T. D.; Batey, R. A. Org. Lett. 2003, 5, 1381.

239.Gérard, A.-L.; Bouillon, A.; Mahatsekake, C.; Collot, V.; Rault, S. Tetrahedron Lett. 2006, 47, 4665.

240.Moore, J. E.; Davies, M. W.; Goodenough, K. M.; Wybrow, R. A. J.; York, M.; Johnson, C. N.; Harrity, J. P. A. Tetrahedron 2005, 61, 6707.

241.Kaae, B. H.; Krogsgaard-Larsen, P.; Johansen, T. N. J. Org. Chem. 2004, 69, 1401.

242. Matondo, H.; Souirty, S.; Baboulène, M. Synth. Commun. 2003, 33, 795.

243. Bouillon, A.; Lancelot, J.-C.; de Oliveira Santos, J. S.; Collot, V.; Bovy, P. R.; Rault, S. Tetrahedron 2003, 59, 10043.

244. Mkhalid, I. A. I.; Coventry, D. N.; Albesa-Jove, D.; Batsanov, A. S.; Howard, J. A. K.; Perutz, R. N.; Marder, T. B. Angew. Chem. Int. Ed. 2006, 45, 489.

245.(a) Hodgson, P. B.; Salingue, F. H. Tetrahedron Lett. 2004, 45, 685. (b) Gros, P.; Doudouh, A.; Fort, Y. Tetrahedron Lett. 2004, 45, 6239.

246.(a) Bouillon, A.; Voisin, A. S.; Robic, A.; Lancelot, J.-C.; Collot, V.; Rault, S. J. Org. Chem. 2003, 68, 10178. (b) Leflemme, N.; Dallemagne, P.; Rault, S. Tetrahedron 2004, 60, 4861. (c) Parry, P. R.; Bryce, M. R.; Tarbit, B. Synthesis 2003, 1035. (d) Rebstock, A.-S.; Mongin, F.; Trécourt, F.; Quéguiner, G. Tetrahedron 2003, 59, 4973. (e) Denton, T. T.; Zhang, X.; Cashman, J. R. J. Med. Chem. 2005, 48, 224. (f) Thompson, A. E.; Hughes, G.; Batsanov, A. S.; Bryce, M. R.; Parry, P. R.; Tarbit, B. J. Org. Chem. 2005, 70, 388. (g) Malpass, J. R.; Handa, S.; White, R. Org. Lett. 2005, 7, 2759. (h) Cailly, T.; Fabis, F.; Bouillon, A.; Lemaître, S.; Sopkova, J.; de Santos, O.; Rault, S. Synlett 2006, 53. (i) Tilly, D.; Castanet, A.-S.; Mortier, J. Tetrahedron Lett. 2006, 47, 1121.

247.Thompson, A. E.; Batsanov, A. S.; Bryce, M. R.; Saygili, N.; Parry, P. R.; Tarbit, B. Tetrahedron 2005, 61, 5131.

248.Benniston, A. C.; Harriman, A.; Li, P.; Rostron, J. P. Tetrahedron Lett. 2005, 46, 7291. 249.Maki, T.; Ishihara, K.; Yamamoto, H. Org. Lett. 2005, 7, 5043.

250.Voisin, A. S.; Bouillon, A.; Lancelot, J.-C.; Lesnard, A.; Oulyadi, H.; Rault, S. Tetrahedron Lett. 2006, 47, 2165.

251.(a) Arterburn, J. B.; Bryant, Bj. K.; DaJun, C. Chem. Commun. 2003, 1890. (b) Baron, O.; Knochel, P. Angew. Chem. Int. Ed. 2005, 44, 3133. (c) DiMauro, J. R.; Vitullo, J. R. J. Org. Chem. 2006, 71, 3959. (d) Zhang, J.; Zhao, L.; Song, M.; Mak, T. C. W.; Wu, Y. J. Organomet. Chem. 2006, 691, 1301. 
252.Chan, D. M. T.; Monaco, K. L.; Li, R.; Bonne, D.; Clark, C. G.; Lam, P. Y. S. Tetrahedron Lett. 2003, 44, 3863.

253. Voisin, A. S.; Bouillon, A.; Lancelot, J.-C.; Lesnard, A.; Rault, S. Tetrahedron 2006, 62, 6000 .

254.Cioffi, C. L.; Spencer, W. T.; Richards, J. J.; Herr, R. J. J. Org. Chem. 2004, 69, 2210.

255.Helm, M. D.; Moore, J. E.; Plant, A.; Harrity, J. P. A. Angew. Chem. Int. Ed. 2005, 44, 3889.

256. Saygili, N.; Batsanov, A.; Bryce, M. R. Org. Biomol. Chem. 2004, 2, 852.

257.Belfaitah, A.; Isly, M.; Carboni, B. Tetrahedron Lett. 2004, 45, 1969.

258.Denmark, S. E.; Baird, J. D. Org. Lett. 2006, 8, 793.

259.Denmark, S. E.; Baird, J. D. Org. Lett. 2004, 6, 3649.

260.Zhao, Z.; Snieckus, V. Org. Lett. 2005, 7, 2523.

261.Hartung, C. G.; Fecher, A.; Chapell, B.; Sniekus, V. Org. Lett. 2003, 5, 1899.

262.(a) Bagal, S. K.; Adlington, R. M.; Marquez, R.; Cowley, A. R.; Baldwin, J. E. Tetrahedron

Lett. 2003, 44, 4993. (b) Tanaka, K.; Hata, T.; Hara, H.; Katsumura, S. Tetrahedron 2003, 59, 4945. (c) Miyashita, M.; Sasaki, M.; Hattori, I.; Sakai, M.; Tanino, K. Science 2004, 305, 495. (d) Furiuchi, N.; Hara, H.; Osaki, T.; Nakano, M.; Mori, H.; Katsumura, S. J. Org. Chem. 2004, 69, 7949. (e) Bagal, S. K.; Adlington, R. M.; Baldwin, J. E.; Marquez, R. J. Org. Chem. 2004, 69, 9100. (f) Hogan, P. C.; Corey, E. J. J. Am. Chem. Soc. 2005, 127, 15386.

263.Sofikiti, N.; Tofi, M.; Montagnon, T.; Vassilikogiannakis, G.; Stratakis, M. Org. Lett. 2005, $7,2357$.

264.Anderson, E. A.; Alexanian, E. J.; Sorensen, E. J. Angew. Chem. Int. Ed. 2004, 43, 1998.

265.Rigby, J. H.; Chouraqui, G. Synlett 2005, 2501.

266.Yim, H.-K.; Liao, Y.; Wong, H. N. C. Tetrahedron 2003, 59, 1877.

267.Donohoe, T. J.; Fisher, J. W.; Edwards, P. J. Org. Lett. 2004, 6, 465.

268.(a) Lee, K.-H.; Ohshita, J.; Kunai, A. Organometallics 2004, 23, 5365. (b) Zhang, X.; Côté, A. P.; Matzger, A. J. J. Am. Chem. Soc. 2005, 127, 10502. (c) Ohshita, J.; Kim, D.-H.; Kunugi, Y.; Kunai, A. Organometallics 2005, 24, 4494. (d) Nicolas, Y.; Blanchard, P.; Roncali, J.; Allain, M.; Mercier, N.; Deman, A.-L.; Tardy, J. Org. Lett. 2005, 7, 3513.(e)

Kim, D.-H.; Ohshita, J.; Lee, K.-H.; Kunugi, Y.; Kunai, A. Organometallics 2006, 25, 1511. 269. Baumgartner, T. Appl. Organomet. Chem. 2005, 19, 859.

270.Baumgartner, T.; Wilk, W. Org. Lett. 2006, 8, 503.

271.Fauvel, A.; Deleuze, H.; Landais, Y. Eur. J. Org. Chem. 2005, 3900.

272.Bouillon, J.-P.; Capperucci, A.; Portella, C.; Degl'Innocenti, A. Tetrahedron Lett. 2004, 45, 87.

273.Lee, Y.; Seomoon, D.; Kim, S.; Han, H.; Chang, S.; Lee, P. H. J. Org. Chem. 2004, 69, 1741.

274.Calle, M.; Calvo, L. A.; González-Ortega, A.; González-Nogal, A. M. Tetrahedron 2006, $62,611$.

275.Shoji, Y.; Hari, Y.; Aoyama, T. Tetrahedron Lett. 2004, 45, 1769. 
276.Hari, Y.; Shoji, Y.; Aoyama, T. Synthesis 2004, 1183.

277.Hari, Y.; Shoji, Y.; Aoyama, T. Tetrahedron Lett. 2005, 46, 3771.

278.Gimisis, T.; Arsenyan, P.; Georganakis, D.; Leondiadis, L. Synlett 2003, 1451.

279.(a) Tong, Y.; Lin, N.-H.; Wang, L.; Hasvold, L.; Wang, W.; Leonard, N.; Li, T.; Li, Q.; Cohen, J.; Gu, W.-Z.; Zhang, H.; Stoll, V.; Bauch, J.; Marsh, K.; Rosenberg, S. H.; Sham, H. L. Bioorg. Med. Chem. Lett. 2003, 13, 1571. (b) Frankowski, A.; Deredas, D.; Dubost, E.; Gessier, F.; Jankowski, S.; Neuburger, M.; Seliga, C.; Tschamber, T.; Weinberg, K. Tetrahedron 2003, 59, 6503.

280.Zanirato, P.; Cerini, S. Org. Biomol. Chem. 2005, 3, 1508.

281. Miller, R. A.; Smith, R. M.; Marcune, B. J. Org. Chem. 2005, 70, 9074.

282.Frey, L. F.; Marcantonio, K. M.; Chen, C.; Wallace, D. J.; Murry, J. A.; Tan, L.; Chen, W.;

Dolling, U. H.; Grabowski, E. J. J. Tetrahedron 2003, 59, 6363.

283.Zarudnitskii, E.; Perkav, I. I.; Merkulov, A. S.; Yurchenko, A. A.; Tolmalev, A. A.;

Pinchuk, A. M. Synthesis 2006, 1279.

284.Bagley, M. C.; Dale, J. W.; Xiong, X.; Bower, J. Org. Lett. 2003, 5, 4421.

285.Boga, C.; Stengel, R.; Abdayem, R.; Del Vecchi, E.; Forlani, L.; Todesco, P. E. J. Org.

Chem. 2004, 69, 8903.

286.Ueno, M.; Hori, C.; Suzawa, K.; Ebisawa, M.; Kondo, Y. Eur. J. Org. Chem. 2005, 1965.

287.Pierrat, P.; Gros, P.; Fort, Y. Org. Lett. 2005, 7, 697.

288.Itami, K.; Yoshida, J. Synlett 2006, 157.

289.(a) Kamei, T.; Fujita, K.; Itami, K.; Yoshida, J. Org. Lett. 2005, 7, 4725. (b) Itami, K.; Ohashi, Y.; Yoshida, J. J. Org. Chem. 2005, 70, 2778.

290.Nokami, T.; Tomida, Y.; Kamei, K.; Yoshida, J. Org. Lett. 2006, 8, 729.

291.(a) Schlosser, M.; Rausis, T.; Bobbio, C. Org. Lett. 2005, 7, 127. (b) Schlosser, M.; Bobbio, C.; Rausis, T. J. Org. Chem. 2005, 70, 2494.

292.Beierle, J. M.; Osimboni, E. B.; Metallinos, C.; Zhao, Y.; Kelly, T. R. J. Org. Chem. 2003, $68,4970$.

293.Gutnov, A.; Abaev, V.; Redkin, D.; Fischer, C.; Bonrath, W.; Heller, B. Synlett 2005, 1188.

294.Kuethe, J. T.; Comins, D. L. J. Org. Chem. 2004, 69, 5219.

295.Comins, D. L.; Sahn, J. J. Org. Lett. 2005, 7, 5227.

296.Hoesl, C. E.; Höffner, G.; Wanner, K. T. Tetrahedron 2004, 60, 307.

297.Yagi, K.; Shinokubo, H.; Oshima, K. Org. Lett. 2004, 6, 4339.

298. Venderhoydonck, B.; Stevens, C. V. Synthesis 2004, 722.

299.Kuramochi, K.; Nagata, S.; Itaya, H.; Matsubara, Y.; Sunoki, T.; Uchiro, H.; Takao, K.; Kobayashi, S. Tetrahedron 2003, 59, 9743.

300.Hodgson, D. M.; Kirton, E. H. M.; Miles, S. M.; Norsikian, S. L. M. Org. Biomol, Chem. 2005, 3, 1893.

301.Hodgson, D. M.; Kirton, E. H. M. Synlett 2004, 1610. 
302.(a) Srikanth, A.; Nagendrappa, G.; Chandrasekaran, S. Tetrahedron 2003, 59, 7761. (b) Thorimbert, S.; Taillier, C.; Bareyt, S.; Humilière, D.; Malacria, M. Tetrahedron Lett. 2004, 45, 9123.

303.Courillon, C.; Marié, J.-C.; Malacria, M. Tetrahedron 2003, 59, 9759.

304.(a) Okugawa, S.; Takeda, K. Org. Lett. 2004, 6, 2973. (b) Matsumoto, T.; Masu, H.; Yamaguchi, K.; Takeda, K. Org. Lett. 2004, 6, 4367. (c) Sasaki, M.; Takeda, K. Org. Lett. Org. Lett. 2004, 6, 4849. (d) Tanaka, K.; Masu, H.; Yamaguchi, K.; Takeda, K. Tetrahedron Lett. 2005, 46, 6429. (e) Sasaki, M.; Higashi, M.; Masu, H.; Yamaguchi, K.; Takeda, K. Org. Lett. 2005, 7, 5913. (f) Marion, F.; Calvet, S.; Marié, J.-C.; Courillon, C.; Malacria, M. Eur. J. Org. Chem. 2006, 453.

305.Cuadrado, P.; González-Nogal, A. M.; Sarmentero, M. A. Chem. Eur. J. 2004, 10, 4491.

306.(a) Huang, H.; Panek, J. S. Org. Lett. 2003, 5, 1991-1993. (b) Su, Q.; Panek, J. S. J. Am. Chem. Soc. 2004, 126, 2425.

307.Boglio, C.; Stahlke, S.; Thorimbert, S.; Malacria, M. Org. Lett. 2005, 7, 4851.

308. Suzuki, K.; Inomata, K.; Endo, Y. Org. Lett. 2004, 6, 409.

309. Marié, J.-C.; Courillon, C.; Malacria, M. Eur. J. Org. Chem. 2006, 463.

310.Heffron, T. P.; Jamison, T. F. Org. Lett. 2003, 5, 2339.

311.Simpson, G. L.; Heffron, T. P.; Merino, E.; Jamison, T. F. J. Am. Chem. Soc. 2006, 128, 1056.

312. Valentine, J. C.; McDonald, F. E.; Neiwert, W. A.; Hardcastle, K. I. J. Am. Chem. Soc. 2005, 127, 4586.

313.Maruyama, T.; Suga, S.; Yoshida, J. Tetrahedron 2006, 62, 6519.

314.González-Nogal, A. M.; Calle, M.; Calvo, L. A.; Cuadrado, P.; González-Ortega, A. Eur. J. Org. Chem. 2005, 4663.

315.(a) Archibald, S. C.; Barden, D. J.; Bazin, J. F. Y.; Fleming, I.; Foster, C. F.; Mandal, A. K.; Mandal, A. K.; Parker, D.; Takashi, K.; Ware, A. C.; Williams, A. R. B.; Zwicky, A. B. Org. Biomol. Chem. 2004, 2, 1051. (b) Honda, M.; Naitou, T.; Hoshino, H.; Takagi, S.; Segi, M.; Nakajima, T. Tetrahedron Lett. 2005, 46, 7345.

316.Smith, E. D.; Février, F. C.; Comins, D. L. Org. Lett. 2006, 8, 179.

317.Trost, B. M.; Rudd, M. T.; Costa, M. G.; Lee, P. I.; Pomerantz, A. E. Org. Lett. 2004, 6, 4235.

318.Wnuk, S. F.; García, Jr., P. I.; Wang, Z. Org. Lett. 2004, 6, 2047.

319. Spivey, A. C.; Turner, D. J.; Turner, M.L.; Yeates, S. Synlett 2004, 111.

320. Spivey, A. C.; Gripton, C. J. G.; Noban, C.; Parr, N. J. Synlett 2005, 2167.

321.Basarić, N.; Marinić, Ž.; Šindler-Kulyk, M. Tetrahedron Lett. 2003, 44, 7337.

322.Piatek, P.; Lynch, V. M.; Sessier, J. L. J. Am. Chem. Soc. 2004, 126, 16073.

323.Edder, C.; Armstrong, P. B.; Prado, K. B.; Fréchet, J. M. J. Chem. Commun. 2006, 1965.

324. Torun, L.; Liu, S.; Madras, B. K.; Meltzer, P. C. Tetrahedron Lett. 2006, 47, 599.

325.Basarić, N.; Baruah, M.; Qin, W.; Metten, B.; Smet, M.; Dehaen, W.; Boens, N. Org. Biomol. Chem. 2005, 3, 2755. 
326.Salman, H.; Abraham, Y.; Tal, S.; Meltzman, S.; Kapon, M.; Tessler, N.; Speiser, S.; Eichen, Y. Eur. J. Org. Chem. 2005, 2207.

327.Zonta, C.; Fabris, F.; De Lucchi, O. Org. Lett. 2005, 7, 1003.

328. (a) Peyron, C.; Benhida, R.; Bories, C.; Loiseau, P. M. Bioorg. Chem. 2005, 33, 439. (b) Padwa, A.; Lynch, S. M.; Mejía-Oneto, J. M.; Zhang, H. J. Org. Chem. 2005, 70, 2206.

329.Harper, S.; Avolio, S.; Pacini, B.; Di Filippo, M.; Altamura, S.; Tomei, L.; Paonessa, G.; Di Marco, S.; Carfi, A.; Giuliano, C.; Padron, J.; Bonelli, F.; Migliaccio, G.; De Francesco, R. D.; Laufer, R.; Rowley, M.; Narjes, F. J. Med. Chem. 2005, 48, 4547.

330.Kuo, G.-H.; Prouty, C.; DeAngelis, A.; Shen, L.; O’Neill, D. J.; Shah, C.; Connolly, P. J.; Murray, W. V.; Conway, B. R.; Cheung, P.; Westover, L.; Xu, J. Z.; Look, R. A.; Demarest, K. T.; Emanuel, S.; Middleton, S. A.; Jolliffe, L.; Beavers, M. P.; Chen, X. J. Med. Chem. 2003, 46, 4021.

331.Lefoix, M.; Daillant, J.-P.; Routier, S.; Mérour, J.-Y.; Gillaizeau, I.; Coudert, G. Synthesis 2005, 3581.

332.(a) Stephens, C. E.; Brun, R.; Salem, M. M.; Werbovetz, K. A.; Tanious, F.; Wilson, W. D.; Boykin, D. W. Bioorg. Med. Chem. Lett. 2003, 13, 2065. (b) Duffy, J. L.; Rano, T. A.; Kevin, N. J.; Chapman, K. T.; Schleif, W. A.; Olsen, D. B.; Stahlhut, M.; Rutkowski, C. A.; Kuo, L. C.; Jin, L.; Lin, J. H.; Emini, E. A.; Tata, J. R. Bioorg. Med. Chem. Lett. 2003, 13, 2569. (c) Kusturin, C.; Liebeskind, L. S.; Rahman, H.; Sample, K.; Schweitzer, B.; Srogl, J.; Neumann, W. L. Org. Lett. 2003, 5, 4349. (d) Shanmugham, M. S.; White, J. D. Chem. Commun. 2004, 44. (e) Alphonse, F.-A.; Suzenet, F.; Keromnes, A.; Lebret, B.; Guillaumet, G. Synthesis 2004, 2893. (f) Oumouch, S.; Bourotte, M.; Scmitt, M.; Bourguignon, J.-J. Synthesis 2005, 25. (g) Bour, C.; Suffert, J. Org. Lett. 2005, 7, 653. (h) Bakkestuen, A. K.; Gundersen, L.-L.; Utenova, B. T. J. Med. Chem. 2005, 48, 2710. (i) Karimi, F.; Barletta, J.; Långström, B. Eur. J. Org. Chem. 2005, 2374. (j) Sajisha, V. S.; Radhakrishnan, K. V. Adv. Synth. Catal. 2006, 348, 924. (k) Pereira, R.; Gaudon, C.; Iglesias, B.; Germain, P.; Gronemeyer, H.; de Lera, A. R. Bioorg. Med. Chem. Lett. 2006, 16, 49. (1) Mace, L. H.; Shanmugham, M. S.; White, J. D.; Drew, M. G. B. Org. Biomol. Chem. 2006, 4, 1020. (m) Anwar, U.; Fielding, M. R.; Grigg, R.; Sridharan, V.; Urch, C. J. J. Organomet. Chem. 2006, $691,1476$.

333. Tokumaru, K.; Arai, S.; Nishira, A. Org. Lett. 2006, 8, 27.

334.Roethle, P. A.; Trauner, D. Org. Lett. 2006, 8, 345.

335.Fernández-Mateos, A.; Pascual Coca, G.; Rubio González, R. Tetrahedron 2005, 61, 8699.

336.Mee, S. P. H.; Lee, V.; Baldwin, J. E. Synth. Commun. 2003, 33, 3205.

337.Mee, S. P. H.; Lee, V.; Baldwin, J. E.; Cowley, A. Tetrahedron 2004, 60, 3695.

338.(a) Tabet, A.; Schröder, A.; Hartmann, H.; Rohde, D.; Dunsch, L. Org. Lett. 2003, 5, 1817.

(b) Edder, C.; Fréchet, J. M. J. Org. Lett. 2003, 5, 1879. (c) Jousselme, B.; Blanchard, P.; Gallego-Planas, N.; Levillain, E.; Delauny, J.; Allain, M.; Richomme, P.; Roncali, J. Chem. Eur. J. 2003, 9, 5297. (d) Wakamiya, A.; Yamazaki, D.; Nishinaga, T.; Kitagawa, T.; Komatsu, K. J. Org. Chem. 2003, 68, 8305. (e) Nicolas, Y.; Blanchard, P.; Levillain, E.; 
Allain, M.; Mercier, N.; Roncali, J. Org. Lett. 2004, 6, 273. (f) Yamazaki, T.; Murata, Y.; Komatsu, K.; Furukawa, K.; Morita, M.; Maruyama, N.; Yamao, T.; Fujita, S. Org. Lett. 2004, 6, 4865. (g) Raposo, M. M. M.; Fonseca, A. M. C.; Kirsch, G. Tetrahedron 2004, 60, 4071. (h) Ewbank, P. C.; Loewe, R. S.; Zhai, L.; Reddinger, J.; Sauvé, G.; McCullough, R. D. Tetrahedron 2004, 60, 11269. (i) Liu, J.; Tanaka, T.; Sivula, K.; Alivisatos, A. P.; Fréchet, J. M. J. J. Am. Chem. Soc. 2004, 126, 6550. (j) Messmore, B. W.; Hulvat, J. F.; Sone, E. D.; Stupp, S. I. J. Am. Chem. Soc. 2004, 126, 14452. (k) Kanato, H.; Takimiya, K.; Otsubo, T.; Aso, Y.; Nakamura, T.; Araki, Y.; Ito, O. J. Org. Chem. 2004, 69, 7183. (1) Radke, K. R.; Ogawa, K.; Ramussen, S. C. Org. Lett. 2005, 7, 5253. (m) Rahman, G. M. A.; Guldi, D. M.; Cagnoli, R.; Mucci, A.; Schenetti, L.; Vaccari, L.; Prato, M. J. Am. Chem. Soc. 2005, 127, 10051. (n) Sundararaman, A.; Victor, M.; Varughese, R.; Jäkle, F. J. Am. Chem. Soc. 2005, 127, 13748. (o) Turbiez, M.; Frère, P.; Allain, M.; Videlot, C.; Ackermann, J.; Roncali, J. Chem. Eur. J. 2005, 11, 3742. (p) Kawano, S.; Fujita, N.; Shinkai, S. Chem. Eur. J. 2005, 11, 4735. (q) Kim, D.-H.; Ohshita, J.; Kosuge, T.; Kunugi, Y.; Kunai, A. Chem. Lett. 2006, 35, 266. (r) Wada, H.; Tuguchi, T.; Goto, M.; Kambayashi, T.; Mori, T.; Ishikawa, K.; Takezoe, H. Chem. Lett. 2006, 35, 280. (s) Nurataki, M.; Takimiya, K.; Otsubo, T.; Harima, Y.; Zhang, H.; Araki, Y.; Ito, O. J. Org. Chem. 2006, 71, 1761. (t) Hou, J.; Tan, Z.; Yan, Y.; He, Y.; Yang, C.; Li, Y. J. Am. Chem. Soc. 2006, 128, 4911. (u) Henze, O.; Feast, W. J.; Gardebien, F.; Jonkheijm, P.; Lazzaroni, R.; Leclère, P.; Meijer, E. W.; Schenning, A. P. H. J. J. Am. Chem. Soc. 2006, 128, 5923. (w) Zhao, C.; Zhang, Y.; Wang, C.; Rothberg, L.; Ng, M.-K. Org. Lett. 2006, 8, 1585.

339.(a) Sołoducho, J.; Doskocz, J.; Cabaj, J.; Roszak, S. Tetrahedron 2003, 59, 4761. (b) Mushrush, M.; Facchetti, A.; Lefenfeld, M.; Katz, H. E.; Marks, T. J. J. Am. Chem. Soc. 2003, 125, 9414. (c) Facchetti, A.; Yoon, M.-H.; Stern, C. L.; Katz, H. E.; Marks, T. J. Angew. Chem. Int. Ed. 2003, 42, 3900. (d) Kim, T. H.; Swager, T. M. Angew. Chem. Int. Ed. 2003, 42, 4803. (e) Kim, S.; Song, K.; Kang, S. O.; Ko, J. Chem. Commun. 2004, 68. (f) Jiang, P.; Morales, G. M.; You, W.; Yu, L. Angew. Chem. Int. Ed. 2004, 43, 4471. (g) Crouch, D. J.; Skaba, P. J.; Heeney, M.; McCulloch, I.; Coles, S. J.; Hursthouse, M. B. Chem. Commun. 2005, 1465. (h) Goto, H.; Akagi, K. Angew. Chem. Int. Ed. 2005, 44, 4322. (i) Wan, J.-H.; Feng, J.-C.; Wen, G.-A.; Wang, H.-Y.; Fan, Q.-L.; Wei, W.; Huang, C.-H.; Huang, W. Tetrahedron Lett. 2006, 47, 2829. (j) Cravino, A.; Roquet, S.; Leriche, P.; Alévêque, O.; Frère, P.; Roncali, J. Chem. Commun. 2006, 1416. (k) Zhang, X.; Tian, H.; Liu, Q.; Wang, L.; Geng, Y.; Wang, F. J. Org. Chem. 2006, 71, 4332. (1) Roquet, S.; Cravino, A.; Leriche, P.; Alévêque, O.; Frère, P.; Roncali, J. J. Am. Chem. Soc. 2006, 128, 3459 .

340.Nesterov, E. E.; Skoch, J.; Hyman, B. T.; Klunk, W. E.; Bacskai, B. J.; Swager, T. M. Angew. Chem. Int. Ed. 2005, 44, 5452.

341.Hocke, C.; Prante, O.; Löber, S.; Hübner, H.; Gmeiner, P.; Kuwert, T. Bioorg. Med. Chem. Lett. 2004, 14, 3963.

342. Velusamy, M.; Thomas, K. R. J.; Lin, J. T.; Hsu, Y.-C.; Ho, K.-C. Org. Lett. 2005, 7, 1899. 
343.Merlo, J. A.; Newman, C. R.; Gerlach, C. P.; Kelley, T. W.; Muyres, D. V.; Fritz, S. E.; Toney, M. F.; Frisbie, C. D. J. Am. Chem. Soc. 2005, 127, 3997.

344. Boens, N.; Avcıbaş1, N.; Samanta, S. S.; Kilonda, A.; Hoornaert, G. J.; Van der Eycken, E. Tetrahedron 2006, 62, 684.

345.Hakala, H.; Mukkala, V.-M.; Sutela, T.; Hovinen, J. Org. Biomol. Chem. 2006, 4, 1383.

346. Tiberghien, A. C.; Hagan, D.; Howard, P. W.; Thurston, D. E. Bioorg. Med. Chem. Lett. 2004, 14, 504.

347.(a) Joseph, B.; Béhard, A.; Lesur, B.; Guillaumet, G. Synlett 2003, 1542. (b) Kim, W.-S.; Kim, H.-J.; Cho, C.-G. J. Am. Chem. Soc. 2003, 125, 14288.

348.Derdau, V.; Oekonomopulos, R.; Schubert, G. J. Org. Chem. 2003, 68, 5168.

349.Hanamoto, T.; Hakoshima, Y.; Egashira, M. Tetrahedron Lett. 2004, 45, 7573.

350.Hanamoto, T.; Koga, Y.; Kido, E.; Kawanami, T.; Furuno, H.; Inanaga, J. Chem. Commun. 2005, 2041.

351.Hanamoto, T.; Egashira, M.; Ishuzuka, K.; Furuno, H.; Inanaga, J. Tetrahedron 2006, 62, 6332.

352.Quan, M. L.; Lam, P. Y. S.; Han, Q.; Pinto, D. J. P.; He, M. Y.; Li, R.; Ellis, C. D.; Clark, C. G.; Teleha, C. A.; Sun, J.-H.; Alexander, R. S.; Bai, S.; Luettgen, J. M.; Knabb, R. M.; Wong, P. C.; Wexler, R. R. J. Med. Chem. 2005, 48, 1729.

353.(a) Hervet, M.; Théry, I.; Gueiffier, A.; Enguehard-Gueiffier, C. Helv. Chim. Acta 2003, 86, 3461. (b) Rozners, E.; Smicius, R.; Uchiyama, C. Chem. Commun. 2005, 5778.

354.Lee, J. S.; Cho, Y. S.; Chang, M. H.; Koh, H. Y.; Chung, B. Y.; Pae, A. N. Bioorg. Med. Chem. Lett. 2003, 13, 4117.

355.Krebs, O.; Taylor, R. J. K. Org. Lett. 2005, 7, 1063.

356.Smith, III, A. B.; Razler, T. M.; Ciavarry, J. P.; Hirose, T.; Ishikawa, T. Org. Lett. 2005, 7, 4399.

357.(a) Smith, III, A. B.; Razier, T. M.; Pettit, G. R.; Chapuis, J.-C. Org. Lett. 2005, 7, 4403. (b) Smith, III, A. B.; Razier, T. M.; Meis, R. M.; Pettit, G. R. Org. Lett. 2006, 8, 797.

358.Delbecq, F.; Cordonnier, G.; Pommery, N.; Barbry, D.; Hénichart, J.-P. Bioorg. Med. Chem. Lett. 2004, 14, 1119.

359.Cheng, H.; DeMello, K. M. L.; LI, J.; Sakya, S. M.; Ando, K.; Kawamura, K.; Kato, T.; Rafka, R. J.; Jaynes, B. H.; Ziegler, C. B.; Stevens, R.; Lund, L. A.; Mann, DS. W.; Kilroy, C.; Haven, M. L.; Nimz, E. L.; Dutra, J. K.; Li, C.; Minich, M. L.; Kolosko, N. L.; Petras, C.; Silvia, A. M.; Seibel, S. B. Bioorg. Med. Chem. Lett. 2006, 16, 2076.

360.Nicolaou, K. C.; Sasmal, P. K.; Rassias, G.; Reddy, M. V.; Altmann, K.-H.; Wartmann, M.; O’Brate, A.; Giannakakou, P. Angew. Chem. Int. Ed. 2003, 42, 3515.

361. Shao, J.; Panek, J. S. Org. Lett. 2004, 6, 3083.

362. Standgeland, E. L.; Sammakia, T. J. Org. Chem. 2004, 69, 2381.

363.Heckmann, G.; Bach, T. Angew. Chem. Int. Ed. 2005, 44, 1199.

364.Guianvarc'h, D.; Fourrey, J.-L.; Maurisse, R.; Sun, J.-S.; Benhida, R. Bioorg. Med. Chem. Lett. 2003, 11, 2751. 
365.(a) Mathieu, J.; Marsura, A. Synth. Commun. 2003, 33, 409. (b) Shen, X.; Moriuchi, T.; Hirao, T. Tetrahedron Lett. 2003, 44, 7711. (c) Duan, X.-F.; Li, X.-H.; Huang, C.-H. Synth. Commun. 2004, 34, 3227. (d) Duan, X.-F.; Li, X.-H.; Li, F.-Y.; Huang, C.-H. Synthesis 2004, 2614. (e) Zoppellaro, G.; Enkelmann, V.; Geies, A.; Baumgarten, M. Org. Lett. 2004, 6, 4929. (f) Opris, D. M. Franke, P.; Schlüter, A. D. Eur. J. Org. Chem. 2005, 822. (g) Patroniak, V.; Kubicki, M.; Stefankiewicz, A. R.; Grochowska, A. M. Tetrahedron 2005, 61, 5475. (h) Brotschi, C.; Mathis, G.; Leumann, C. J. Chem. Eur. J. 2005, 11, 1911. (i) Zong, R.; Wang, D.; Hammitt, R.; Thummel, R. P. J. Org. Chem. 2006, 71, 167. (j) Tanada, M.; Tsujita, S.; Kataoka, T.; Sasaki, S. Org. Lett. 2006, 8, 2475.

366.(a) Grave, C.; Lentz, D.; Schäfer, A.; Samori, P.; Rabe, J. P.; Franke, P.; Schlüter, D. J. Am. Chem. Soc. 2003, 125, 6907. (b) Baxter, P. N. W. Chem. Eur. J. 2003, 9, 5011. (c) Galaup, C.; Couchet, J.-M.; Bedel, S.; Tisnès, P.; Picard, C. J. Org. Chem. 2005, 70, 2274. (d) Champouret, Y. D. M.; Chaggar, R. K.; Dadhiwala, I.; Fawcett, J.; Solan, G. A. Tetrahedron 2006, 62, 79. (e) Linke-Schaetzel, M.; Anson, C. E.; Powell, A. K.; Buth, G.; Palomares, E.; Durrant, J. D.; Balaban, T. S.; Lehn, J.-M. Chem. Eur. J. 2006, 12, 1931.

367.Ikeda, M.; Nobori, T.; Schmutz, M.; Lehn, J.-M. Chem. Eur. J. 2005, 11, 662.

368.Lu, W.; Zhang, L.-H.; Ye, X.-S.; Su, J.; Yu, Z. Tetrahedron 2006, 62, 1806.

369.Honda, T.; Takahashi, R.; Namiki, H. J. Org. Chem. 2005, 70, 499.

370.Keaton, K. A.; Philips, A. J. J. Am. Chem. Soc. 2006, 128, 408.

371.Richardson, C.; Rewcastle, G. W.; Hoyer, D.; Denny, W. A. J. Org. Chem. 2005, 70, 7436.

372. Tashiro, S.; Tominaga, M.; Kusukawa, T.; Kawano, M.; Sakamoto, S.; Yamaguchi, K.; Fujita, M. Angew. Chem. Int. Ed. 2003, 42, 3267.

373.(a) Riger, G.; Lagnel, B.; Rouden, J.; Besret, L.; Valette, H.; Demphel, S.; Gosipetti, J. M.; Coulon, C.; Ottaviani, M.; Wrenn, L. A.; Letchworth, S. R.; Bohme, G. A.; Benavides, J.; Lasne, M.-C.; Bottlaender, M.; Dollé, F. Bioorg. Med. Chem. 2003, 11, 5333. (b) Chellappan, S. K.; Xiao, Y.; Tueckmantel, W.; Kellar, K. J.; Kozikowski, A. P. J. Med. Chem. 2006, 49, 2673.

374.Gao, X.; Matsuo, Y.; Snider, B. B. Org. Lett. 2006, 8, 2123.

375.Brenner, E.; Baldwin, R. M.; Tamagnan, G. Tetrahedron Lett. 2004, 45, 3607.

376.Swahn, B.-M.; Xue, Y.; Arzel, E.; Kallin, E.; Magnus, A.; Plobeck, N.; Viklund, J. Bioorg. Med. Chem. Lett. 2006, 16, 1397.

377.(a) Tumambac, G. E.; Mei, X.; Wolf, C. Eur. J. Org. Chem. 2004, 3850. (b) Tumambac, G. E.; Wolf, C. J. Org. Chem. 2004, 69, 2048. (c) Tumambac, G. E.; Wolf, C. Org. Lett. 2005, 7, 4045.

378. Tumambac, G. E.; Wolf, C. J. Org. Chem. 2005, 70, 2930.

379. Kawai, H.; Takeda, T.; Fujiwara, K.; Suzuki, T. Tetrahedron Lett. 2004, 45, 8289.

380. Wolf, C.; Mei, X.; Rokadia, H. K. Tetrahedron Lett. 2004, 45, 7867.

381.(a) Mei, X.; Wolf, C. J. Am. Chem. Soc. 2004, 126, 14736. (b) Mei, X.; Martin, R. M.; Wolf, C. J. Org. Chem. 2006, 71, 2854. 
382.van Niel, M. B.; Wilson, K.; Adkins, C. H.; Atack, J. R.; Castro, J. L.; Clarke, D. E.; Fletcher, S.; Gerhard, U.; Mackey, M. M.; Malpas, S.; Maubach, K.; Newman, R.; O’Connor, D.; Pillai, G. V.; Simpson, P. B.; Thomas, S. R.; MacLeod, A. M. J. Med. Chem. 2005, 48, 6004.

383.Kamei, K.; Maeda, N.; Katsuragi-Ogino, R.; Koyama, M.; Nakajima, M.; Tatsuoka, T.; Ohno, T.; Inoue, T. Bioorg. Med. Chem. Lett. 2005, 15, 2990.

384. Mendiola, J.; Baeza, A.; Alvarez-Builla, J.; Vaquero, J. J. J. Org. Chem. 2004, 69, 4974.

385.(a) Ahaidar, A.; Fernández, D.; Pérez, O.; Danelón, G.; Cuevas, C.; Manzanares, I.; Albericio, F.; Joulé, J. A.; Alvarez, M. Tetrahedron Lett. 2003, 44, 6191. (b) Ahaidar, A.; Fernández, D.; Danelón, G.; Cuevas, C.; Manzanares, I.; Albericio, F.; Joule, J.A.; Alvarez, M. J. Org. Chem. 2003, 68, 10020.

386. Minakawa, N.; Kojima, N.; Hikishima, S.; Sasaki, T.; Kiyosue, A.; Atsumi, N.; Ueno, Y.; Matsuda, A. J. Am. Chem. Soc. 2003, 125, 9970.

387. Balaban, T. S.; Eichhöfer, A.; Krische, M. J.; Lehn, J.-M. Helv. Chim. Acta 2006, 89, 333.

388. Toudic, F.; Heynderickx, A.; Plé, N.; Turck, A.; Quéguiner, G. Tetrahedron 2003, 59, 6375. 389.Buron, F.; Plé, N.; Turck, A.; Quéguiner, G. J. Org. Chem. 2005, 70, 2616.

390.Kuo, G.-H.; DeAngelis, A.; Emanuel, S.; Wang, A.; Zhang, Y.; Connolly, P. J.; Chen, X.; Gruninger, R. H.; Rugg, C.; Fuentes-Pesquera, A.; Middleton, S. A.; Jolliffe, L.; Murray, W. V. J. Med. Chem. 2005, 48, 4535.

391.Darabantu, M.; Boully, L.; Turck, A.; Plé, N. Tetrahedron 2005, 61, 2897.

392.Elzein, E.; Palle, V.; Wu, Y.; Maa, T.; Zeng, D.; Zablocki, J. J. Med. Chem. 2004, 47, 4766.

393. Taddei, D.; Killian, P.; Slawin, A. M. Z.; Woollins, J. D. Org. Biomol. Chem. 2004, 2, 665.

394. Mathieu, R.; Baurand, A.; Schmitt, M.; Gachet, C.; Bourguignon J.-J. Bioorg. Med. Chem. 2004, 12, 1769.

395.Fargeas, V.; Favresse, F.; Mathieu, D.; Beaudet, I.; Charrue, P.; Lebret, B.; Piteau, M.; Quintard, J.-P. Eur. J. Org. Chem. 2003, 1711.

396.(a) Vedejs, E.; Little, J. D.; Seaney, L. M. J. Org. Chem. 2004, 69, 1788. (b) Vedejs, E.; Little, J. D. J. Org. Chem. 2004, 69, 1794-1799. (c) Kim, M.; Vedejs, E. J. Org. Chem. 2004, 69, 7262.

397.Hodgson, D. M.; Buxton, T. J.; Cameron, I. D.; Gras, E.; Kirton, E. H. M. Org. Biomol. Chem. 2003, 1, 4293.

398.Hodgson, D. M.; Reynolds, N. J.; Coote, S. J. Org. Lett. 2004, 6, 4187.

399. Gawley, R. E.; Narayan, S.; Vicic, D. A. J. Org. Chem. 2005, 70, 328.

400.(a) Gawley, R. E.; Barolli, Madan, S.; Saverin, M.; O’Connor, S. Tetrahedron Lett. 2004, 45, 1759. (b) Madan, S.; Milano, P.; Eddings, D. B.; Gawley, R. E. J. Org. Chem. 2005, 70, 3066.

401.Santiago, M.; Low, E.; Chambournier, G.; Gawley, R. E. J. Org. Chem. 2003, 68, 8480.

402.Huntley, R. J.; Funk, R. L. Org. Lett. 2006, 8, 3403.

403.Attwood, M. R.; Gilbert, P. S.; Lewis, M. L.; Mills, K.; Quayle, P.; Thompson, S. P.; Wang, S. Tetrahedron Lett. 2006, 47, 3607. 
404.Robertson, J.; Tyrrell, A. J.; Skerratt, S. Tetrahedron Lett. 2006, 47, 6285.

405.Pour, M.; Špulák, M.; Balšanek, V.; Kuneš, J.; Kubanová, P.; Buchta, V. Bioorg. Med. Chem. 2003, 11, 2843.

406.Clark, J. S.; Marlin, F.; Nay, B.; Wilson, C. Org. Lett. 2003, 5, 89.

407.Wüst, F. R.; Höhne, A.; Metz, P. Org. Biomol. Chem. 2005, 3, 503.

408.de Vicente, J.; Betzemeier, B.; Rychnovsky, S. D. Org. Lett. 2005, 7, 1853.

409.Koo, B.; McDonald, F. E. Org. Lett. 2005, 7, 3621.

410.(a) Nicolaou, K. C.; Vyskocil, S.; Koftis, T. V.; Yamada, Y. M. A.; Ling, T.; Chen, D. Y.-

K.; Tang, W.; Petrovic, G.; Frederick, M. O.; Li, Y.; Satake, M. Angew. Chem. Int. Ed. 2004, 43, 4312. (b) Nicolaou, K. C.; Koftis, T. V.; Vyskocil, S.; Petrovic, G.; Tang, W.; Frederick, M. O.; Chen, D. Y.-K.; Li, Y.; Ling, T.; Yamada, Y. M. A. J. Am. Chem. Soc. 2006, 128, 2859. (c) Nicolaou, K. C.; Frederick, M. O.; Petrovic, G.; Cole, K. P.; Loizidou, E. Z. Angew. Chem. Int. Ed. 2006, 45, 2609.

411. Conway, J.; Urch, C. J.; Quayle, P.; Xu, J. Synlett 2006, 776. 412.Kagawa, N.; Ihara, M.; Toyota, M. Org. Lett. 2006, 8, 875.

413. Dubbaka, S. R.; Steunenberg, P.; Vogel, P. Synlett 2004, 1235. 414. Yao, T.; Zhang, X.; Larock, R. C. J. Org. Chem. 2005, 70, 7679. 415. Yue, D.; Yao, T.; Larock, R. C. J. Org. Chem. 2005, 70, 10292.

416.(a) Kloc, K.; Maliszewska, I.; Mlochowski, J. Synth. Commun. 2003, 33, 3805. (b) Frederickson, M.; Vuillard, L.; Abell, C. Tetrahedron Lett. 2003, 44, 7925. (c) Fenner, T.; White, J. M.; Schiesser, C. H. Org. Biomol. Chem. 2006, 4, 466.

417. Beletskaya, I. P.; Sigeev, A. S.; Peregudov, A. S.; Petrovskii, P. V. Tetrahedron Lett. 2003, 44, 7039.

418. Murakami, S.; Ishii, H.; Tajima, T.; Fuchigami, T. Tetrahedron 2006, 62, 3761.

419.(a) Hernández, R.; León, E. I.; Moreno, P.; Riesco-Fagundo, C.; Suárez, E. J. Org. Chem. 2004, 69, 8437. (b) Dong, S.; Paquette, L. A. J. Org. Chem. 2006, 71, 1647.

420.(a) Chambers, D. J.; Evans, G. R.; Fairbanks, A. J. Tetrahedron Lett. 2003, 44, 5221. (b) Chambers, D. J.; Evans, G. R.; Faibanks, A. J. Tetrahedron 2004, 60, 8411. (c) Osborn, H. M. I.; Meo, P.; Nijjar, R. K. Tetrahedron: Asymmetry 2005, 16, 1935.

421.Hayes, W.; Osborn, H. M. I.; Osborne, S. D.; Rastall, R. A.; Romagnoli, B. Tetrahedron 2003, 59, 7983.

422.Crich, D.; Suk, D.-H.; Sun, S. Tetrahedron: Asymmetry 2003, 14, 2861.

423.Knapp, S.; Darout, E. Org. Lett. 2005, 7, 203.

424.(a) Kawai, Y.; Ando, H.; Ozeki, H.; Koketsu, M.; Isihara, H. Org. Lett. 2005, 7, 4653. (b) Ahn, S. J.; Koketsu, M.; Ishihara, H.; Lee, S. M.; Ha, S. K.; Lee, K. H.; Kang, T. H.; Kim, S. Y. Chem. Pharm. Bull. 2006, 54, 281.

425.Mukherjee, C.; Tiwari, P.; Misra, A. K. Tetrahedron Lett. 2006, 47, 441.

426. Tiwari, P.; Misra, A. K. Tetrahedron Lett. 2006, 47, 2345. 
427.(a) Mironov, Y. V.; Sherman, A. A.; Nifantiev, N. E. Tetrahedron Lett. 2004, 45, 9107. (b) Litjens, R. E. J. N.; den Heeten, R.; Timmer, M. S. M.; Overkleef, H. S.; van der Marel, G. A. Chem. Eur. J. 2005, 11, 1010. (c) Bedini, E.; Esposito, D.; Parrilli, M. Synlett 2006, 825. 428. Terauchi, M.; Yahiro, Y.; Abe, H.; Ichikawa, S.; Tovey, S. C.; Dedos, S. G.; Taylor, C. W.; Potter, B. V. L.; Matsuda, A.; Shuto, S. Tetrahedron 2005, 61, 3697. 429. Terauchi, M.; Matsuda, A.; Shuto, S. Tetrahedron Lett. 2005, 46, 6555. 430.(a) Ma, S.; Pan, F.; Hao, X.; Huang, X. Synlett 2004, 85. (b) Chen, G.; Fu, C.; Ma, S. Tetrahedron 2006, 62, 4444.

431.Petragnani, N.; Stefani, H. A. Tetrahedron 2005, 61, 1613. 432. Kumar, S.; Engman, L. J. Org. Chem. 2006, 71, 5400. 433.Zeni, G.; Braga, A. L.; Stefani, H. A. Acc. Chem. Res. 2003, 36, 731. 434.Cella, R.; Cunha, R. L. O. R.; Reis, A. E. S.; Pimenta, D. C.; Klitzke, C. F.; Stefani, H. A. J. Org. Chem. 2006, 71, 244. 435. Cella, R.; Stefani, H. A. Tetrahedron 2006, 62, 5656. 436. Bhasin, K. K.; Arora, V.; Klapötke, T. M.; Crwford, M.-J. Eur. J. Inorg. Chem. 2004, 4781. 437. Milton, M. D.; Kumar, N.; Sokhi, S.; Singh, S.; Singh, J. D. Tetrahedron Lett. 2004, 45, 6453.

438.Xu, Q.; Huang, X.; Yuan, J. J. Org. Chem. 2005, 70, 6948. 439. Boukuovalas, J.; Wang, J.-X.; Marion, O.; Ndzi, B. J. Org. Chem. 2006, 71, 6670. 440. Sibi, M. P.; He, L. Org. Lett. 2004, 6, 1749. 441.Comins, D. L.; King, L. S.; Smith, E. D.; Février, F. C. Org. Lett. 2005, 7, 5059. 442.(a) White, J. D.; Wang, G.; Quaranta, L. Org. Lett. 2003, 5, 4983. (b) Ashton, W. T.; Dong, H.; Sisco, R. M.; Doss, G. A.; Leiting, B.; Patel, R. A.; Wu, J. K.; Marsilio, F.; Thornberry, N. A.; Weber, A. E. Bioorg. Med. Chem. Lett. 2004, 14, 859. (c) Castelani, P.; Luque, S.; Comasseto, J. V. Tetrahedron Lett. 2004, 45, 4473. (d) Rodeschini, V.; van de Weghe, P.; Salomon, E.; Tarnus, C.; Eustache, J. J. Org. Chem. 2005, 70, 2409. (e) Clive, D. L. J.; Liu, D. Tetrahedron Lett. 2005, 46, 5305. (f) Kerr, W. J.; Pearson, C. M.; Thurston, G. J. Org. Biomol. Chem. 2006, 4, 47.

443.Cunha, R. L. O. R.; Diego, D. G.; Simonelli, F.; Comasseto, J. V. Tetrahedron Lett. 2005, 46, 2539.

444.Pan, W.; Zhang, Y.; Liang, G.; Vincent, S. P.; Sinaÿ, P. Chem. Commun. 2005, 3445.

445.Inamoto, K.; Yamamoto, A.; Ahsawa, K.; Hiroya, K.; Sakamoto, T. Chem. Pharm. Bull. 2005, 53, 1502.

446. Yang, X.; Knochel, P. Chem. Commun. 2006, 2170.

447. Marino, J. P.; Nguyen, H. N. Tetrahedron Lett. 2003, 44, 7395.

448.Luo, S.; Fang, F.; Zhao, M.; Zhai, H. Tetrahedron 2004, 60, 5353.

449.Dieter, R. K.; Chen, N.; Watson, R. T. Tetrahedron 2005, 61, 3221.

450.Watson, R. T.; Gore, V. K.; Chandupatla, K. R.; Dieter, R. K.; Snyder, J. P. J. Org. Chem. 2004, 69, 6105.

451.Dieter, R. K.; Chen, N. J. Org. Chem. 2006, 71, 5674. 
452.Dieter, R. K.; Li, S.; Chen, N. J. Org. Chem. 2004, 69, 2867.

453.Passarella, D.; Favia, R.; Giardini, A.; Lesma, G.; Martinelly, M.; Silvani, A.; Danieli, B.; Efange, S. M. N.; Mash, D. C. Bioorg. Med. Chem. 2003, 11, 1007.

454.Gavryushin, A.; Kofink, C.; Manolikakes, G.; Knochel, P. Org. Lett. 2005, 7, 4871. 455.Nakamura, M.; Ito, S.; Matsuo, K.; Nakamura, E. Synlett 2005, 1794.

456.Xue, S.; Han, K.-Z.; He, L.; Guo, Q.-X. Synlett 2003, 870.

457.Korn, T. J.; Knochel, P. Synlett 2005, 1185.

458. Gosmini, C.; Amatore, M.; Claudel, S.; Périchon, J. Synlett 2005, 2171.

459.Mutule, I.; Suna, E. Tetrahedron Lett. 2004, 45, 3909.

460.Krasovskiy, A.; Malakhov, V.; Gavryushin, A.; Knochel, P. Angew. Chem. Int. Ed. 2006, 45, 6040 .

461.Kneisel, F. F.; Dochnahl, M.; Knochel, P. Angew. Chem. Int. Ed. 2004, 43, 1017.

462.Krascsenicsová, K.; Walla, P.; Kasák, P.; Uray, G.; Kappe, C. O.; Putala, M. Chem. Commun. 2004, 2606.

463. Vachal, P.; Toth, L. M. Tetrahedron Lett. 2004, 45, 7157.

464.Crombie, A. L.; Kane, Jr., J. L.; Shea, K. M.; Danheiser, R. L. J. Org. Chem. 2004, 69, 8652.

465.Bois, F.; Baldwin, R. M.; Kula, N. S.; Baldessarini, R. J.; Innis, R. B.; Tamagnan, G. Bioorg. Med. Chem. Lett. 2004, 14, 2117.

466. Beletskaya, I. P.; Bregadze, V. I.; Ivushkin, V. A. Petrovskii, P. V.; Sivaev, I. B.; Sjöberg, S.; Zhigareva, G. G. J. Organomet. Chem. 2004, 689, 2920.

467.Lin, X.; Murray, J. M.; Rico, A. C.; Wang, M. X.; Chu, D. T.; Zhou, Y.; Del Rosario, M.; Kaufman, S.; Ma, S.; Fang, E.; Crawford, K.; Jefferson, A. B. Bioorg. Med. Chem. Lett. 2006, 16, 4163.

468.Xu, C.; Yang, L.; Bhandari, A.; Holmes, C. P. Tetrahedron Lett. 2006, 47, 4885.

469. Wang, J.-L.; Duan, X.-F.; Jiang, B.; Gan, L.-B.; Pei, J.; He, C.; Li, Y-F. J. Org. Chem. 2006, 71,4400 .

470. Takahashi, H.; Hossain, K. M.; Nishihara, Y.; Shibata, T.; Takagi, K. J. Org. Chem. 2006, 71,671 .

471.Lipshutz, B. H.; Frieman, B.; Birkedal, H. Org. Lett. 2004, 6, 2305.

472.Heckmann, G.; Bach, T. Angew. Chem. Int. Ed. 2005, 44, 1199.

473.(a) Bunlaksananusorn, T.; Polborn, K.; Knochel, P. Angew. Chem. Int. Ed. 2003, 42, 3941.

(b) Lützen, A.; Hapke, M.; Staats, H.; Bunzen, J. Eur. J. Org. Chem. 2003, 3948. (c) Roppe,

J. R.; Wang, B.; Huang, D.; Tehrani, L.; Kamenecka, T.; Scweiger, E. J.; Anderson, J. J.;

Brodkin, J.; Jiang, X.; Cramer, M.; Chung, J.; Reyes-Manalo, G.; Munoz, B.; Cosford, N. D.

P. Bioorg. Med. Chim. Lett. 2004, 14, 3993. (d) Lorthiois, E.; Bernardelli, P.; Vergne, F.;

Oliveira, C.; Mafroud, A.-K.; Proust, E.; Heuze, L.; Moreau, F.; Idrissi, M.; Tertre, A.; Bertin, B.; Coupe, M.; Wrigglesworth, R.; Descours, A.; Soulard, P.; Berna, P. Bioorg. Med. Chem. Lett. 2004, 14, 4623. (e) Bourrain, S.; Ridgill, M.; Collins, I. Synlett 2004, 795. (f) Nguyen, T.; Wicki, M. A.; Snieckus, V. J. Org. Chem. 2004, 69, 7816. (g) Boulton, L. T.; 
Fox, M. E.; Hodgson, P. B.; Lennon, I. C. Tetrahedron Lett. 2005, 46, 983. (h) Nurkkala, L. J.; Steen, R. O.; Dunne, S. J. Synthesis 2006, 1295.

474.(a) Switzer, C.; Sinha, S.; Kim, P. H.; Heuberger, B. D. Angew. Chem. Int. Ed. 2005, 44, 1529. (b) Switzer, C.; Shin, D. Chem. Commun. 2005, 1342.

475. Stanetty, P.; Schnürch, M.; Mihovilovic, M. D. Synlett 2003, 1862.

476. Stanetty, P.; Röhrling, J.; Schnürch, M.; Mihovilovic, M. D. Tetrahedron 2006, 62, 2380.

477.(a) Berman, A. M.; Johnson, J. S. J. Am. Chem. Soc. 2004, 126, 5680. (b) Berman, A. M.; Johnson, J. S. J. Org. Chem. 2006, 71, 219.

478. Conway, J. C.; Quayle, P.; Regan, A. C.; Urch, C. J. Tetrahedron 2005, 61, 11910.

479. Tseng, J.-C.; Chen, J.-H.; Luh, T.-Y. Synlett 2006, 1209.

480.Meng, H.; Perepichka, D. F.; Bendikov, M.; Wudl, F.; Pan, G. Z.; Yu, W.; Dong, W.; Brown, S. J. Am. Chem. Soc. 2003, 125, 15151.

\section{Biographical Sketches}

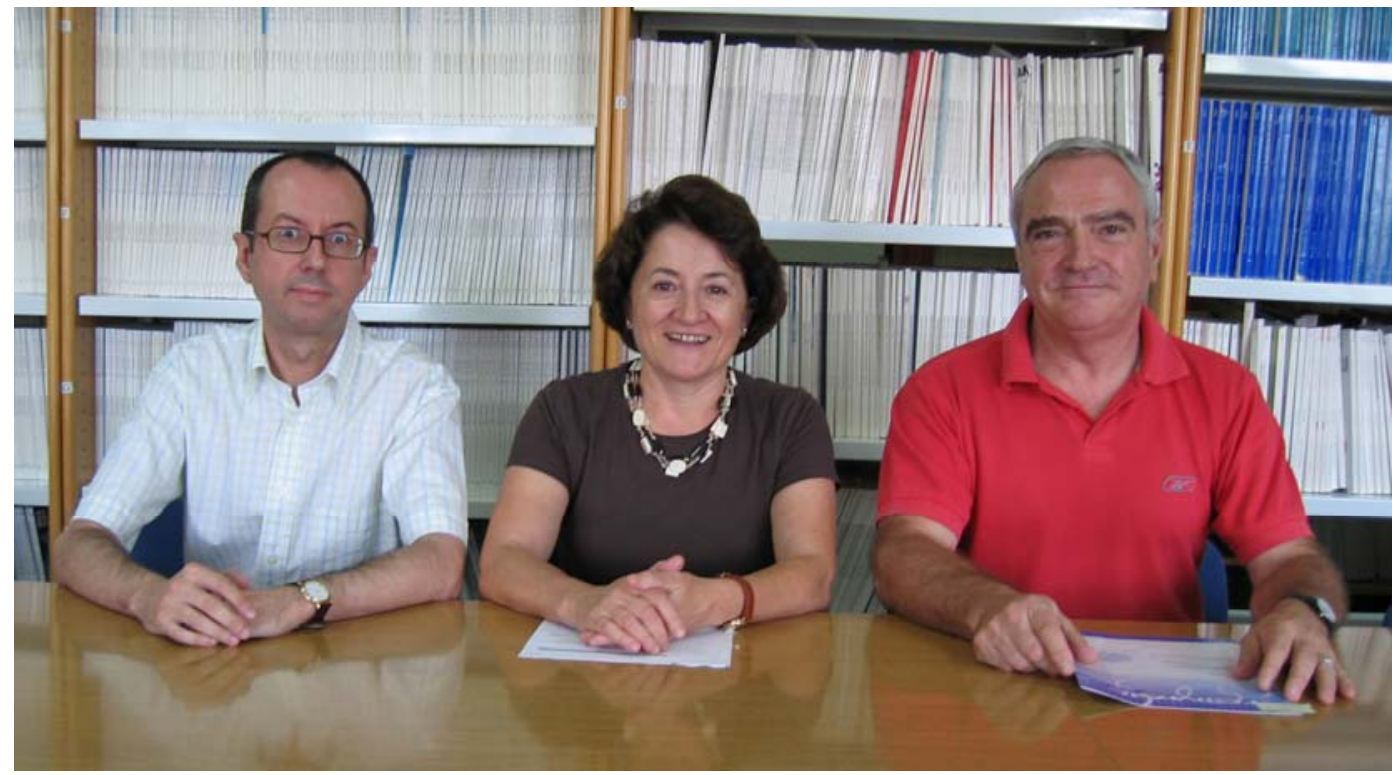

Rafael Chinchilla (left) was born in Alicante and studied chemistry in the University of Alicante from which he was graduated (1985) and doctorated (1990). After a postdoctoral stay at the University of Uppsala, Sweden (1991-1992), he moved back to the University of Alicante where he was appointed Associate Professor in 1997. He is co-author of 70 papers and four patents. His current research interest includes asymmetric synthesis, amino acid and peptide synthesis, and solid-supported reagents.

Carmen Nájera (middle) was born in Nájera (La Rioja) and was graduated from the University of Zaragoza in 1973, obtaining her doctorate in chemistry from the University of Oviedo in 1979. Postdoctoral stays at the ETH (Zurich), the Dyson Perrins Laboratory (Oxford), Harvard University, and Uppsala University. Associate Professor in 1985 at the University of 
Oviedo and Full Professor in 1993 at the University of Alicante. She is coauthor of more than 200 papers and 30 reviews, and has been visiting professor at different universities, such as University of Arizona (Tucson, USA), Universidad Nacional del Sur (Bahia Blanca, Argentina), Université Louis Pasteur (Strassbourg, France) and Ecole Nationale Superiéure de Chimie de Paris (France). Prof. Nájera has received the 2006 Janssen Cilag Organic Chemistry Price from the Spanish Royal Chemical Society of Chemistry and the 2006 Rosalind Franklin International Lectureship from the English Royal Society. She is co-founder of a new chemical company MEDALCHEMY, S. L. as a spin-off of the University of Alicante. Her current research interest is focused on sulfones, amino acids, polymer-supported reagents, asymmetric catalysis and palladium catalysis.

Miguel Yus (right) was born in Zaragoza (Spain) in 1947, and received his BSc (1969), MSc (1971) and PhD (1973) degrees from the University of Zaragoza. After spending two years as a postdoctoral fellow at the Max Planck Institut für Kohlenforschung in Mülheim a.d. Ruhr he returned to Spain to the University of Oviedo where he became associate professor in 1977 , being promoted to full professor in 1987 at the same university. In 1988 he moved to a chair in Organic Chemistry at the University of Alicante where he is currently the head of the Organic Synthesis Institute (ISO). Professor Yus has been visiting professor at different institutions and universities such as ETH-Zentrum, Oxford, Harvard, Uppsala, Tucson, Okayama, Paris and Strasbourg. He is co-author of more than 400 papers mainly in the field of the development of new methodologies involving organometallic intermediates and three patents. Professor Yus is member of the Advisory Board of the journals Tetrahedron, Tetrahedron Letters, Chemistry Letters, European Journal of Organic Chemistry, Trends in Organic Chemistry and Current Chemical Biology, being also Regional Editor of Letters in Organic Chemistry. He has given more than 100 lectures, most of them abroad and supervised $39 \mathrm{PhD}$ students. Among others he has received the Japan Society for the Promotion of Science Prize (1999), the French-Spanish Prize of the Societé Française de Chimie (1999), the C.A. Stiefvater Memorial Lecture Award (University of Nebraska, 2001), the Nagase Science and Technology Foundation fellowship (Japan, 2003) and the Cellchem Lectureship (Sheffield, 2005). His current research interest is focused on the preparation of very reactive functionalized organometallic compounds and their use in synthetic organic chemistry, arene-catalyzed activation of different metals and preparation of new metal-based catalysts for homogeneous and heterogeneous selective reactions. Last year, he and other members of the ISO founded the new chemical company MEDALCHEMY, S.L,. to commercialize fine chemicals. 